\title{
Meditative Breathing - A catalyst for positive change
}

\author{
By \\ Robyn Browne
}

A thesis submitted in partial fulfilment of the requirements for the degree of Masters of Education,

Victoria University of Wellington.

2020 


\begin{abstract}
The New Zealand government faces substantive challenges in meeting both the health and education needs of a significant number of our children who are vulnerable to alienation and inform the statistics of mental health distress and academic underachievement. The New Zealand Ministry of Education acknowledges that the education system is not meeting the needs of its most disadvantaged young people. This research explored whether a programme of meditative breathing might contribute to the alleviation of this situation by supporting the development of self-regulation and well-being in students. It also sought to enable student agency by adding nuanced student voice to the literature in this field. While there is an increasing number of peer-reviewed studies in this field, there are few studies that encourage the participants to describe their experiences directly in their own words or images. The main research question was 'What are student's experience of guided meditative breathing?' The sub-questions were 'What does it contribute to their wellbeing?' and 'Does it contribute to their learning?'. Students participated in a ten-week programme of daily meditative breathing. Data was collected from the weekly cogenerative dialogue, journals, from a heuristic and teacher recorded reflections with a three-month follow-up. The meditative breathing intervention intervention was described by students and the classroom teacher as leading to a calmer and more peaceful classroom climate. They indicated reduced anxiety, increased clarity of thinking, improved self-regulation and engagement. A number of students described taking the skills that they had learned in the programme and regularly applying them in other contexts. Implications for teachers and teacher training are discussed.
\end{abstract}




\section{Acknowledgements}

I would like to acknowledge those who directly and indirectly helped me to undertake and complete this study. My dad who from the time that I was tiny encouraged in me, through example, adventurous thinking. As a journalist and photographer, later a returned soldier and philosopher, he was deeply interested in alternative paradigms and refreshing perspectives. I vividly remember a hefty volume of Bertrand Russell dominating our coffee table on the farm. I first started reading the writings of the Dalai Lama as a teenager.

I'd like to thank my partner Richard who has supported me, patiently picking up tasks that needed to be done and proof-reading my efforts.

My children Nick and Stella who have been an important source of inspiration and information encouraging me and sharing their expertise, helping me to complete this undertaking, as they too were completing their own master's studies.

My principal, parents and Board of Trustees have been very supportive of this undertaking, encouraging me and supporting my application for study leave. My co-researchers, the nine and tenyear-old students who generously and courageously participated in and critiqued the process. My buddy teacher Adi whose mature reflection was invaluable to the research process.

My appreciative thanks to my supervisor Associate Professor Joanna Higgins for her inspiration, patience and guidance.

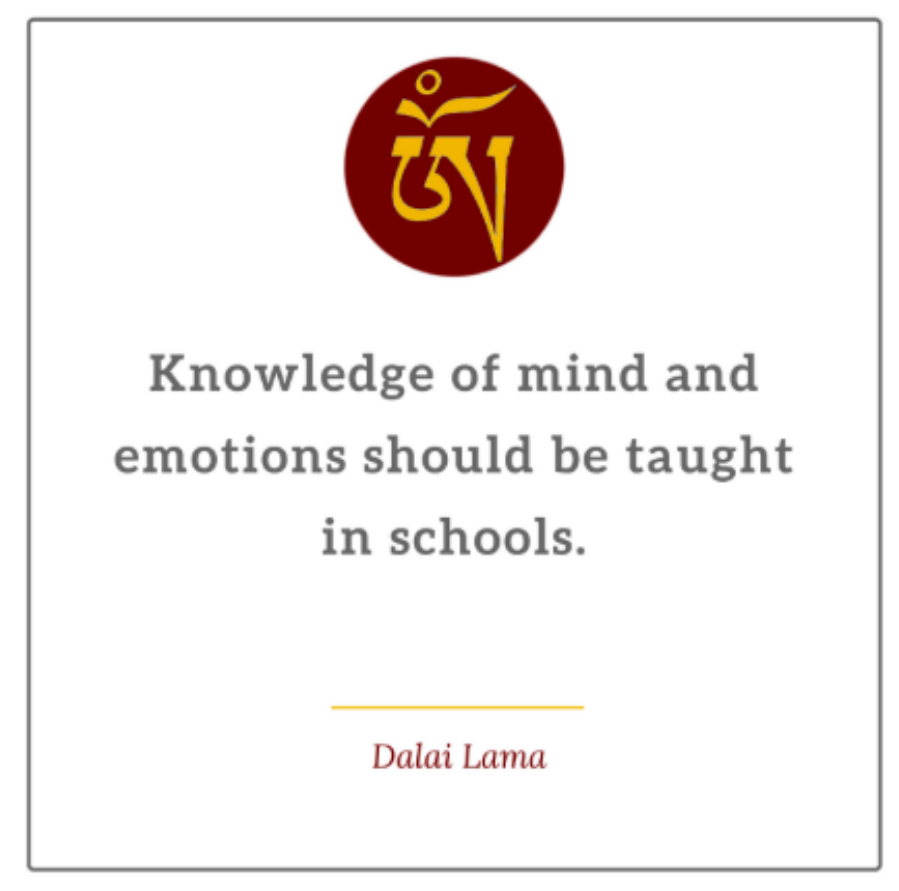




\section{CONTENTS}

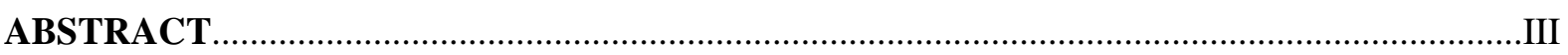

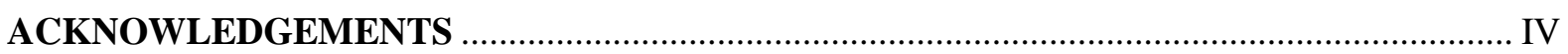

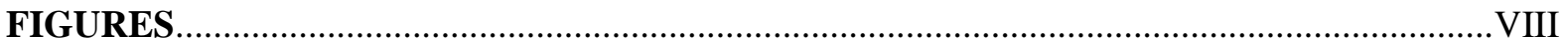

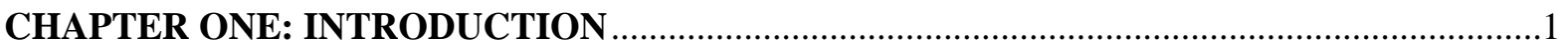

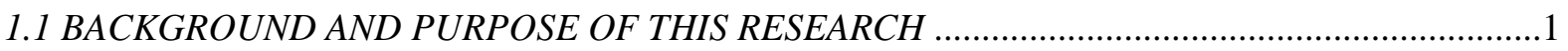

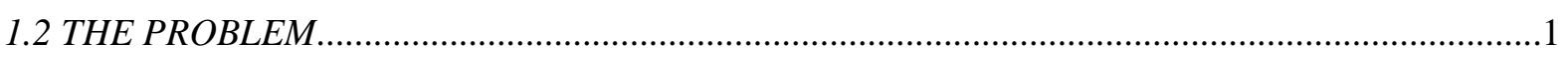

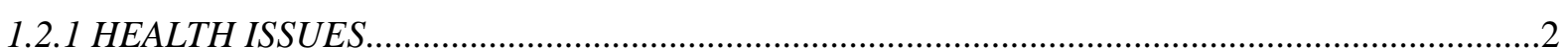

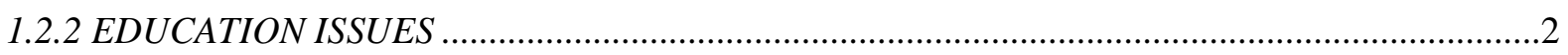

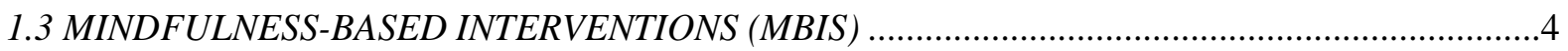

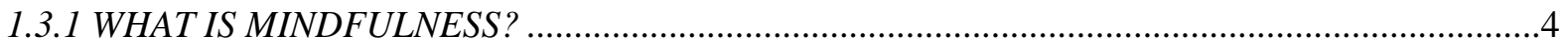

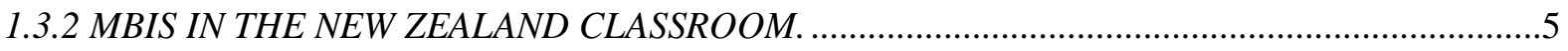

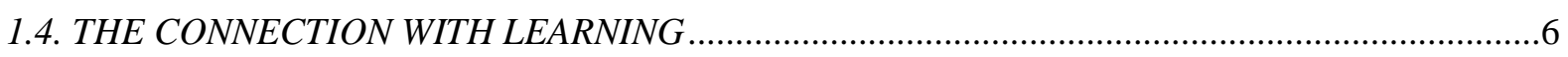

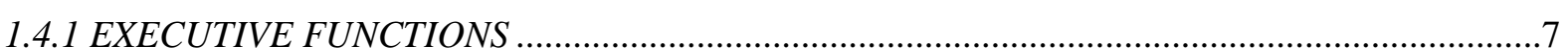

1.5 STUDENT VOICE EXTENDED BY COGENERATIVE DIALOGUE …...........................................

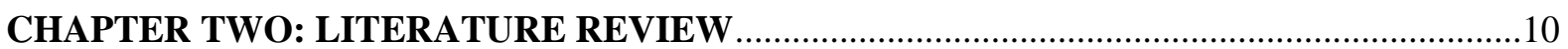

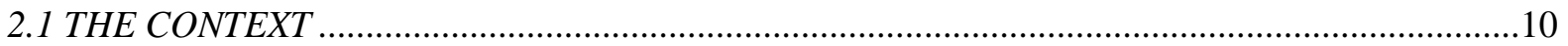

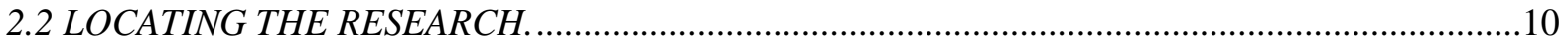

2.3 CONTRIBUTIONS TO RESEARCH ON MBIS IN SCHOOLS....................................................11

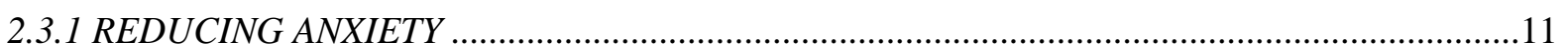

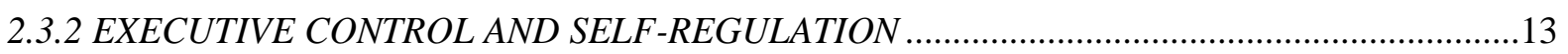

2.3.3 SELF-REGULATION LEADING TO INHIBITORY CONTROL ..................................................

2.3.4 MECHANISMS THAT MAY FACILITATE MINDFULNESS …................................................16

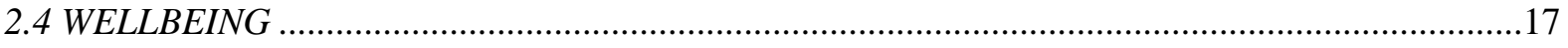

2.4.1 STUDENT'S PERSPECTIVES ON WHAT CONTRIBUTES TO WELL-BEING ........................18

2.4.2 THE POTENTIAL ROLE OF MBIS IN ENHANCING WELL-BEING .......................................20

2.5 INTERVENTIONS TARGETING STRESSED AND DISADVANTAGED GROUPS .......................26

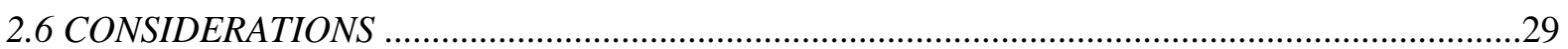

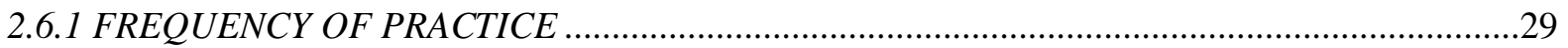

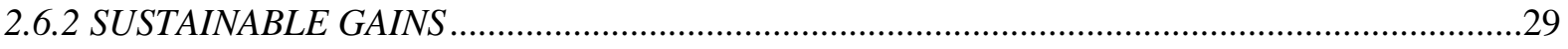

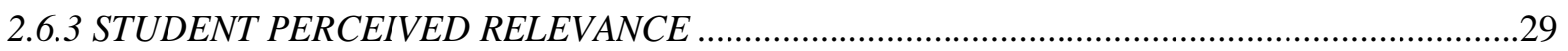

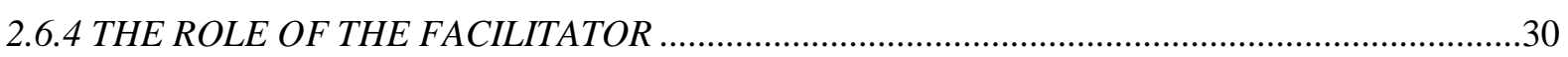

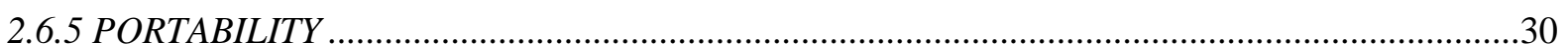

2.6.6 CLASSROOM CLIMATE AND POTENTIAL TEACHER BENEFIT …..........................................

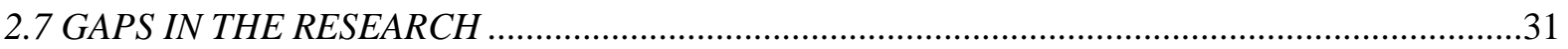

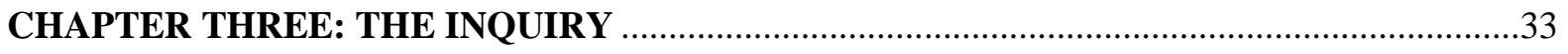

3.1. CONCEPTUAL FRAMEWORK AND PHILOSOPHICAL UNDERPINNINGS ............................33 


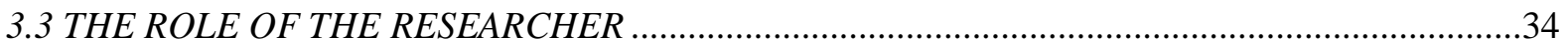

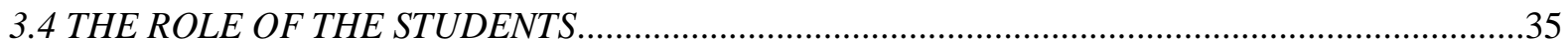

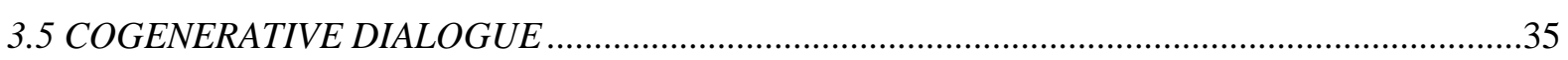

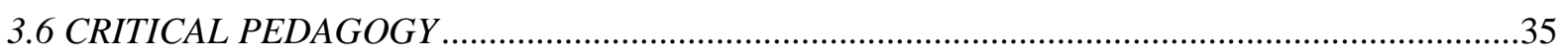

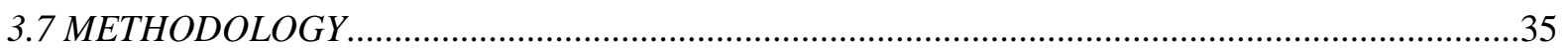

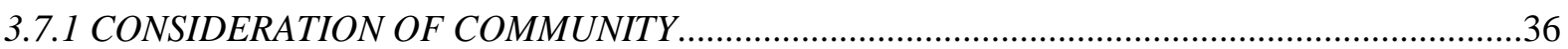

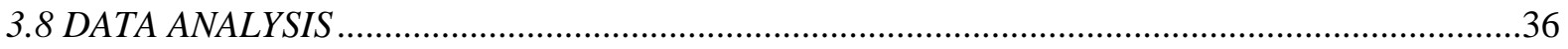

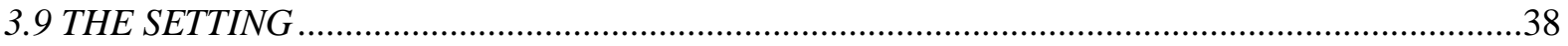

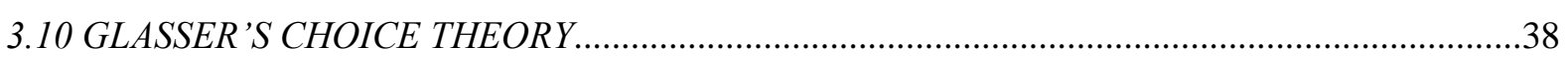

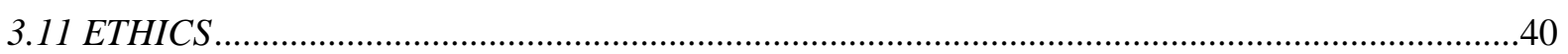

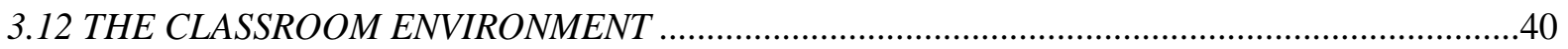

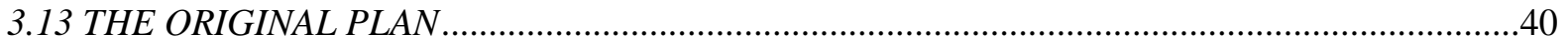

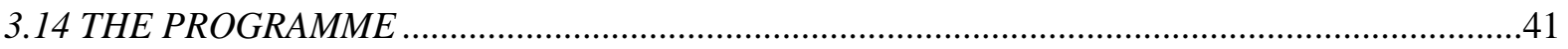

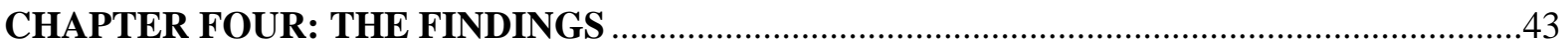

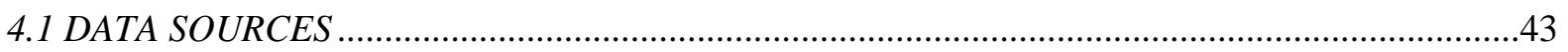

4.2 THREAD 1: MEDITATIVE BREATHING - A CATALYST ENABLING CALM .............................43

4.2.1 MEDITATIVE BREATHING - A CATALYST ENABLING CALM AFTER EXERCISE................46

4.3 THREAD 2: MEDITATIVE BREATHING - A CATALYST PROMOTING WELL-BEING BY: .....47

4.4 THREAD 3: MEDITATIVE BREATHING - A CATALYST FOR INSIGHT AND SELF-

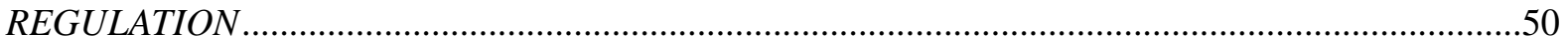

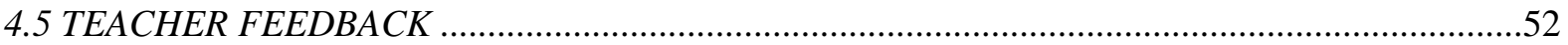

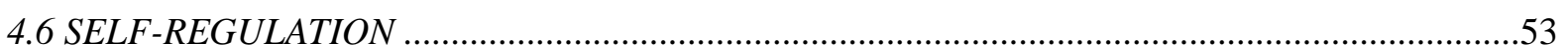

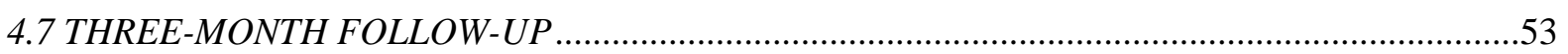

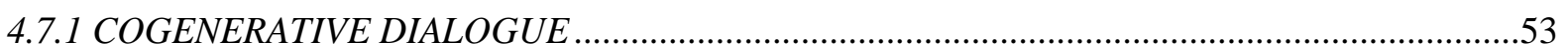

4.7.2 THREAD 1: MEDITATIVE BREATHING - A CATALYST ENABLING CALM ...........................54

4.7.3 THREAD 2: MEDITATIVE BREATHING - A CATALYST PROMOTING WELL-BEING..........54

4.7.4 THREAD 3: MEDITATIVE BREATHING - A CATALYST FOR SELF-REGULATION .............55

4.8 MEDITATIVE BREATHING IS MORE EFFECTIVE WITH PRACTICE ......................................56

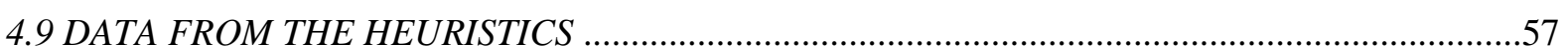

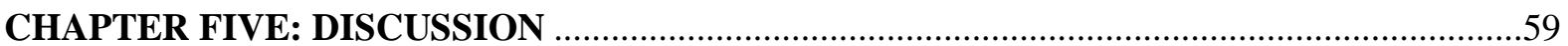

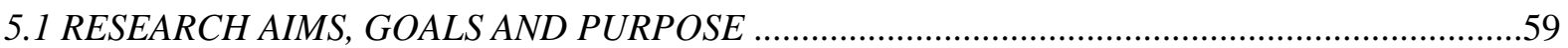

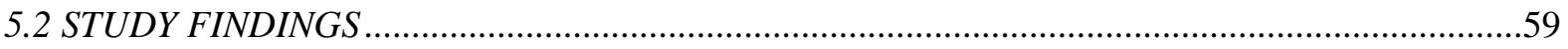

5.2.1 STUDENTS' EXPERIENCES OF MEDITATIVE BREATHING .............................................60

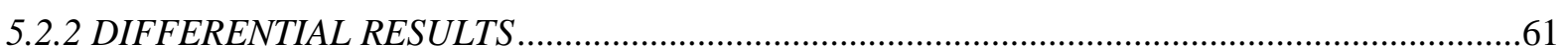

5.2.3 MB A CATALYST FOR INSIGHT AT THREE-MONTH FOLLOW-UP ....................................61

5.2.4 MEDITATIVE SKILLS IMPROVE WITH PRACTICE ……...................................................62

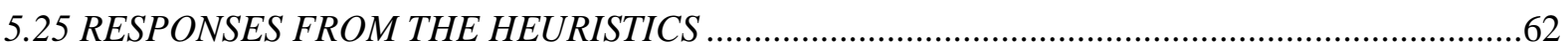


5.3 HOW DOES MB INFLUENCE STUDENTS AND THEIR LEARNING?...

5.4 WHAT ARE THE CRITICAL INFLUENCES ON MB PROGRAMME'S OUTCOMES IN THE

SCHOOL SETTING?

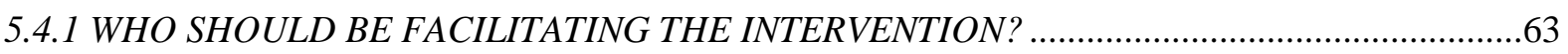

5.4.2 IS THE DEVELOPMENTAL STAGE IMPORTANT? ……......................................................64

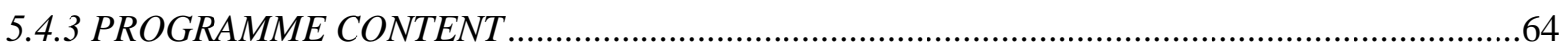

5.4.4 DURATION OF PROGRAMME AND FREQUENCY OF PRACTICE .......................................66

5.4.5 POTENTIAL INFLUENCE OF MB ON CLASS AND SCHOOL CLIMATE .............................66

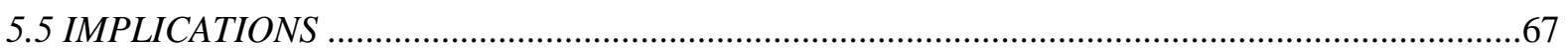

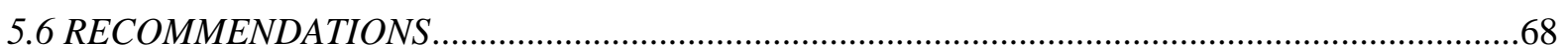

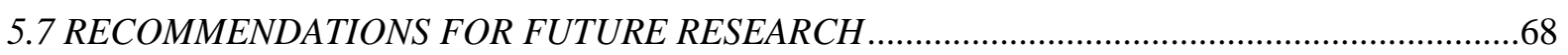

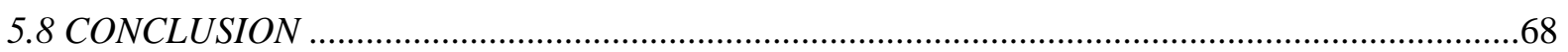

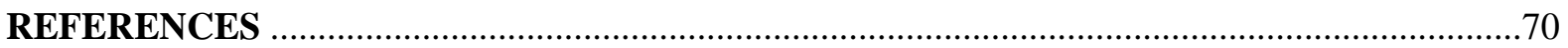

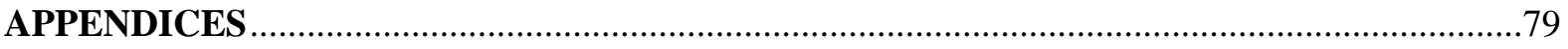

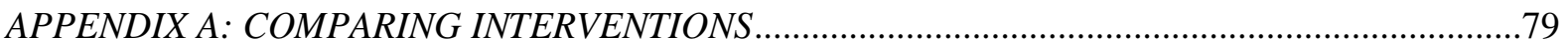

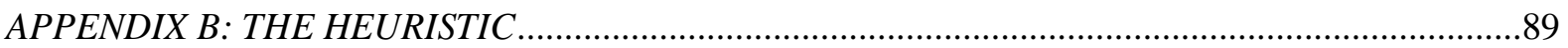

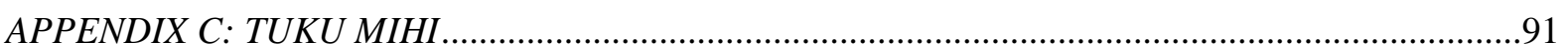

APPENDIX D: INFORMATION AND CONSENT FORM FOR PRINCIPAL, PARENTS AND STUDENTS...... 


\section{Figures}

FIGURE 1 CATEGORIES OF CONCEPTIONS OF MINDFULNESS ............... 4

FIGURE 2 THE DEVELOPMENT OF MINDFULNESS .......................... 6

FIGURE 3 HIGHER ORDER EXCECUTIVE FUNCTIONS DEVELOPED FROM THE BASE OF CORE EXECUTIVE FUNCTIONS...................................

FIGURE 4 THE SCHOOL-BASED MEDITATION MODEL........................ 17

FIGURE 5 DESIRED OUTCOMES FOR STUDENT'S WELL-BEING .............. 18

FIGURE 6 WELL-BEING PRIORITIES: STUDENT VOICE......................... 19

FIGURE 7 CLUSTER OF KEY THEMES FROM: WHAT MAKES A GOOD

LIFE?

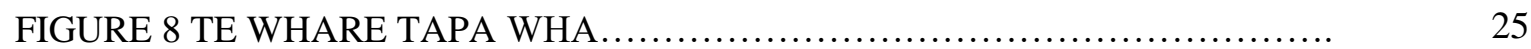

FIGURE 9 EMERGING THEMES............................................. 37

FIGURE 10 CHOICE THEORY METAPHORICAL STRUCTURES.................. 39

FIGURE 11 MB IS CALMING AND IT BALANCES ME.........................

FIGURE 12 THUMBS UP TO MB............................................

FIGURE 13 IS THERE CHANGE OVER TIME? ...................................................... 58

FIGURE 14 THE ESSENTIAL (WARP) AND FLEXIBLE (WEFT) OF MBIS ......... 65 


\section{Chapter One: Introduction}

\subsection{Background and purpose of this research}

This research explores the efficacy of Mindfulness-Based Interventions (MBIs) in the school setting, specifically, meditative breathing. The second purpose is to add nuanced New Zealand student voice (using their own words) to the research on MBIs in schools. I hypothesise that MBIs involving preadolescents, in the classroom may have the potential to support the development of self-regulation and wellbeing in students. The regular and sustained practice of meditative breathing may support the students in becoming self-regulated, focussed learners. This may, over time, lead to a consequent improvement in academic engagement and achievement (Hölzel, 2011).

While there have been studies using student self-report, responding to given questions, there are few studies that encourage the participants to describe their experiences directly in their own words or images. A notable exception is Higgins and Eden (2018). Following on from this authentic, participatory inquiry (Alexakos, 2015), I sought to share and analyse the described experiences of nine to ten-year-old participants in a ten-week programme of daily meditative breathing. Toshallis and Nakkula (2012) describe the use of student voice as an ideal application of motivation and engagement research.

This study involves three inter-related interventions, guided meditative breathing and cogenerative dialogue (cogen $)_{1}$ and a heuristic2. At the end of each week, the participants were involved in a cogenerative discussion describing their experiences before recording their reflections in their Google Doc. The students, as co-researchers, also made recommendations for adjusting the programme for the following weeks. They were aware that the other teachers at the school would discuss the suggestions that they made, and that these suggestions were likely to be considered for use in classroom programmes and possibly, on publication, by a wider education audience. This study gives students agentic voice, and the opportunity to inform change in our education system.

\subsection{The problem}

This research is important because the New Zealand government faces substantive challenges in meeting both the health and education needs of a significant number of our children who are vulnerable to alienation and inform the statistics of mental health distress and academic underachievement (Tomorrow's Schools Independent Task Force, 2018).

\footnotetext{
${ }^{1}$ Cogenerative dialogue is a for of productive dialogue in which all participants learn from each other.

${ }^{2}$ A heuristic is a form of Likert Scale that supports the students in developing their learning.
} 


\subsubsection{Health issues}

A significant number of children in New Zealand are vulnerable to mental health stressors and consequent learning issues as "New Zealand has amongst the highest reported rates of family violence in the developed world" (Ministry of Social Development, 2019). More than 25\% of New Zealand children have witnessed family violence. These children are vulnerable to stress that may undermine brain development, delay cognitive development and lead to mental health problems, including health-risk behaviours, as well as poor school performance.

The Strengths and Difficulties Questionnaire is a frequently used screening tool that measures social, emotional and behavioural problems in children. In New Zealand, it is used as part of the B4 School Check which assesses all four-year-old children. Parents complete the SDQ. It asks them to rate their child on 25 statements, covering five aspects of children's development: emotions, peer relationships, hyperactivity, conduct, and prosocial behaviour. The 2018 results of this screening indicate that 57,000 (approximately 8\%) of New Zealand children between the ages of three and 14 years had a total difficulties score indicating concern (approximately 8\%). A further estimated 50,000 children (7\%) had a 'borderline' total difficulties score. 12\% of Maori children, $10 \%$ of Pacific children and $12 \%$ of children living in areas of high deprivation, had a 'concerning' SDQ score (Ministry of Health, 2018).

Anxiety and Attention Deficit Hyperactivity Disorder (ADHD) are the most significant contributors to disability in young people aged 10-24 years (Whiteford, Ferrari \& Degenhardt, 2015). ADHD is a neurodevelopment disorder with a persistent pattern of behaviours characterised by inattention, hyperactivity, and impulsivity (American Psychiatric Association, 2000).

\subsubsection{Education issues}

New Zealand continues to have a very wide gap between its highest and lowest educational achievers (Tomorrows Schools Independent Task Force, 2018). Recent major education interventions have included the Maori Education Strategy 'Ka Hikitia Accelerating Success 2013-2017' (New Zealand Ministry of Education, 2018 ongoing). and 'Kotahitanga' (Bishop \& Berryman, 2006) with their focus on Maori children enjoying education success as Maori However, New Zealand has not narrowed the gap in performance between students attributed to differences in socioeconomic disparity and the marginalisation of those who are members of cultural minorities (Bishop, O'Sullivan \& Berryman, 2010). Students from disadvantaged backgrounds are less likely to succeed, particularly those who are also Māori, Pasifika, new migrants, refugees, or who have additional learning needs (Berryman, 2018). 
The New Zealand government has a legally binding responsibility to address this situation. The Treaty of Waitangi is the founding document of New Zealand. It specifies the responsibility of the crown to all of its citizens. The requirements in this document are intrinsic to the state education system's responsibility to redress these inequalities (Tomorrow's Schools Independent Task Force, 2018). Notably, the Treaty of Waitangi is one of the seven Principles of the New Zealand Curriculum Framework (2007) along with high expectations; cultural diversity; inclusion; learning to learn; community engagement; coherence; and future focus.

This is an on-going, unproductive situation as noted by the government's Education and Science Committee.

“...until the disparity in Maori achievement is corrected, Maori will continue to feature disproportionately in indicators of poor outcomes, and will be a wasted resource for New Zealand" (Education and Science Committee, 2008, p.10).

The research office of the United Nations International Children's Emergency Fund describes New Zealand as an example of one of 41 of the world's wealthier countries in which some children are not achieving as well as others because of circumstances beyond their control, e.g. parental occupation, (Innocenti, 2019). The Innocenti Report Card 15 places New Zealand at 36th out of 41 in the ladder of disparity in reading achievement at 15 years of age. In 2018 the New Zealand Ministry of Education conducted a review to consider whether the New Zealand schooling system is fit for purpose. The report concluded "the system is not working well enough for our most disadvantaged children and young people" (Tomorrow's Schools Independent Task Force, 2018, p.17). The gap between our best performing and worst-performing students has increased.

Self-regulation has a critical impact on developmental outcomes, including social and emotional wellbeing and academic functioning (Liew, 2010). Many of these underachieving students have limited self-regulatory skills. They struggle to focus and engage in their learning, are easily distracted, and have difficulty retaining new learning. This makes it difficult for them to progress with their learning and to think critically and abstractly (McClelland \& Cameron, 2011). They do not thrive as learners in the classroom environment and inform the statistics of low achievement.

Moreover, New Zealand does not have separate learning support classrooms for students with learning disabilities. These students are included in mainstream classrooms in New Zealand, and teachers frequently struggle to meet their learning needs satisfactorily and accommodate both their needs and those of the other students. 


\subsection{Mindfulness-based interventions (MBIs)}

Mindfulness based interventions (MBIs) are showing success in improving outcomes for students who have limited self- regulatory skills and consequently, do not achieve well at school (Desmond \& Hanich, 2010). Evidence suggests that training in mindfulness improves well-being and nurtures a variety of self-regulatory skills (Meiklejohn et al., 2012; Schonert-Reichl, et al, 2015). It appears that because of the brain's neuroplasticity (the way in which it can create new neurons and neural connections) the individual can alter their brain structure to increase brain health and enhance the quality of their life (Holzel et al., 2011).

\subsubsection{What is mindfulness?}

Mindfulness was historically a religious, spiritual practice embraced in different ways by a diversity of religions. Adapted forms of the practices of mindfulness are now used as a tool in behavioural medicine and, increasingly, education. In the 1980s and 90s, the first evidence-based interventions resulted in the first empirical studies of mindfulness-based stress reduction (MBSR). The term mindfulness means different things to different people, see figure one, where Baer, Smith, Hopkins, Krietemeyer and Toney (2018) note that the degrees of overlap are unclear and so depicted arbitrarily.

Figure 1. Categories of conceptions of mindfulness (Baer et al. 2006, p.44).

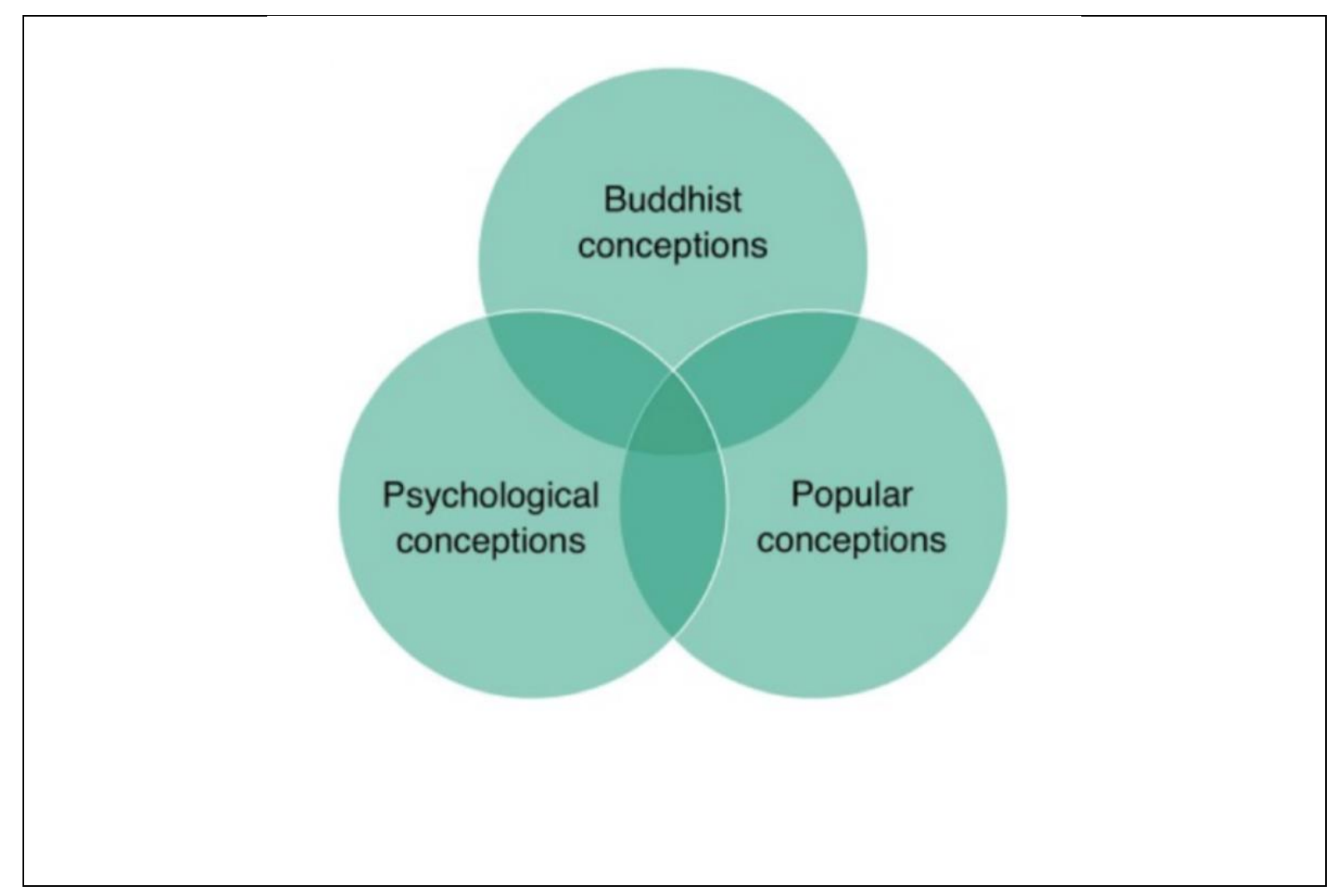


A definition couched in neuroscience describes mindfulness as a set of attention-based, regulatory and self-training systems (Allen, et al., 2012). From an equal opportunity/disability perspective, mindfulness is described as a way of training (through sustained practice) a less automatic way of being, decreasing reactivity in thinking, emotions, and behaviours as well as enhancing awareness of internal processes (Chapman, et al., 2013). The architect of Mindfulness-Based Stress Reduction (MBSR) Kabat-Zinn describes mindfulness from both a behavioural science and a contemplative perspective, as an innate capacity that can be drawn on, cultivated and deepened through practice. $\mathrm{He}$ portrays it as embodying the qualities of gentleness, benevolence, compassion, curiosity, inquiry, investigation, openness, availability, engagement, stillness and silence (Kabat-Zinn, 1994). From a psychological and psychiatric frame of reference (Bishop, 2004) describes mindfulness as " [A] kind of non-elaborative, non-judgemental, present-centred awareness in which each thought, feeling, or sensation that arises in the attentional field is acknowledged and accepted as it is." (p232).

The mindfulness concept of 'learning to be' is referred to in Gethin's (2011) description of mindfulness, that incorporates ancient and current definitions of mindfulness. He points out that ancient Buddhist texts describe it as a quality of 'presence of mind'. This presence of mind (a differing state from absentmindedness) is something that reminds us of who we are and what our values are. In the Theravada tradition (the teachings of the Buddha) it is described as a form of gatekeeper guarding the gates of the eye and other senses, enabling the practitioner to exercise restraint, helping us not to be overcome by feelings, perceptions, states of mind and emotions. It is my experience that children struggling with ADHD share feelings of relief when they learn to meditate and just 'be', however briefly.

\subsubsection{MBIs in the New Zealand classroom.}

Managing self is a key competency of the New Zealand Curriculum Framework (New Zealand. Ministry of Education, 2007). More complex than skills, key competencies are described as drawing "on knowledge, attitudes and values in ways that lead to action" (p.12). Students who can manage themselves are well prepared for life and learning with their capabilities to be resourceful, resilient, and have strategies for meeting challenges. In the context of this research and from my own experience as a meditation practitioner, I see the potential for students to develop increasingly nuanced and deepening experiences and understandings of mindfulness as their skills and knowledge increase over time.

The Mental Health Foundation of New Zealand (2012) advocates for the integration of mindfulness practice into educational settings. It points out that:

... the harmful effects of stress, anxiety, depression, and negative affect can be significantly reduced as a result of mindfulness practices, and that positive well-being and learning 
outcomes are facilitated, including an increased ability to be attentive, cognitive flexibility in learning, the capacity to retain and apply instructional knowledge from previous learning to new situations, positive effects on executive functions important in learning, increased resilience, calmness, and behavioural regulation (Mental Health Foundation of New Zealand, 2019).

Tang, Holzel and Posner (2015) represent this potential skill development in the broader context of attention control, emotion control and self-awareness moving through mindfulness meditation to selfregulation. They suggest that mindfulness meditation is comprised of at least three elements that interact synergistically bringing improved self-regulation, enhanced attention control, improved emotion regulation and altered self-awareness, refer part (a) of Figure Two. The second part (b) represents this as a developmental process moving through three stages from the early stage of effortful doing, through the middle stage of efforts to reduce mind-wandering to the advanced stage of effortless being. They suggest that each of these stages requires a different amount of effort.

Figure 2. The development of mindfulness (Tang, Holzel and Posner, 2015, p.2).

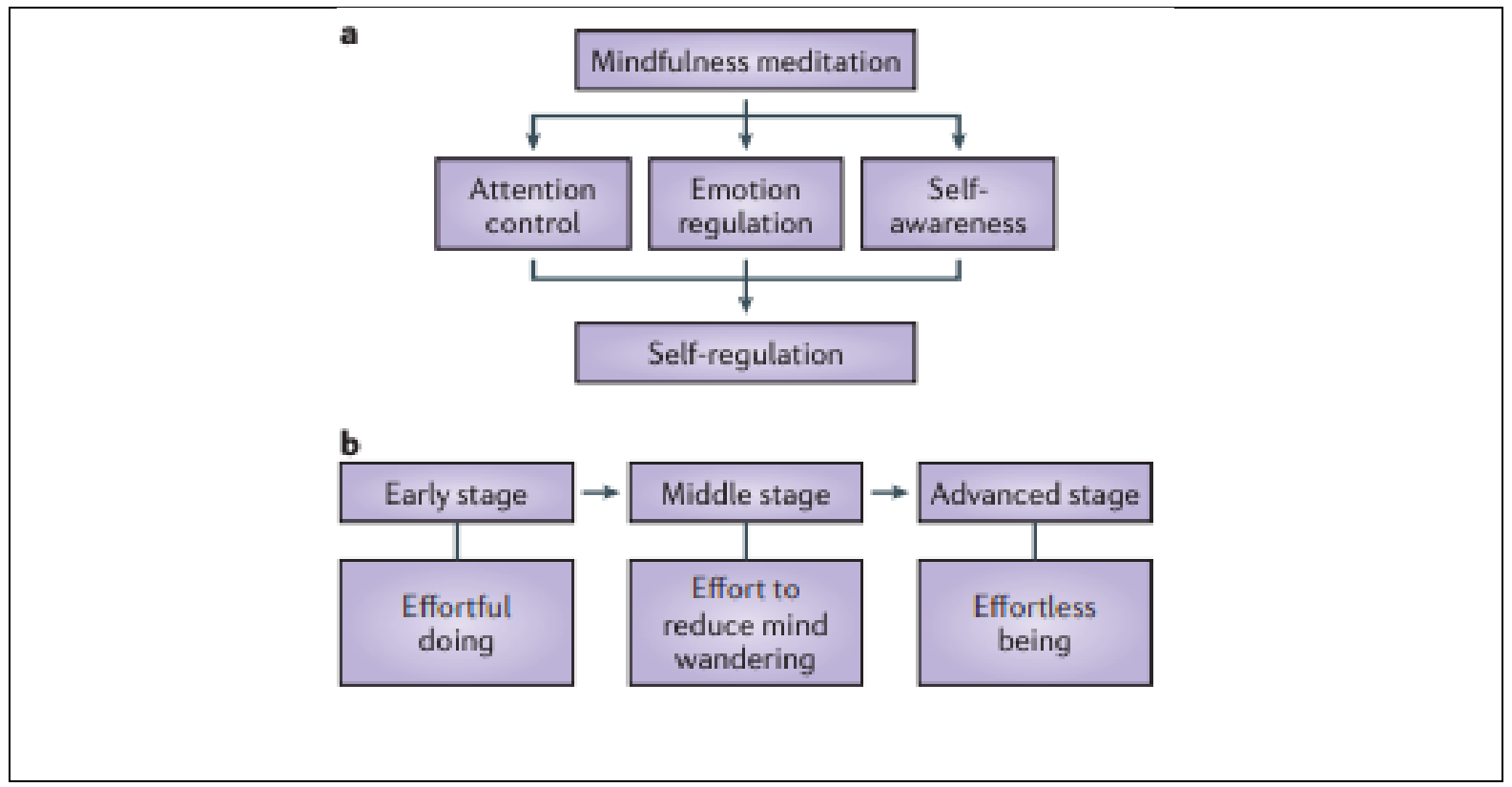

\subsection{The connection with learning}

MBIs in school programmes merit due consideration by educationalists in the context of the high rate of children and youth with anxiety and ADHD in New Zealand. A meta-analysis of ten studies investigating the efficacy of MBIs on individuals diagnosed with ADHD, (Cairncross \& Miller, 2016) found that MBIs significantly decreased inattention and improved self-regulation of the participants. More recently, Dunning et al. (2018) in their meta-analysis of randomised, controlled trials found: “...support for significant effects of a MBI, relative to the comparison condition, for measures of 
mindfulness, executive functions and attention, depression, anxiety, stress and negative behaviours" (p. 255).

\subsubsection{Executive functions}

Executive functions are described as the skills involved in the cognitive processes that manage and regulate the helpful behaviours of children who can persist with challenging tasks, continue to work and not be distracted, respect classroom rules, limit inappropriate behaviour, and focus on classroom activities (Blair \& Diamond, 2008). Research indicates that the development of working memory and inhibitory control skills can be accelerated through training (Molfese et al., 2010). With practice, mindfulness enables students to regulate their emotions, which progressively impacts on their behaviour, levels of stress, interpersonal relationships, and their capacity to focus their attention (de Carvalho, Pinto \& Maroco, 2016).

Diamond (2013) points out that it is possible to see the adverse effects of stress, sadness, and loneliness at the physiological and neuroanatomical level in the prefrontal cortex. Moreover, it would appear that there may be unique neural mechanisms for developing stages of mindfulness training, e.g. the progression from focussed attention to open awareness (Allen et al., 2012). Different mindfulness mechanisms might be more helpful for different personality types (Holzel, et al., 2011). Studies show positive evidence for mindfulness training beneficially affecting a range of selfregulatory behaviours in pre-adolescents (Flook et al., 2010; Schonert-Reichl et al., 2015).

One of the primary ironies of modern education is that we ask students to "pay attention" dozens of times a day, yet we never teach them how. The practice of mindfulness teaches students how to pay attention, and this way of paying attention enhances both academic and social-emotional learning (Saltzman, 2011, p.1)

\subsection{Student voice extended by cogenerative dialogue}

As an education professional, I am continually seeking opportunities to engage students in deep and meaningful learning. The use of student voice was intended to increase the participants' agency. It was important to allow them to influence decisions that may shape their lives and those of others. In my forty years of experience as a classroom teacher, it has become clear to me that student voice is a key means of increasing student agency and engagement in their learning (Leachman \& Victor, 2003).

In describing student voice as being about agency, Toshalis and Nakkula (2012) locate the degree of efficacy of student voice on a continuum along which are located indicators of increasing growth in students' roles, responsibilities and decision-making authority, as well as their capacity to make transformational change in their learning institution. This is "understood as the capacity to act in a way that produces meaningful change in oneself or the environment, agency is the key to student 
voice" (Toshalis \& Nakkula, 2012, p.27). The use of student voice in this study was expected to create a high level of engagement by the students and to give the researcher access to authentic, nuanced responses regarding the students' experience of the guided meditation programme (Higgins \& Eden, 2018).

This research used an authentic inquiry, a continuous interpretation of data and a heuristic (see Appendix B) to encourage cogen. Cogen was used to gather both individual and collective experiences and perspectives as to whether meditative breathing was useful for them in becoming focussed learners. Cogen is described as:

a means of establishing productive dialogues between teachers and students in which all participants learn from each other ... reflexive activities in which ...they identify what is working satisfactorily, what changes are desirable, what is possible, and what had been accomplished, pp. $5 \& 6$ (Tobin, 2012).

Tobin and Ritchie describe cogen as being an optimal way to discuss mindfulness.

This chapter describes the background and purpose of this research. It outlines New Zealand's current problem in the context of both health and education issues. It undertakes to give a relevant definition of mindfulness, linking it to the New Zealand Curriculum frame work and the key competencies. The chapter explains how MBI connects with learning. Finally, it describes the importance and potential power of student voice and cogenerative dialogue.

Chapter two reviews the relevant peer-reviewed research on MBIs in the education context. The introduction describes the challenges New Zealand faces and suggests the need for new approaches to help the education sector to remediate some student's disadvantage and consequent underachievement. It describes the process undertaken by the author to locate the relevant research within the appropriate literature. The relevant research interventions are described and the outcomes compared. Finally, it addresses the interesting issues that arise, points of conflict in the body of research and areas where more research is needed.

Chapter three begins by explaining the inquiry's conceptual framework, philosophical underpinnings, research aims, and the roles of the researcher and that of the students. It continues by describing cogenerative dialogue, critical pedagogy, the methodology undertaken and the setting. The final part of the chapter introduces the psychiatrist Glasser and outlines the ethics process, the classroom environment, the original plan and the MB programme. Its concluding comments discuss the difficulties of the use of a control group in the primary school setting.

Chapter four describes the sources of data which were co-generative dialogue, journaling, student's responses to a heuristic (which they completed at three points in time) and teacher feedback. It goes 
on to detail the teacher feed-back discusses self-regulation, and the findings from the three-month follow-up.

Chapter five revisits the study's goals, questions and the literature review. It discusses the outcomes in the context of the relevant research to date. It raises the question: What are the key influencers that affect MBI outcomes in the education sector? It goes on to discuss some of the outcomes of the research from the New Zealand perspective. In conclusion, it advocates for the inclusion of mindfulness training in student teacher training programmes and as part of teacher professional development. 


\section{Chapter Two: Literature Review}

This chapter reviews the relevant peer-reviewed research on MBIs in the education context. The introduction describes the challenges New Zealand faces and suggests the need for new approaches to help the education sector to remediate students' disadvantage and consequent underachievement. It describes the process undertaken by the author to locate the relevant research within the appropriate literature. The relevant research interventions are described and the outcomes compared. Finally, it addresses the interesting issues that arise, points of conflict in the body of research and areas where more research is needed.

The literature review explores findings to date in this field. It aims to identify studies that have informed the development of knowledge in this field. It investigates whether a simple form of MBI, guided meditative breathing, might be a new tool that may support educators in more effectively addressing the needs of disadvantaged students.

\subsection{The Context}

The New Zealand education system continues to struggle with a wide gap between its highest and lowest educational achievers (New Zealand Ministry of Education, 2018). A significant number of New Zealand students suffer from anxiety and Anxiety and Attention Deficit Hyperactivity Disorder (ADHD). Anxiety and ADHD are the most significant contributors to disability in young people aged 10-24 years (Whiteford, Ferrari \& Degenhardt, 2015). The research suggests that we need new approaches to help redress this lack of balance. This intervention aims to capture student's experiences of meditative breathing in the classroom.

The need for innovative interventions to address the lack of progress of stressed and disadvantaged learners is urgent if the New Zealand education system is to become "fit for purpose" (New Zealand Ministry of Education, 2018) and meet its responsibilities under the Treaty of Waitangi. Studies discussed in this chapter narrate a high level of acceptance and feasibility for MBI interventions.

\subsection{Locating the research.}

To search for relevant studies, I began by choosing my keywords/phrases - mindfulness, meditation, engagement in learning, elementary students, emotional and social well-being, stress, academic achievement, executive functions, self-regulation, depression, inappropriate behaviour, off-task behaviour, and focus. I accessed information through the Victoria University Library. I used the keywords/phrases to locate further articles using subject guides, advanced Google search, Google Scholar and ERIC. I also used government websites such as the OECD PISA database. I read the reference lists in relevant articles to locate the articles for which I was searching, taking into account the SJR score of the journals as well as the citation number of the articles. I also read related research. 


\subsection{Contributions to research on MBIs in schools.}

The literature review examines extant peer-reviewed literature and examines how the research has contributed to knowledge in this field. An extensive number of peer-reviewed, empirical studies exist that have examined the nature, application and possible effectiveness of mindfulness-based practices in the school setting (Meiklejohn, Phillips, Freedman, Griffin, Biegel, \& Roach, 2012). This chapter begins by describing a number of studies that found positive results for MBIs. These results indicated MBIs reducing anxiety and, secondly, supporting the development of executive control and selfregulation. The chapter goes on to discuss the implications of this research and looks at areas where further research is needed to advance existing knowledge.

\subsubsection{Reducing anxiety}

Interventions aimed at finding ways to reduce anxiety are critical as low-grade depressive symptoms diminish functioning and are a consistent risk factor for depression in adolescents and adults (Kuyken, et al., 2013). While these interventions vary in detail, they represent a variety of settings and populations, including, USA, Spain and the Netherlands. They also involve a range of developmental stages with students aged from five to eighteen. The studies illustrate increasing evidence of MBIs leading to decreased anxiety, improved attentional control, increased well-being and some suggestions of improved academic success.

An early intervention in the United States set the scene and discovered evidence of the potential efficacy of MBIs (particularly for students with ADHD) to impact positively on anxiety (Napoli, Krech \& Holley, 2005). The authors undertook a lengthy exploratory evaluation to investigate whether participation in a mindfulness training programme affected student outcomes on measures of attention. Napoli, et al. (2005) found a significant decrease in test anxiety and an increase in selective attention scores as well as improved social skills. The study took place with 194 students aged five to eight in two elementary schools in a southwestern city in the United States. The 24-week training was designed to help the students to learn to focus and pay attention. The programme included a focus on the breath, body scan3, movement, and sensorimotor awareness activities.

Also in the United States, Beauchemin, Tiffany, Hutchins and Patterson (2008) found improvement in all outcome measures showing decreased state and trait anxiety and enhanced social skills. This was a small early pre-post-test study (with no control group) of 34 students diagnosed as having learning disabilities, aged 13-18 years. The intervention involved five weeks of 45-minute sessions. The programme had a focus on breathing in order to develop a state of calm and a non-engaged, nonjudgemental observation of thoughts and feelings.

\footnotetext{
${ }^{3}$ Body scan involves progressively moving one's attention through the body with the intention of relaxing it.
} 
In an outpatient psychiatric facility, Biegel, Brown, Shapiro and Schubert (2009) sought to extend the nascent research on the helpfulness of mindfulness training with adolescents. Self-reported results described decreases in symptoms of anxiety, depression and somatic distress as well as increased selfesteem and quality of sleep. 102 adolescents aged 14-18 years received two hourly weekly training for eight weeks, with a three-month follow-up. The programme involved body scan, meditation, sitting meditation, hatha yoga and walking meditation. The instructors were experienced and trained in MBSR.

Franco, Manus, Cangos and Gallego (2011) analysed the effects of a mindfulness programme on 61 sixteen to eighteen-year-old students in Spain. They found significant decreases in anxiety as well as a significant improvement in academic performance and self-concept.

Back in the education setting van de Weijer-Bergsma, Langenberg, Brandsma, Oort and Bogels, (2014) carried out a primary prevention intervention to reduce stress and stress-related mental health problems. This randomised, wait-list (students in this group took part in the programme later in the year) control study involved 208 children aged 8-12 years in Amsterdam, the Netherlands. The participants received twelve 30 minute sessions over 12 weeks. The programme was written by two of the authors and was modelled after the MBSR (Kabat-Zinn, 1990) and Mindfulness Based Cognitive Therapy (MBCT) (Segal, Williams and Teasdale, 2002) training for adults. The participants received lessons in non-judgemental awareness of sounds, bodily sensations, breath, thoughts, and emotions. The classroom teacher was present during sessions and was asked to perform five-minute exercises with the class on the remaining school days. Children received a flyer after every session, which contained a further illustration of session themes and suggestions for optional practice at home. The intervention was facilitated by one of the authors, who is an experienced mindfulness trainer for adult groups with a background as a yoga teacher, schoolteacher, and family counsellor.

Data included multiple outcome measures and multiple informants followed by multi-level analysis. Results indicated only a few primary prevention effects on stress and well-being directly after the training; however, more effects were reported by both children and parents on follow-up leading authors to propose that such training has a prolonged effect.

Moving to England, Kuyken, et al. (2013) found positive outcomes concerning the potential for MBIs to ameliorate symptoms of anxiety in their non-randomized control feasibility study in England with a large sample group of 522 students aged 12-16 years. The authors used the programme Mindfulness in Schools Programme (MiSP) which is designed to teach young people the skills to work positively with mental states and stress in such a way as to promote their well-being and mental health. The programme involves nine scripted lessons of 40 minutes to an hour. Both the intervention and control schools were selected from the group of schools that either had teachers trained in the MiSP 
curriculum or teachers who had expressed an interest in being trained. The curriculum was developed, with teacher contributions, from a combination of contemplation and mindfulness traditions, MBSR (Kabat-Zinn, 1990) and from MBCT (Segal, et al., 2002). Self-report measures and a questionnaire were used to assess outcomes.

\subsubsection{Executive control and self-regulation}

The human executive function associated with the frontal lobes of the brain has a monitoring capacity which can predict action outcomes and maximise rewards (Collins \& Koechlin, 2012). Executive functions are described as a set of skills that arise from the cognitive processes that manage and regulate helpful behaviours of those children who are able to persist with challenging tasks, continue to work and not be distracted, respect classroom rules, limit inappropriate behaviour, and focus on classroom activities (Blair \& Diamond, 2008). They point out that these are the skills and behaviours of self-regulation behaviour: inhibiting, shifting, emotional controlling, initiating, working memory, planning and organizing of materials and monitoring.

Executive control (EC), is a significant predictor of academic success and well-being. It is possible to improve executive functions, e.g. self-regulation through repeated practise.

Training students with less well-developed EC may afford them the chance to perform as well as their peers (Diamond 2012). The further development of EC would be helpful to all students and is critical for underachieving students.

The peer-reviewed literature documents a developing understanding of the potential of MBIs to affect positive change for students. Reported results vary in their significance from indicative of the potential to describing a significant change in the treatment groups. MBIs appear to be particularly useful for students whose self-regulation skills are underdeveloped. 


\section{Different types of Executive Functions}

Core executive functions appear to develop earlier and to support the development of higher-order executive functions (Diamond, 2013).

Figure 3. Higher-order executive functions developed from the base of the core executive functions. Developed from Diamond (2013).

\begin{tabular}{|c|c|c|}
\hline \multicolumn{3}{|c|}{ Higher-order executive functions } \\
\hline \multirow[t]{2}{*}{ Reasoning } & Problem-solving & Planning \\
\hline & \multicolumn{2}{|l|}{ Core executive functions } \\
\hline$\uparrow$ & $\uparrow$ & $\uparrow$ \\
\hline Inhibitory control & Working memory & Cognitive flexibility \\
\hline Controlling one's behaviour & \multirow{3}{*}{$\begin{array}{l}\text { Holding information in the } \\
\text { mind and mentally working } \\
\text { on it. }\end{array}$} & \multirow{2}{*}{$\begin{array}{c}\text { The ability to change } \\
\text { perspectives }\end{array}$} \\
\hline Controlling one's attention & & \\
\hline Controlling one's emotions & & \\
\hline
\end{tabular}

Inhibitory control enables individuals to reconsider the choices that they make and change their behaviour patterns (Diamond, 2013). It aids the selective paying of attention, ignoring distractions, managing emotional responses and generally controlling behaviour. Executive functions are trainable and can be further developed through practice. Interventions with a focus on executive function, focus on particular aspects of this set of skills, e.g. the skill of self-regulation leading to attentional focus.

\subsubsection{Self-regulation leading to inhibitory control}

In their review of research and curricula on the integration of mindfulness training into K-12 (primary and secondary education) Meiklejohn et al. (2012) argue that mindfulness training can improve students' skills in self-regulation of attention and emotions and protect the developing brain from the adverse effects of excessive stress. The following studies describe the steadily growing body of evidence in this area. 
Studies based in the USA e.g. Napoli (2005); Mendelson (2010) found positive results for selfregulation and attentional control. Teachers and parents reported generalizability of these improvements as well as an overall trend for improved executive control (Flook et al, 2010). Additionally, Desmond and Hanich (2013) results indicated improved metacognition. These findings are very relevant to the New Zealand context where underdeveloped self-regulation skills and engagement contribute to reduced achievement levels in the socio-economically disadvantaged parts of the student population (Bishop, O'Sullivan \& Berryman, 2010).

In an early study, Napoli, et al. (2005) found that in addition to reducing anxiety (discussed in 2.3.1) MBIs (particularly for students with ADHD) have a potential positive impact positively on student focus and, reported improved social skills. Their results indicated a statistically significant difference between their experimental and control groups in their study with five to eight-year-olds. These included a decrease in test anxiety as well as an increase in selective attention scores. Interestingly it was the students who were less well-regulated who showed more significant improvement in executive functioning compared with the control group. They showed gains in behavioural regulation, metacognition, and overall global executive control. Both teachers and parents reported changes suggesting that improvements in children's behavioural regulation generalised across settings (i.e., behaviours observed by teachers in the school setting were also observed by parents at home). The students received tuition twice a month for 24 weeks. The Attention Academy programme included a focus on the breath, body scan, movement, and sensorimotor awareness activities.

Ten years later Flook et al. (2010) investigated the effects of training students in self-regulation in an MBI which focused on less well-regulated students. Their results showed substantial improvement with participants moving from the low executive function range to the average range on selfregulation outcomes. This study took place in Los Angeles, USA. The eight-week intervention involved 64 seven to nine-year-olds and took place in an on-campus elementary school. The curriculum which was developed by one of the authors included sitting meditation, body scan, sensory awareness, attention regulation, awareness of other people and awareness of the environment.

Over the intervention period, the twice-weekly sessions gradually increased in duration to 30 minutes. The participants who were less well-regulated showed more significant improvement than those in the control group. On measures of behavioural regulation, metacognition and overall executive control, the children who were in the low executive function range at the start of the programme were in the average range after the programme. Teachers and parents also described the generalizability of these behaviours. The mindfulness training was developed by one of the authors and focused on games and exercises to promote awareness of self, awareness of others and awareness of the environment.

Designed as a replication of research in this area, Desmond and Hanich (2010) found analagous results, indicating regression for non-treatment 11-12-year-olds contrasting sharply with the control 
group results. The authors found a significant effect for the treatment group in the ability to shift attention as well as a positive trend and improvement in metacognition. This RCT using standardised measures took place in the United States. It involved 40 eleven to twelve-year-old students in a lowincome urban middle school. The authors used the programme Wellness Works. The intervention assessed and analysed eight domains of self- regulation behaviour and executive function: inhibiting, shifting emotional controlling, initiating, working memory, planning and organising of materials, and monitoring. The treatment students either sustained or improved their level of executive attention, while the non-treatment group regressed.

An increase in self-regulation was reported by teachers in Black and Fernando (2013). The purpose of this field intervention trial was to evaluate the effect of a five-week mindfulness-based curriculum on teacher ratings of student class behaviour at a low-income, ethnically-diverse public elementary school in California. The trial included 409 children and 17 teachers. The Mindful Schools (MS) K-5 grade curriculum includes mindful listening, breathing, body awareness, heartfulness, mindful walking, eating and test-taking as well as discussion about thoughts and emotions. Both groups received the programme from experienced mindfulness teachers. All classrooms were randomly assigned to receive the MS curriculum or MS+. Participants in the MS + group received an additional seven weeks of 15 minutes once each week lessons which were composed of a review of the content delivered in the first 5 weeks intervention. The programme was comprised of three fifteen-minute sessions per week for five weeks. Teachers were asked to administer two-minute practices on the days that the facilitators were absent.

\subsubsection{Mechanisms that may facilitate mindfulness}

Moving the research conversation from somewhat fragmented outcomes to causal variables, Waters, Barsky, Ridd, and Allen (2014) developed a conceptual map in order to aid the understanding of the underlying mechanisms that facilitate the influence of meditation on student outcomes. They proposed that meditation has a positive impact on student success (i.e., well-being, social competence and academic achievement) by increasing cognitive functioning, including attention, learning and memory in students. They further suggest that meditation positively influences students' success by improving students' emotion self-regulation. They explain that the "School-Based the Meditation Model" in Figure Four has been developed using three strands of research: firstly, research from education showing that cognitive function and emotional regulation are positively associated with well-been informed by research in education, secondly from adult neuro-science and thirdly, from contemplative education. 
Figure 4. The School-Based Meditation Model (Waters et al., 2014).

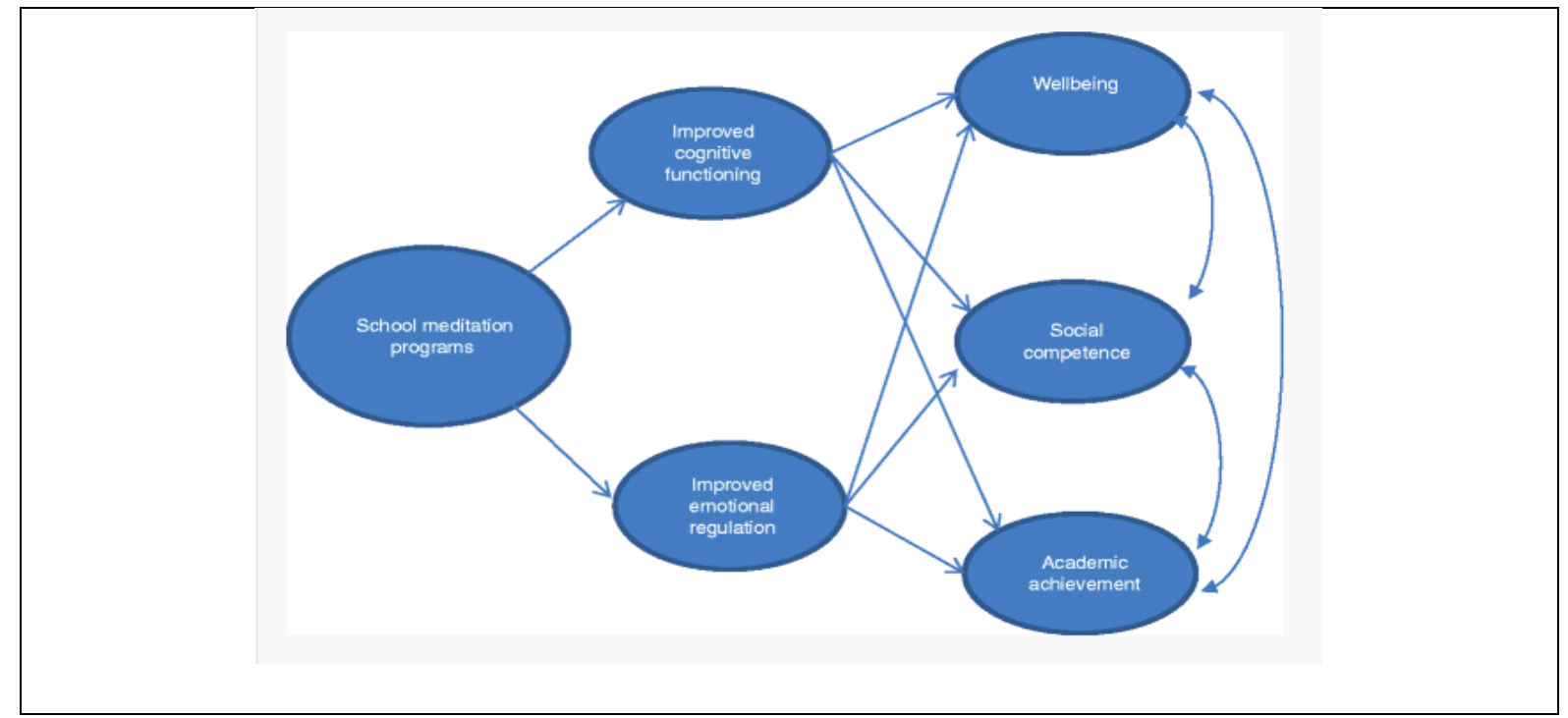

\subsection{Wellbeing}

Personal well-being, which rests on the essential supports of self-management, self-awareness, responsible decision-making, relationship skills, and social awareness, is key to the development of a healthy, happy, engaged student.

The New Zealand Education Review Office frames the discussion of what comprises well-being in the educational context, positively describing it in terms of the desired outcomes for student's wellbeing. 
Figure 5. Desired outcomes for students' well-being (Education Review Office, 2015, p.7).

\section{Students have a sense of belonging}

Students experience achievement and success

Students are resilient and have the capacity to bounce back

Students are socially and emotionally competent, are socially aware, have good relationship skills, are self-confident, are able to lead, self-manage and are responsible decision-makers

Students are physically active and lead healthy lifestyles

Students are nurtured and cared for by teachers at school, have adults to turn to who grow their potential, celebrate their successes, discuss options and work through problems

Students feel safe and secure at school, relationships are valued, and expectations are clear

Students are included, involved, engaged, invited to participate and make positive contributions

Students understand their place in the world, have confidence in their identity and are optimistic about the future

\subsubsection{Student's perspectives on what contributes to well-being.}

Consistent with the focus on student's voice in this inquiry, the New Zealand Office of the Children's Commissioner and Oranga Tamariki-Ministry for Children (2018) surveyed 58 primary and intermediate schools and 29 secondary schools and alternative education facilities. This comprised a total of 5631 students in order to find out what well-being means for them. Their responses are listed below. 
Figure 6. Well-being Priorities: Student Voice (Office of the Children's Commissioner and Orangi Tamariki, 2019).

\begin{tabular}{|lll|}
\hline Responses & $\begin{array}{l}\text { Number of } \\
\text { respondents }\end{array}$ & $\begin{array}{l}\text { Percentage of } \\
\text { respondents }\end{array}$ \\
Everyone should have their basic needs met & 510 & $15 \%$ \\
Education is important & 456 & $14 \%$ \\
We all need family, friends, people who will love and care for us & 427 & $13 \%$ \\
Support my health and mental health & 343 & $10 \%$ \\
Keep us safe & 314 & $9 \%$ \\
Jobs and employment make a big difference & 208 & $6 \%$ \\
Support us to have good lives & 199 & $6 \%$ \\
Value and respect us & 174 & $5 \%$ \\
Money matters & 91 & $3 \%$ \\
Opportunities & 108 & $3 \%$ \\
\hline
\end{tabular}

The students' responses illustrate the importance to them of happiness and enjoyment, supportive family and friends, and having their basic needs met. 
Figure 7. Cluster of key themes from: What makes a good life? (Office of the Children's Commissioner and Orangi Tamariki, 2019, p.5).

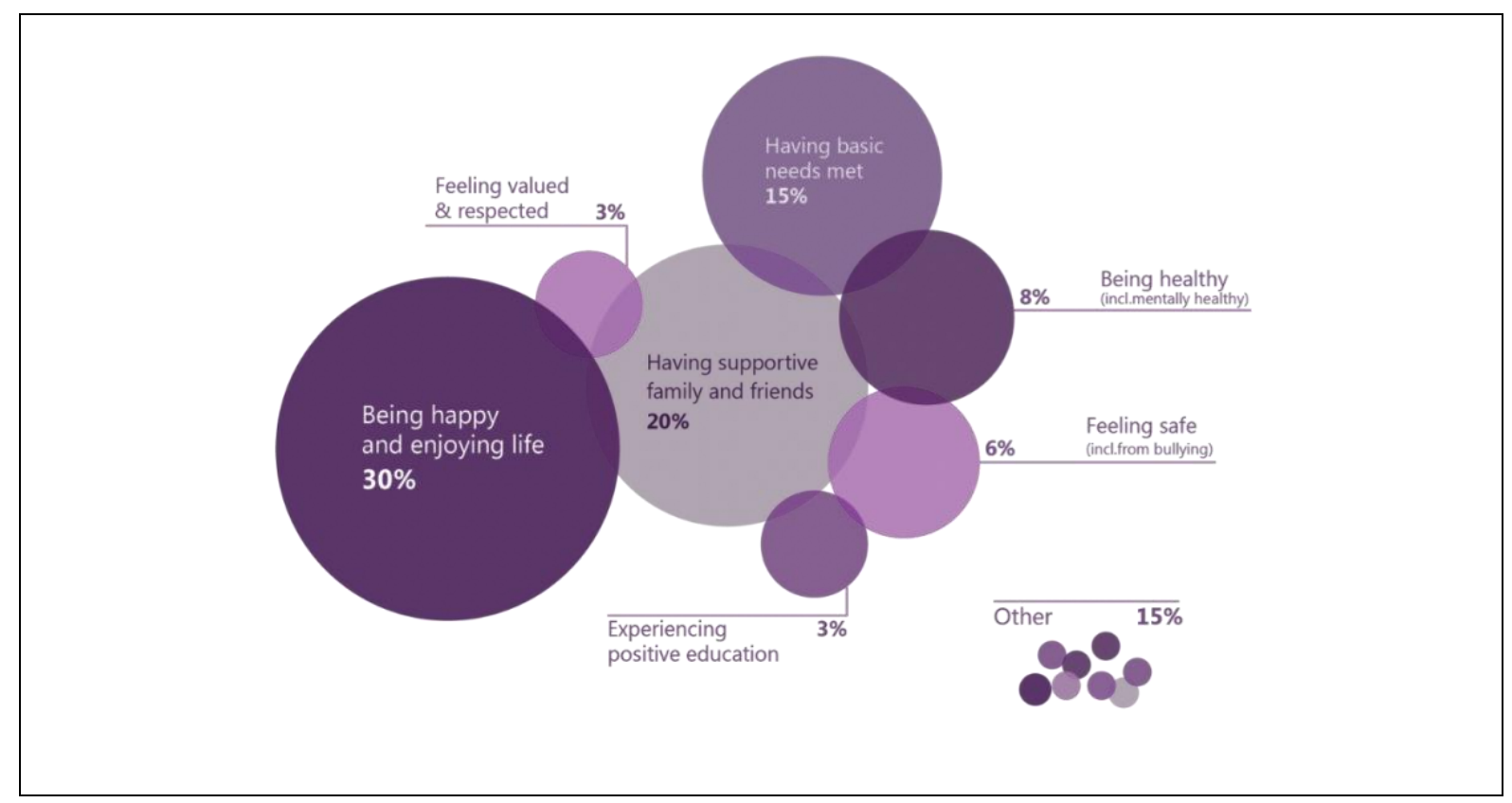

\subsubsection{The potential role of MBIs in enhancing well-being.}

Moffit et al. (2011) discussing the The Dunedin Study - Dunedin Multidisciplinary Health \& Development Research Unit, 2019) point out that:

“...childhood self-control predicts physical health, substance dependence, personal finances, and offending criminal outcomes, following a gradient of self-control”, p.1.

If self-control develops in a gradient, small changes have the potential, over time, to affect significant change in not only the individual student's, but also in those with whom the individual interacts. This literature review described the positive results that have been found by a number of interventions. As an experienced classroom teacher, I have frequently noticed that positive change occurring for one child in the class creates a change in the classroom learning dynamic and overall classroom climate.

Decreased anxiety, increased well-being and improved social skills have been reported in a number of studies, (e.g., Napoli, et al., 2008) described improved social skills as an outcome of their intervention with five and-eight-year-olds.

Similarly, Beauchemin et al. (2008) found improvement in all outcome measures showing decreased state and trait anxiety and enhanced social skills following a 5-week 45- minute session, mindfulness meditation intervention. This was a small early pre- post-test study of 34 students aged 13-18 years, diagnosed as having learning disabilities in a private residential school in Vermont, United States. The 
intervention comprised a focus on breathing in order to develop a state of calm and a non-engaged, non-judgemental observation of thoughts and feelings.

Consistent with Napoli et al. (2005)'s findings, Mendelson et al. (2010) found student reported gains in behavioural regulation and overall executive functioning in nine to eleven-year-olds. This study which involved 97 disadvantaged youth, aged nine to eleven years in Baltimore, USA, found that the students reported a positive experience learning skills that helped them in their day-to-day lives and that all of the teachers who were involved with the programme were supportive of the training. They used the Holistic Life Foundation programme which involves yoga and attention to the breath.

In the same year Schonert-Reichl and Lawlor (2010) found teacher-reported positive efficacy regarding the MindUP programme's potential to positively influence the development of social and emotional skills in pre-and early adolescents. The intervention involved 246 students aged seven to thirteen years in a large city in western Canada. The programme comprised ten fifty minute lessons with an additional three-minute focus three times each day.

In a study focusing on wellbeing Huppert and Johnson (2010) investigated approaches that could benefit children's wellbeing, they found outcomes showing some evidence of improvement in student's psychological well-being related to how much independent practice the students had undertaken. This four-week, controlled trial using standardised quantitative measures with 173 students aged 14 and 15 years in England. The programme was based on a well-established curriculum arising from the MBSR programme (Kabat-Zinn, 2009) comprising four weekly, 40 minute classes supported with practice CDs.

Framing their investigation in the classroom culture Rix and Bernay (2014) found that students developed more positive relationships, their ability to see other's points of view, improved emotional regulation and happier classroom culture. Their study investigated how an MBI could support wellbeing and academic achievement. Participants reported using the practices at home or showing them to their parents, improved emotional regulation and happier classroom culture. Teachers also benefitted with increased calm and stress reduction.

This New Zealand based eight-week-long qualitative investigation (with a three-month follow-up), to explore the potential positive effects of a classroom-based mindfulness programme on the well-being of students. The intervention involved 126 students aged $6-11$ years old and six classroom teachers in five primary schools. The programme Pause, Breathe, Smile was written by the study authors and is aligned with the Key Competencies of the New Zealand Curriculum (2007), in particular, the wellbeing 'Hauora'4 This dimension of the health curriculum, 'Hauora', is a holistic construct in the indigenously informed health curriculum, with a focus on the well-being of students. The programme

\footnotetext{
${ }^{4}$ The term Hauora refers to the Maori concept of total health
} 
included breath-body awareness, sensory awareness, practices for promoting kindness and gratitude, emotion-regulation, and interconnectedness.

The authors found that all schools involved described improved calmness of classes and that children showed improved focus over time. The authors facilitated the intervention. Both teachers and students found ways to use the practices to help them with the challenges of their day. It is the first study that I am aware of that includes teacher reports of teachers using the skills to help them with stressful situations.

Including classroom teachers in programme development, Broderick and Frank (2014) found reductions in negative mood and improvements in calmness. The authors adopted a manualised training programme that was adapted from MBSR (Kabat-Zinn, 2009). It was designed to be used as part of the school's health curriculum. The curriculum was designed to enhance emotion regulation, strengthen attention and support the academic performance, reduce stress, teach stress management, and help students integrate mindfulness into everyday life. It comprises six, twelve or eighteen lessons which can be adjusted to meet the needs of the students. Activities based on MBSR, body scan, awareness of thoughts and feelings, mindful movement, and loving-kindness practice have also been adapted for younger groups. Each lesson includes a brief introduction to the topic, a selection of activities for group participation and discussion to engage students in the lesson, as well as in-class mindfulness practice.

Building on their 2010 study Schonert-Reichl, et al. (2015) investigated the potential for an MBI to improve cognitive function and to promote well-being and positive school outcomes. Their results showed significant improvements in the participants on self-reported measures of well-being and other psychological variables as well as self-and peer-reported pro-social behaviour. The teacher reported efficacy regarding the intervention's potential to positively influence the development of social and emotional skills. The authors suggest that the three times daily for three minutes of practice led by the classroom teachers may have led to the observed improved inhibitory control, leading to improved emotional control and decreased aggression.

The introduction of classroom teachers facilitating this highly frequent level of practice is new and consistent with encouragement to practice regularly and frequently (Napoli, Krech and Holley, 2005). The programme had an emphasis on extending key content to other areas of the curriculum and the students' lives outside school.

Extending the theory and practice debate as to which is the most effective form of MBI intervention to effect positive change in children's learning, Bakosh, Snow, Tobias, Houlihan, and Barbosa-Leiker (2015) tested the feasibility and effectiveness of the first teacher-independent, audio-guided MBI intervention to effect quarterly grade achievements in reading and maths. Results showed improved quarterly grades in reading and science. Ninety-three nine and ten-year-old students in two US 
elementary schools took part. The mindful-based social and emotional learning (MBSEL) intervention required ten minutes practice daily for eight weeks. This quasi-experimental trial comprised a series of guided mindful-based awareness and attention focusing practices to encourage students to engage with social and emotional learning (SEL) concepts.

Moving the inquiry to older adolescents Sanger and Dorjee (2016) findings suggest that a schoolbased MBI can enhance older adolescent's task-relevant inhibitory control of attention and perceived mental competency. Their results suggest that a school-based MBI can enhance older adolescents task-relevant inhibitory control of attention and perceived mental competency. The intervention involved eight weeks of hourly lessons. The 22 students aged 16-18 years attended four different schools in Wales. The authors described the results as adding further support to the hypothesis that such training helps the development of metacognitive awareness and well-being with the potential to support academic success.

They used the electroencephalogram (EEG) as a source of data in their wait-list control trial. The purpose of this intervention was to investigate whether an MBI delivered by school teachers as a part of the school curriculum could have a positive impact on attention processing in adolescents. The intervention involved 40 participants aged 16 to 18 years using self-report measures and computerised tasks. They used an age-appropriate form of the .b Foundations programme, Mindfulness in Schools Programme (MiSP) in eight 50 minute long weekly sessions. This study used classroom teachers rather than external trainers to deliver the programme. The authors described the results of the mindfulness training as adding further support to the hypothesis that such training helps the development of metacognitive awareness and well-being with the potential to support academic success. They challenge the findings that frequency of mindfulness practice is a critical factor in promoting change (Kuyken, et al. 2013) with their findings suggesting that it is the quality of engagement that is key (further discussed in 5.8).

Within the broader parameters of psychological health Bennet and Dorjee (2016) results indicated improvement in depression and anxiety. The authors claimed that this improved psychological health would support them in achieving their academic potential. Bennet and Dorjee utilised the MBSR course with a focus on a body scan, mindful awareness and sitting practice. The eight-week intervention, with a three-month follow-up, involved 23 sixteen to nineteen-year-olds took place in North West England. The weekly sessions were held after school and were two hours long for eight weeks. Students were encouraged to do 45 minutes of home practice every day.

Vickery and Dorjee (2016) add to the developing knowledge finding that seven to nine-year-olds showed signs of improved metacognition as a result of their participation in an MBI. The authors investigated the feasibility and impact of mindfulness programmes on emotional well-being when delivered by school teachers to pre-adolescent children. This controlled pilot study found significant 
improvements in metacognition at follow-up and teacher-reported improvement in metacognition. Seventy-one seven to nine years-olds from three primary schools in North Wales were involved in this study. The authors claimed these findings as initial evidence that the Paws. b programme may significantly decrease negative affect and improve meta-cognition.

In the New Zealand context adding to the literature with an indigenously informed, national curriculum-aligned programme, Devcich, Rix, Bernay and Graham (2017) found a high level of acceptability in their eight-week study. It included a time-matched active control (emotional literacy programme) study with 106 participants aged 9-11 years in New Zealand. The purpose of this study was to investigate the effectiveness of their MBI on children's self-reported well-being. Participants reported that they enjoyed taking part in the programme and that they generally perceived the classes to be beneficial. The authors found 'significant' increase in mindfulness scores for the participant group and some indication of the sustainability of effects at 12 weeks.

The Mental Health Foundation of New Zealand developed the Pause, Breathe, Smile programme used in this study. It embraces values regarding health and well-being. It was informed through consultation and guidance from elders of the New Zealand indigenous Maori population (Rix \& Bernay, 2014). It incorporates models of health and well-being (Hauora) from the New Zealand Health Curriculum (2007) including physical well-being (taha tinana), mental and emotional wellbeing (taha hinengaro), family and social well-being (taha whanau), and spiritual well-being (taha wairua). The figure below shows the concepts in the metaphor of a Maori meeting house. 
Figure 8. Te Whare Tapa Wha, developed by Rix and Bernay (2014) p.207 from (Durie, 1984).

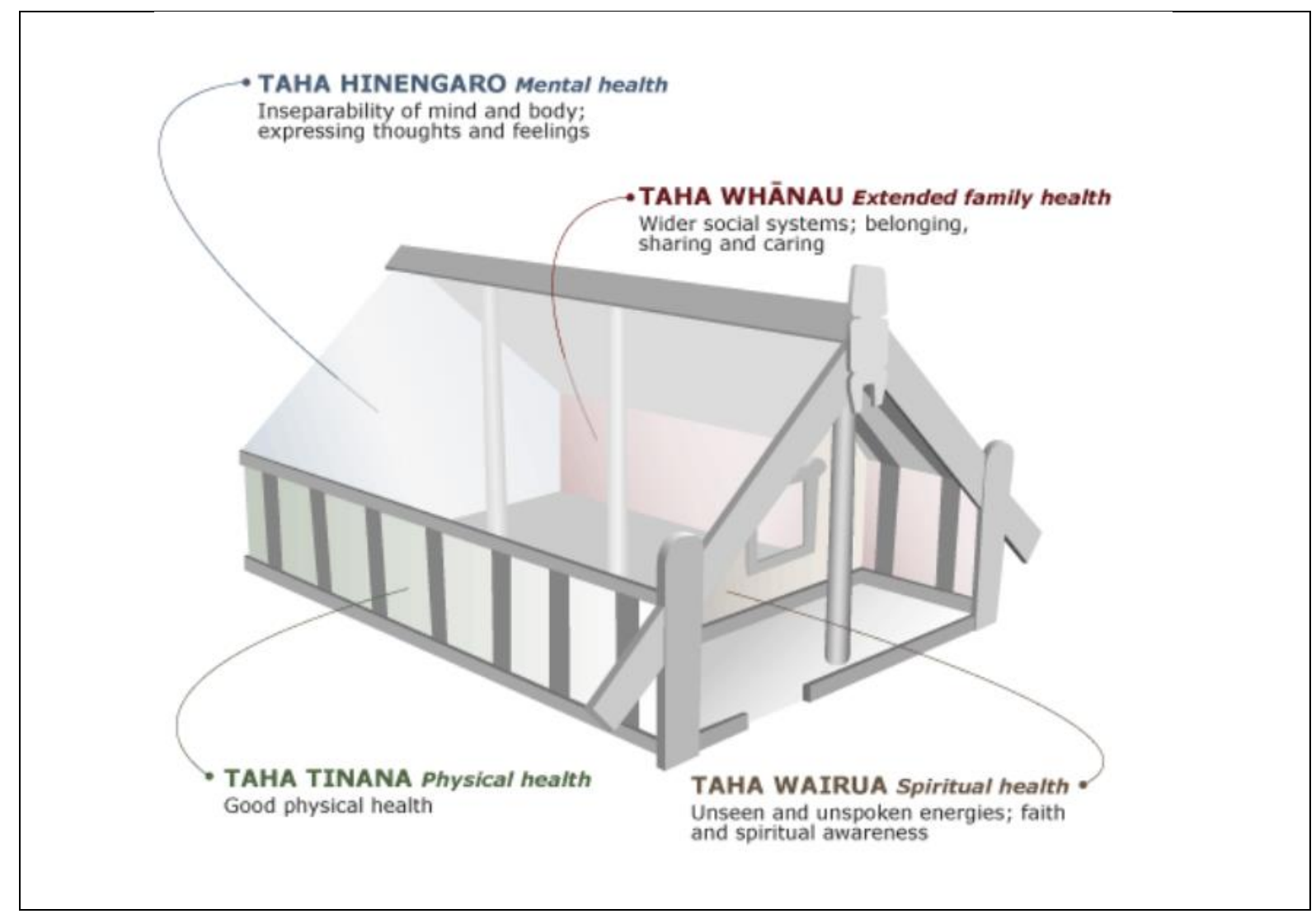

Student agency is an important contributor to student well-being. Seeking to promote student and teacher agency, a study that 'walks its talk' is an authentic inquiry (Alexakos, 2015) in which Higgens and Eden (2018) used a multi-theoretical approach to gain student, teacher and researcher perspectives on teaching and learning as emotional work. They found that the cogen as a hybridised space supported the participants in developing their understandings of the negotiated collective meanings of mindfulness-based breathing.

The study employed "collective sense-making through cogenerative dialogue" (Higgens \& Eden, 2018, p. 678) of a mindfulness-based breathing practice. The authors were interested in students creating nuanced claims of the collective experiences of mindfulness-based breathing and how this contributed to the all of the participants' awareness of emotions and learning environments.

Mindfulness-based breathing practices acted as a heuristic for thinking about learning environments leading to new forms of class culture more orientated to student agency. The study took place in a typical New Zealand public school in a large urban area. It involved 30 students aged 10-12 years old. The teacher used a publicly available audio clip to introduce the practice. The focus was on the posture of sitting to allow the breath to flow through the body, emphasised stillness, staying upright, 
attention to comfortably resting the limbs, while maintaining non-judgemental attention to one's mental state, mind-wandering, and connections between energy and calmness.

Students attitudes towards the programme are very likely to influence their degree of engagement and expectations. Studies that focussed on the acceptability of programmes found high levels of acceptability. In Arthurson (2015) study the overall rating for the acceptability of the programme was high and Bluth, Campo and Pruteanu-Malininci, Reams, Mullarkey, and Broderick (2016) found that with older students, acceptability increased with time.

\subsection{Interventions targeting stressed and disadvantaged groups}

The potential for MBIs to positively impact the wellbeing and the learning of our most vulnerable and stressed students has been realised in a number of interventions. Studies that target, or are informed by, the results of academically struggling children and youth show positive results across a range of ages and developmental stages. Students who are experiencing stress and distress in their lives appear to make the most significant progress with these interventions.

An increasingly subtle analysis of the factors contributing to the acceptability of interventions is found in a randomised pre-post-test mindfulness intervention with 27 ethnically diverse youth enrolled in an alternative high school in North Carolina (Bluth, et al., 2016). The authors found the acceptability of the Learning to BREATHE programme (Broderick \& Frank, 2014) improved over time with increased familiarity with the person delivering the programme and an improved location in which the programme was delivered.

With results that further illustrate this point Mendelson et al. (2010) conducted a pilot randomised controlled (wait-list) trial in Baltimore (USA) involving 97 students aged 9 - 11 years. This 12-week intervention involved 45 minutes of instruction and practice four days each week. The authors sought to enhance the students' self-regulatory capacities with the potential for improved mental health outcomes and social adjustment. The programme comprised yoga-based physical activity, breathing techniques, and guided mindfulness practices. The authors concluded that the intervention showed promise and added to the developing literature in this area. The results showed gains in behavioural regulation and overall executive functioning. Students reported a positive experience learning skills that helped them in their day-to-day lives and all teachers who were involved with the programme were supportive of the training. They called for research that randomised participants by children or class within the school and non-self-report assessment methods including teacher reports, student grades as well as physiological measures, e.g. cortisol level.

Positive findings with regard to executive function were found by Desmond and Hanich (2010). The authors conducted a ten-week RCT involving 40 students aged 11-12 year in an urban low-income middle school in the northeast of the United States. The results showed a significant effect for the 
treatment group in the ability to shift (attention) as well as a positive trend and improvement in the overall scores on the metacognitive index and the global executive composite of the BRIEF. The intervention assessed and analysed eight domains of self-regulation behaviour and executive function: inhibiting, shifting emotional controlling, initiating, working memory, planning and organising of materials, and monitoring. The treatment students either sustained or improved their level of executive attention and one of the executive control behaviours while the students in the control group regressed in all areas. The intervention used a programme developed by one of the authors, which includes attention shifting, breathing, movement and relaxation activities, and group discussion. Lessons were for 25-45 minutes once a week.

In a small study that is relevant to New Zealand's challenges with its high rate of students with ADHD, van de Weijer-Bergsma, Formsma, Bruin and Bogels (2012) conducted a study to evaluate the direct, middle-term, and longer-term effects of mindfulness training for ten adolescents diagnosed as suffering from ADHD, aged 11-15 years. The authors found that the majority of their results pointed to an improvement in attention and behaviour. The intervention comprised of eight weekly 30 minute sessions of mindfulness exercises, followed by a booster session including both students and their parents. It also included parallel mindfulness training for parents. The MBI was delivered in a group format with the participants receiving training in focus, attention, awareness, and self-control. Despite the small study size and therefore the need for caution in generalising from it, this study adds to the research with the inclusion of parents in the study who may be instrumental in encouraging participants to practice at home, thus increasing the likelihood of the generalisation of the practice to other settings.

Housing security is an increasing issue in New Zealand with high sale prices pushing up the cost of rental properties. This has resulted in an increase in the number of families struggling to find accommodation to the point where homelessness is increasing in New Zealand (Johnson, HowdenChapman \& Eaqub, 2018). Viafora, Mathiesen and Unsworth (2014) found that youth facing homelessness were significantly more likely to find an MBI helpful. This was a quasi-experimental design which included two treatment groups and a non-equivalent control group with 48 students aged 11 to 13 in England. The purpose of this study was to evaluate the acceptability, generalizability, and overall effectiveness of an eight-week mindfulness course for traditional middle school students and another group of middle school students facing homelessness. The eight-week programme included listening, eating, guided sitting meditation, pleasant experiences, test-taking, movement, and home practice activities.

Moving to the European context Ricarte, Ros, Latorre et al. (2015) conducted an RCT involving 90 children aged seven to nine years in Spain. Their results showed significant decreases in trait anxiety levels and improved well-being. The study took place in a rural school in Spain in an area with a low 
socio-economic profile, with most young people discontinuing their education at the primary level. The six-week programme comprised breathing meditation, mandala meditation, present moment meditation on sounds and body scan.

At-risk adolescents' perception of an MBI improved over time (Bluth et al, 2016) a randomised prepost-test mindfulness intervention was delivered over 11 sessions of 50 minutes. It involved 27 ethnically diverse youth enrolled in an alternative high school in North Carolina. The Learning to BREATHE programme used was designed for adolescents. It is based on the themes used in MBSR, including the body scan, sitting meditation, loving-kindness practice, walking meditation and mindful movement. The delivery of the programme was adjusted to meet the needs of the students in the school and included restorative yoga. The increasingly positive student perception of the programme may have been influence by their increased familiarity with the facilitator and because the programme was delivered in a more appropriate environment. Youth living in a shelter for homeless families or vulnerable to doing so, reported high levels of programme acceptability as expressed by the students recommending the programme to friends (Bluth, Campo \& Prutenau, 2016).

Likewise, Milligan et al. (2017) intervened with a self and teacher-selected MBI (Integra Mindfulness Martial Arts). The purpose of this study was to explore the acceptability of an MBI for stressed highschool students with emotional regulation challenges. The study examined the impact, on teacher and student reported academic outcomes, social confidence, emotional regulation, and self-confidence. The programme involved 24 at-risk secondary students from a poor rural area in Canada.

This qualitative intervention found teacher and student (both high and low risk) reported ratings showed an increase in approaching social interactions, making friends, interactions with peers and teachers. Results suggest that student behaviours became more adaptive and appropriate with improved emotional regulation, including behaviour and anger management, improved selfconfidence and increased awareness of themselves and their environment. The authors describe findings of increasing awareness, calm, attention, and acceptance, all supporting positive change.

The instructor, who was experienced in mindfulness practice also participated in 10-week web-based training for teaching mindfulness to children and adolescents taught by Dr Saltzman (Saltzman, 2019) between delivering the course to the two training groups. The two instruction manuals used were: Planting Seeds: Practicing Mindfulness with Children (Nhat Hanh, 2011) and Still Quiet Places: practices for Children and Adolescents to Discover Peace and Happiness (Saltzman, 2008). Students facing homelessness reported significantly higher evaluations of the course, greater emotional wellbeing from mindfulness practice. They were more likely to use mindfulness practice at school, in interpersonal situations, for dealing with anger and other challenging emotions and recommending it to friends. 


\subsection{Considerations}

The comparison of research in this field is complex as there are a number of factors that may contribute to varying outcomes.

\subsubsection{Frequency of practice}

The frequency with which the students practice their developing skills appears to have a significant impact on student outcomes (Huppert \& Johnson, 2010). Their study found evidence of improved well-being depending upon how much independent practice had been put in by the participants. Beigel et al. (2010) whose results showed a significant reduction in anxiety and depression had the class teacher administering five-minute practice sessions on the four days that the authors were not in the classroom.

\subsubsection{Sustainable gains}

The retention and tracking of improvements after study completion are vital issues for the efficacy of MB programmes. Black and Fernando (2013) found that their MS+ group which received on-going training after the intervention continued to increase in attention regulation compared to the flattening of skills in the group that did not receive the additional training. In addition to the duration of the programme, another substantive issue concerning prolonged effect is the influence of programme follow-up and what form this should take. Van de Weijer-Bergsman et al. (2014)'s results showed a waning at the sixteen-week follow-up, indicating the importance of follow-up and suggesting a prolonged effect on the students who had participated.

\subsubsection{Student perceived relevance}

Reflecting on the key factors contributing to the efficacy of MBI interventions, Sanger \& Dorjee (2016) challenge the findings (Kuyken et al., 2013) that it is frequency and duration of practice that is critical to substantive improvement. They argue that the degree of engagement of participants in the programme is a critical factor in their success. I note that in their intervention, Mendelson et al., (2010) described the programme's facilitators as having a similar ethnic and cultural background to the intervention participants. Such cultural identification may increase the engagement of the students in the intervention.

This emerging debate regarding the relative importance of participant engagement and or practice is highly relevant to New Zealand with studies such as Bishop and Berryman (2006); Higgens \& Eden (2018). In both of these studies students share their voice to evidence the importance of culturally located learning and in the latter study, to explore emotional aspects of the classroom power dynamic. Student's perceptions of the relevance of programme content have the potential to influence intervention outcomes. Bluth et al. (2016) found the acceptability of the Learning to BREATHE 
programme improved over time with increased familiarity with the person delivering the programme and an improved location in which the programme was delivered.

Deviating from the norm van de Weijer-Bergsma, et al. (2014) introduced a reward system that was used to encourage commitment to the training and home practice. This intervention included parallel mindfulness training for parents. The MBI was delivered in a group format with the participants receiving training in focus, attention, awareness, and self-control. Despite the small study size and the consequent difficulty in generalising from it, it is included in this review as it was an intervention that targeted students with ADHD, the population that is highly relevant to the current New Zealand challenges. Moreover, it adds to the research with the inclusion of parents in the study who may be instrumental in encouraging participants to practice at home thus increasing the likelihood of the generalisation of the practice to other settings.

\subsubsection{The role of the facilitator}

The training and experience of the facilitator are likely to influence the programme outcomes. There is disagreement in the literature regarding this critical role. Bakosh et al. (2015) describe success in their teacher independent study audio-guided programme. In contrast Crane et al. (2017) emphatically state that the facilitator of an MBI must have a personal practice of mindfulness and be trained, ideally experienced in the delivery of the programme. The experience and training of the facilitator show considerable variability across studies, as does the role of the classroom teacher. In some studies, the intervention was facilitated by the authors, e.g. (Desmond \& Hanich, 2010; SchonertReichl et al., 2015). In the case of Bakosh et al., the intervention was facilitated by the teacher who had received one hour of training. Crane et al. (2017) emphasise the importance of facilitator training and personal practice of mindfulness advocating for it to be a pre-requisite for MBI facilitators. I advocate for Devcich et al. (2017)'s call for further research to evaluate potential long-term effects and training of facilitators and an examination of the nuances of training teachers to enable them to deliver mindfulness programmes effectively.

\subsubsection{Portability}

Generalizability of location, with the practice taking place outside the school classroom in addition to the programme of facilitated lessons, may be particularly relevant given the importance of the regular practice of mindfulness skills. The opportunity for practice to take place both in and beyond the classroom is referred to by Napoli et al. (2005).

Schonert-Reichland and Lawlor's (2010) programme had an emphasis on extending the key content of the programme to other areas of the curriculum and students' lives beyond school. In Biegel et al.'s (2009) intervention the students received a flyer after every session, which contained a further illustration of session themes and suggestions for optional practice at home. 


\subsubsection{Classroom climate and potential teacher benefit}

Teacher benefit in the form of stress reduction has been found in a number of studies e.g. Rix and Bernay (2014). Teachers are the 'keepers of the code' in the classroom. The socio-emotional skills of the teacher have a significant effect on the classroom climate. The Mindfulness-Based Wellness Education curriculum was designed to help trainee teachers to develop the capabilities for thriving and managing the modern demands of being a classroom teacher (Soloway, Poulin \& MacKenzie, 2011). Its objectives were to enhance trainee teachers' capabilities to respond rather than to react, investigate their understanding and experience of varying aspects of wellness and to learn teaching strategies for incorporating wellness and mindfulness in their classrooms. This programme was adapted from MBSR with the addition of a formal component to enhance well-being.

Furthermore, the authors introduced, and the trainee students practised, methods of practicing mindfulness in the classroom. A new mindful teaching strategy was introduced and discussed each week. The programme sought to provide trainees with a practice-based body of experience which they could utilise in the classroom and beyond. Their study indicated that compared to the control group, teachers who had participated in the training showed significantly higher increases in mindfulness, life satisfaction and teaching self-efficacy.

A replication study with a longer follow-up assessment found that these teachers described a personal transformation that influenced their pedagogy and self-concept as teachers.

providing them with new pedagogical perspectives, strategies, and practices for creating and supporting an inclusive and calm classroom community (Soloway, et al., 2011, p.225).

The protective effects of mindfulness against burnout in teachers were investigated by Abenavoli, Jennings, Greenberg, Harris and Katz (2013). They used teacher self-report in their study to investigate the potentially malleable characteristics of those teachers who cope better with the stresses of the classroom dynamic. This study which involved 64 teachers in the UK sought to inform potential supports for teachers to help them to avoid increasing 'burnout' and the accompanying cycle of deteriorating classroom climate. Their results suggested that the educator's mindfulness had a strong protective effect against emotional exhaustion, depersonalisation, and low personal accomplishment.

\subsection{Gaps in the research}

While this chapter discusses the large number of studies that describe positive findings regarding the potential effect of MBIs on child anxiety, ADHD, stress and distress they are all written from the perspective of researchers, teachers and parents. This research seeks to inform the developing body of 
research by capturing nuanced, authentic, potentially agentic student voice. It uses the process of cogen to support the students in collaboratively developing and articulating their experiences.

Chapter two reminds the reader of the New Zealand context and explains the author's process of locating the research. It goes on to describe the contributions that a number of studies have made to research in this field. It focuses on research studies that inform the developing knowledge regarding reducing anxiety, executive control, self-regulation leading to inhibitory control, and mechanisms that research indicates may facilitate mindfulness. It looks at research on well-being and considers students' perspectives, the potential role of MBIs in enhancing well-being, as well as interventions that have specifically targeted stressed or disadvantaged groups similar to those in New Zealand. Finally, it discusses issues for consideration including frequency of practice, sustainable gains, student perceived relevance, the role of the facilitator, portability and classroom climate and potential teacher benefit. This sets the scene for chapter three's discussion of the Inquiry. 


\section{Chapter Three: The Inquiry}

This chapter begins by explaining the inquiry's conceptual framework, philosophical underpinnings, research aims, and the roles of the researcher and that of the students. It continues by describing cogen, critical pedagogy, the methodology undertaken and the setting. The final part of the chapter refers to the psychiatrist Glasser (1999), and outlines the ethics process, the classroom environment, the original plan and the MB programme.

\subsection{Conceptual framework and philosophical underpinnings}

This authentic inquiry is framed in the ontology of social constructivism as it seeks to gain knowledge of how the participants make meaning of their world through meta-construction (Ultanir, 2012). It is an authentic inquiry in which the students collaboratively explore their experiences through cogen and record them using text and drawings. As a researcher, I am looking to explore and capture the essence of the participants' experiences (Cresswell, 2007).

I chose a descriptive phenomenological approach because of the limited information that is available regarding children's and young person's experiences of Meditative Breathing (MB). Furthermore, this study employs hermeneutic phenomenology (van Manen, 1990 as cited in Cresswell, 2007) as the research 'process' goals encompass the synergy between identifying what is a highly relevant concern for the participants, considering the defining themes of this 'lived experience', writing a description while keeping a strong focus on the research questions, and equalizing each aspect of the writing to the central thesis. The focus on 'student voice' embraces critical pedagogy and has the potential to position the students as active, resourceful, and reflective individuals who construct new meanings using a range of attributes and skills (Ultanir, 2012).

\subsection{Research Aims}

This study aims:

a) To improve the lives of stakeholders by promoting student self-management and agency.

b) To ease the workload of teachers and to enhance their efficacy by providing insight into student's experiences of MB.

\section{Research Questions:}

The main research question is: What are student's experience of guided meditative breathing?

The sub-questions are:

a) Does it contribute to their wellbeing?

b) Does it contribute to their learning? 


\section{c) Purpose}

The research purpose is to add to the research literature adding nuanced student voice describing their experiences of a meditative breathing programme in the classroom setting. I hypothesize that an MBI, focussing on meditative breathing has the potential to support the development of self-regulation and well-being in students. This may, over time, lead to a consequent improvement in academic engagement and achievement (Holzel et al., 2011).

Collaboration with the students is the central tenet of this inquiry. The inquiry involved three interrelated interventions, guided meditative breathing, cogen dialogue and a heuristic. Cogen was included to provide a vehicle for the capture of nuanced 'student voice' and to enable the participants to be involved as potentially agentic collaborators and co-researchers. The inquiry aimed through the use of cogen to promote a collective understanding of a shared experience (Higgens \& Eden, 2018). This authentic, participatory inquiry (Alexakos, 2015), was designed to capture, analyze and share the described lived experiences of nine to ten-year-old participants in a ten-week programme of daily MB.

\subsection{The role of the researcher}

This research and sought to interpret the student's descriptions of their lived experiences of MB. Constructivism, as a theory, closely aligns to my world view. I have ten years of experience in meditation, using a variety of meditation practices. This familiarity with some forms of meditative practice gave me a familiarity with many of the concepts discussed in the research literature.

The critical task of the researcher in phenomenological research is the interpretation, making sense of the meanings the participants have of their guided meditative breathing (Cresswell, 2003) while collecting open-ended emerging data. I am a teacher with four decades of classroom experience, which affords me substantive experience in observing and reflecting on how students make meaning of their experiences. As a teacher researching my practice, my role as a researcher is "situated inside the Inquiry", (Alexakos, 2015, p. 41). I regularly checked myself to ensure that I was setting aside my experiences and approaching the participant's descriptions of their lived experiences with an openness and a sense of newness which met the research requirements and was consistent with my current meditation practice. As a researcher, I adopted the attitude of attentive openness, again echoing my personal meditation practice and the mindfulness skills and attitudes that the meditative breathing programme seeks to support the participants developing.

As part of the process of analyzing the data, I tracked any assumptions I might be making. I am comfortable in dealing with uncertainty, open-minded, appreciate varying perspectives and practice mindful listening. I constantly interrogated and critically reflected on the data analysis process. In the classroom, my 'modus operandi' is an empowering pedagogy and practice that encourages 
metacognition and collaborative engagement. I value authenticity, integrity, purposeful risk-taking and equity of opportunity for all. My values inform my biases. My motives in this research are to support positive student enabling change.

\subsection{The role of the students}

The use of 'student voice' in this research gave the students as co-researchers the opportunity to create meaningful change in themselves, their class, their school and the broader education community of local primary schools. Discussion arising during the introduction of this research to the students, their families and the immediate school community, situated the outcomes of the research as a resource which was likely to be used by teachers at the school. Furthermore, as a result of interest expressed by the local assistant and deputy principal's group, the initial research findings were shared among the senior teachers of ten local schools, sparking keen interest and discussion. This knowledge created a powerful influence for change from the students.

\subsection{Cogenerative dialogue}

This study used a qualitative, exploratory dialectical process with open-ended questions to encourage cogen. Cogen was used to gather both individual and collective experiences and perspectives on their experiences of meditative breathing. Students were reminded that this dialogue would require attentive listening, maintaining focus, turn-taking so that all voices are heard, positive engagement in the process, being respectful of others and authentic researcher response. Students had already spent between one and four terms in my class and were familiar with the class emphasis on reciprocal respect and that what they had to say was important and valued (consistent with the school culture). Care was taken to encourage all of the students to share their experiences.

\subsection{Critical pedagogy}

Critical pedagogy focuses on understanding the role of schools in transforming social, political and economic life in order to encourage educators to promote democratic and social values in their classrooms (Breuing, 2011). Applying critical pedagogy to teaching and learning is likely to raise the awareness of students so that they can influence their education. It has the potential to empower educators by giving students a voice and the opportunity to change from a passive way of learning to an agentic student-centred learning process (Wink, 2005).

\subsection{Methodology}

In addition to cogen, the study used student's journals in the form of Google Docs, drawings or images selected from the tool 'Explorer' on Google Docs, informal conversations to clarify that I had captured the participants intent, a three month follow up, and an interview with the classroom teacher. 
This was a collection of a large number of pieces of data, much of which I had the opportunity to further interrogate through later clarifying conversations with the students.

The differing responses of the participants as they describe their meditative breathing experiences are connected in varying degrees. A vital aspect of this research is the qualitatively different ways students comprehend and experience a phenomenon (Yates, Partridge \& Bruce, 2012). The focus of this research is on the student's description and interpretation of their experiences (Yates, et al., 2012). I undertook to provide descriptive detail regarding the methodology, thus intending to enable others to draw their conclusions regarding the applicability and possible transferability of the study to their environment and interests (Alexakos, 2015, p.81). Consistent with the reflexive nature of this inquiry further data was gathered using a heuristic. The use of the heuristic was intended to allow the students to raise their awareness and to encourage them to reflect on aspects of their MB experiences that they might not have considered.

Following the methods outlined in Johnson and Christensen (2014), I collected data from the weekly cogen and journals, from the heuristics completed in weeks one, six and ten as well as from teacher recorded reflections. Additionally, I collected data from a three-month follow-up with cogen and journals, interviews with individuals to ensure that I was interpreting their intent accurately, and responses to my sharing of initial data with the participants.

\subsubsection{Consideration of community}

This school has worked hard to build an integrous trust relationship with family and community based on manaakitangas. This posed difficulties for the inclusion of a control group in the study. It was possible that it would have been perceived as not consistently giving all students the best possible opportunities for learning in a school community where the teachers and parents value and promote manaakitanga for all of the students at the school.

\subsection{Data Analysis}

Interim analysis (Johnson \& Christensen, p.558) the cyclical process of collecting and analyzing data was used to analyze participant's texts and drawings. The first stage was familiarization which involved reading and repeatedly re-reading the written and drawn reflections many times. This was followed by a repeating cycle of interrogating the data through segmenting, coding and developing category systems, identifying relationships (themes, patterns, hierarchies, semantic relationships, constructing diagrams, tables or graphs) and corroborating and validating the results. Significant

\footnotetext{
${ }^{5}$ Manaakitanga - 'Mana' refers to authority and 'aki' to the task of urging someone to act (Bishop \& Berryman, 2006, p. 270).
} 
statements were identified, meanings formulated, and clustered into themes, interrogating the data for the emergence of common themes.

Participants drawings and images (most of which were captured using the Explorer tool on Google Docs) were analyzed using visual content analysis to identify the prevalence of particular aspects of the experience. Diem-Wille (2001) describes pictures as a very effective way for a person to describe their emotional state of mind, emphasizing that the explanation of the person is more important than single elements in the picture.

This initial analysis was followed by compilation, phrase by phrase re-reading and analysis through the lens of 'What is happening here? What are they experiencing? What assumptions are they making?' Some participants were approached to clarify whether I had correctly interpreted their intent. This created nine groups (see figure 9) which were further interrogated and narrowed down to seven, and then six specific categories, down to the final three themes, all of which captured the core experiences reported by the students. The participant's experiences of guided meditative breathing are the connection between the themes.

\section{Figure 9. Emerging Themes}

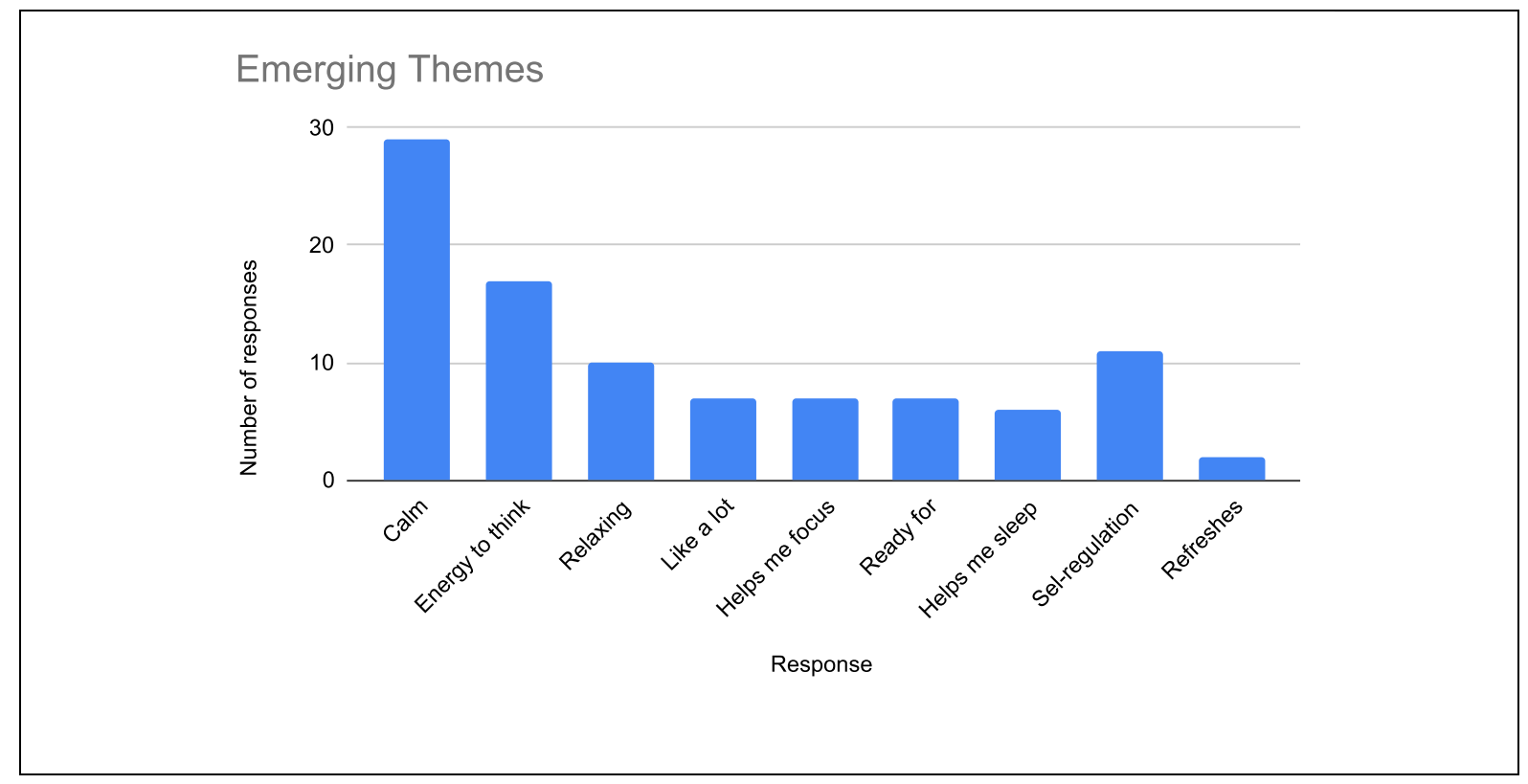

Data was triangulated using different data collection methods to increase data validity (Creswell, 2003). This involved triangulation of data received from student reflections, the participants completing a heuristic in weeks one, six and ten, the teacher interview and a three-month follow-up involving cogen. Students also shared their reflections through writing and drawing. I followed this with impromptu interviews with students to verify the accuracy of my interpretations. After the follow-up, I presented my initial findings to the participants and through a co-generative process, 
sought their feedback and forward. In addition to the discussion, they also recorded their reflections in text, annotated images or drawings.

\subsection{The setting}

The contributing (years one to six) state primary school in which the inquiry took place, is located in a semi-rural environment in the Greater Wellington area, New Zealand. The participants were 28 students aged eight to ten years old. These students come from a variety of backgrounds ranging from parents who are farmers living on lifestyle blocks, daily commuters to nearby Wellington City, to distressed families with family members in prison. The school has a roll of approximately 300 students, $50 \%$ identify as New Zealand Pakeha, $43 \%$ as Māori, $5 \%$ of Pacific heritage and $2 \%$ as Asian.

The school was in its second year of a school-wide inquiry into both neuroscience (in particular, neuroplasticity) and behavioural science. The principal and teachers are particularly interested in neuroplasticity and how the developing understandings in this field can be harnessed as effective teaching and learning tools. Led by the principal, staff were engaged in a continuing process of locating, adapting and trialling a wide range of classroom interventions aimed at increasing the students' understandings of the structure of their brains and ways in which they can utilize these developing understandings to improve their well-being and increase their academic success.

Discussion regarding the children's and teacher's experiences were a vital part of regular professional development days and staff meetings. The principal is piloting an intervention for children whom staff have identified as struggling with their self-management and interpersonal skills, derived from the psychiatrist Glasser's Choice Theory (Glasser, 1999). He shares these perspectives and strategies with both the individual children and, wherever practicable, at least one of their parents in weekly 1-1 learning and discussion sessions.

\subsection{Glasser's Choice theory}

Choice theory (Glasser, 1999) aims to help people to become happier by identifying their basic needs and supporting them in creating congruence between their ideal and their perceived worlds. The central tenets of the theory are that meeting basic needs underpin all behaviour, that the only person whom the individual can control is themselves and that they can only directly control their thoughts and feelings. The internal control psychology of this theory describes individuals as personally responsible for their happiness through the choices (internal control) they make. In contrast, Glasser describes external control psychology in the context of the individual trying to control others or thinking that they are being controlled by others. The internal control habits that enable individuals to connect with others are accepting, negotiating, trusting, listening, encouraging, respecting and supporting. Valuing relationships underpins these habits. 
The external control habits of criticizing, blaming, complaining, nagging, threatening, punishing, bribing and rewarding lead to disconnection with others. Honey (2015) has presented these connecting and disconnecting habits as the useful metaphors of internal control 'open roads' and external control 'dead end roads'.

Glasser postulates that individuals receive all external information through their senses which they make meaning and value judgement of through their total knowledge filter and valuing filter. This perception comprises their perceived world which is compared (represented by scales) with their quality world. The scales show the degree to which the quality world and perceived world correspond with each other (represented by the scales being in equilibrium or otherwise)

Figure 10. Choice theory metaphorical structures developed from Glasser (1999).

- $\quad$ Real World

- Sensory system

- Total Knowledge filter (Can be changed by new information/experiences)

- Valuing filter

- Perceived world

- Quality world, which enables the meeting of needs

Glasser describes the individual's basic needs as belonging, power (to do what you want to do), freedom, fun (including learning), and survival. Using the metaphor of a car for our total behaviourself-management with each of the front wheels representing acting and thinking respectively and the back wheels (following) representing the individual's feelings and physiology.

The 28 participants in this study displayed varying degrees of understanding of the physiology of the brain and the beginnings of an understanding of how they can harness neuroplasticity to support them in their learning and wellbeing. Many of them had some familiarity with Choice theory. All of them had been involved in daily meditative practice for the previous ten weeks, during Term One of the year. The year six students had taken part in a regular practice of daily meditative breathing throughout the previous year, making them very familiar with the practice in the classroom. This practice was simple involving three to ten minutes (the children chose how long by indicating their preferences with a show of fingers) of MB with North American Indian flute as the background music. The reality that these students were not novice to the practice may have influenced their responses, particularly to the taped programme. 


\subsection{Ethics}

Throughout the ethics process, it became clear that the parents and the local community were very positive toward and supportive of the student's involvement in the study. This study met the ethics standards of the Victoria University of Wellington Human Ethics Committee. The research project, participants' information sheets, the heuristic, consent forms, and other documents were approved prior to data collection. This study was guided by the ethical guidelines of the school in which it took place, by the Code of Conduct for teachers of the New Zealand Teachers Council and the ethical guidelines of the Glasgow Institute of Counselling (from which I have a Certificate in Counselling). It was subject to an appropriately rigorous process, given that the participants were children. The ethics committee required a revision of the original proposal, which was duly completed. Permissions were gained from the Board of Trustees, principal, parents of the children and the children themselves. The roles of the researcher as the previous term's teacher and then as researcher (by removing herself from the classroom for the duration of the research) was scrutinized to ensure neither the children, their families, nor the research was compromised. Information sheets were distributed to and discussed with the principal, Board of Trustees, parents, and participants. Students had the right to drop out of the programme at any time. Given the importance of exploring change over time their data would have been excluded from the study

\subsection{The Classroom Environment}

The classroom has desks arranged in groups, with benches underneath the windows also utilized as individual student's designated workspaces. There is an open area at the front of the classroom edged on three sides by staging that the students sit on when collaborating as a classroom group. The guided meditative breathing practice took place in this area.

\subsection{The original plan}

The daily meditative breathing sessions followed Snel (2013)'s programme "Sitting Still Like a Frog" which has an accompanying audio CD voiced by Myla Kabat-Zin. This programme is endorsed in the foreword of the programme by Jon Kabat-Zinn. There are eleven recorded exercises each of less than ten minutes duration. The original plan was to introduce a new exercise each week and to practise it daily for the week. The meditation was introduced in the construct of tuning their instrument of learning or preparing their learning muscles for the day's learning.

These sessions took place at the beginning of each learning day, often after the students had completed twenty minutes of exercise with the other students in their syndicate. Each Friday, participants were involved in cogen led by the researcher. Following this, they were given ten minutes to describe their experience of the week's meditative breathing using their choice of drawing, oral recording their ideas in their Chromebooks or writing about their experiences. In the third week of the 
inquiry, the day was changed to a Thursday to accommodate other demands on the weekly timetable. In weeks one, six and after the study the participants completed a heuristic (in the form of a Likert Scale). This heuristic has ten questions on a five point scale. The set of questions were designed to aid the development of the students understandings about their experience of the meditative breathing programme.

\section{A change in plan}

Despite my having been their classroom teacher for one or four terms, depending on whether they were year five or six, these typically highly articulate students were too shy to speak in front of the camera. There had been a great deal of enthusiastic discussion among parents regarding the research and 'different' behaviours, including the principal managing the permission forms and a different classroom teacher. I suspect that each of these changes in varying degrees contributed to a lack of confidence in expressing their thoughts. Some students said that they felt timid in front of the camera, including one parent who came in to discuss the level of distress his child was experiencing. The participants were keen to continue with the programme but some requested that they share their ideas on Google Docs or drawings and not actively participate in the cogen sessions.

\subsection{The programme}

Session One: 'Sitting still like a frog'. Students are invited to stop whatever they are doing in order to focus and observe using the metaphor of a frog. Sitting still with mindful attention is described as allowing you to find out what you are thinking, feeling and doing. The students were directed to tune into their breathing and associated bodily sensations suggesting that they can use attention and breathing to calm and relax the body.

Session Two: 'The Little Frog' invites the students to focus their calm attention on themselves, acknowledging that it might be challenging to do to start with but that it gets easier with practice. It introduces the body scan, noticing what the body is doing and suggests that using this technique may be helpful if the students have fallen, are angry, tired or want to relax.

Session Three: 'Attention to the breath'. Students are reminded that attention to the breath is the best way to practise mindfulness attention because their breath is always with them. This session touches on distractibility. The metaphor of an attention muscle is used to outline the process of concentration practise (i.e., shifting the attention to the inner world of the body) casting a curious eye over the breathing and moving to deeper breathing, with instructions to simply notice that the attention has been carried away by thoughts and to very gently bring it back to the breathing. Students are reassured that it gets better with practice. 
Session Four: 'The Spaghetti Test' which involves a body scan moving through the body tensing then relaxing like a string of spaghetti.

Session Five: 'The Pause Button'. Students are encouraged to take time for a breather to find out what is going on inside them, to recharge their batteries so that they do not run out. The instructions are to direct very friendly, non-judgemental observations in a scan of the places in their bodies where they feel something, e.g. happy, calm, anxious, warm. This is followed with instructions to stretch and continue with what they were doing before.

Session Six: 'First Aid for Unpleasant Feelings'. The possibility of students feeling upset, sad, angry, nervous or insecure provides an opportunity to pause, focus on breath and open the door wide to the feelings. Students are invited to bring loving non-judgemental attention to the feelings, tune in to their breathing and body scan.

Session Seven: 'A Safe Place'. The speaker asks the students to travel in their minds to a safe place where they will not be disturbed and where they can just be themselves. They are asked to direct the bright light of their attention to their body, body scan and wish themselves all of the safety and happiness in the world.

Session Eight: 'The Conveyer Belt of Worries'. The students receive instructions as to how they can move out of their head into their bodies and focus on a place where their thoughts cannot reach. They are encouraged to observe their thoughts with a curious mind using the metaphor of a spider hovering on a thread using their breath to move down from their heads to their bellies gently.

Session Nine: 'A Little Boost'. The CD reminds students that breathing is always special with the air flowing in and out of their bodies. They are directed to body scan then to do a loving-kindness exercise recalling a moment of kindness and the feeling of happiness it engendered flowing throughout their bodies. It is suggested that they remember that moment throughout the day.

Session Ten: 'The Secret of the Heart Chamber'. Students are asked to focus on their heartbeats, the way that it gives and receives love and can be the recipient of sadness as well as joy. The students are invited to enter this metaphoric chamber and find the treasure of their beautiful, strong, indestructible heart. Reassurances of safety and 'OK' ness are given.

Capturing the essence of the student's varying experiences through the meaning-making process of cogen and journaling resulted in a considerable amount of data. The students described the varying ways in which they experienced MB and how they were able to utilize this new set of skills, primarily in the classroom setting, but also referring to portability, in a multiplicity of settings. 


\section{Chapter Four: The Findings}

Chapter Four describes the sources of data which were co-generative dialogue, journaling, student's responses to a heuristic (which they completed at three points in time) and teacher feedback. Three very clear threads emerged from the data: $\mathrm{MB}$ as a catalyst enabling calm, MB as a catalyst promoting well-being and $\mathrm{MB}$ as a catalyst for insight and self-regulation. This chapter details the teacher feedback discusses self-regulation, and the findings from the three-month follow-up.

\subsection{Data sources}

Chapter Four describes the sources of data. The four sources of data in this intervention were cogenerative dialogue, journaling, student's responses to a heuristic (which they completed at three points in time) and teacher feedback. The co-generative dialogue provided the students with a vehicle for collaboratively developing individual and collective understandings of their evolving experiences of MB. The first cogen group comprised all of the students in the class, the teacher, and the researcher. The second cogen group comprised eight students selected by the teacher as being representative of the class and the researcher. Episodes from the cogen and excerpts (text and visual) from the student's diaries are presented and discussed to describe the varying ways in which the students' experienced and made meaning of the daily meditative breathing. Follow up discussions took place whenever there was a doubt as to the students' intended meaning.

The episodes shared illustrate different conversational threads, texts and pictures describing the students' developing understandings of their experiences of MB. The sequence explores their experiences of MB in three forms. Firstly, MB as a catalyst enabling calm, secondly, MB as a catalyst promoting well-being and thirdly, MB as a tool for insight and self-management. I argue that MB has the potential to be an effective 'anchoring' tool in supporting the students to develop insight into themselves as learners and in enabling them to be agentic in managing their emotions, behaviours and themselves as learners. The student's descriptions are supported by relevant research.

\subsection{Thread 1: Meditative breathing - a catalyst enabling calm}

The first aspect that emerged from the students dialoguing about their experiences of Meditative Breathing $(\mathrm{MB})$ is the transitioning from emotional and mental states such as stress to an experience of calmness.

These episodes from the first exploratory cogen began with the participants dialoguing about how they found MB helped them to alleviate feelings of stress. The students are exploring an elemental aspect of mindfulness; using a focus on the breath to develop an awareness of the physical self (Higgens \& Eden, 2018). 
1. Researcher: What have you been experiencing in your MB this week?

2. A: I find it calms me and helps me to get to sleep.

3. K, E, P, S, simultaneously It makes me feel calm. (K, E, P and S all laugh).

4. Z: It's calm, it helps you feel more calm

5. D: It makes my day happy and calm.

6. Z, O: We find it relaxing (simultaneously and chuckling)

Everyone joins in their laughter

10. F: Very relaxing and enjoyable

11. P: I find it peaceful

There is a general agreement that MB calms with $\mathrm{K}, \mathrm{E}, \mathrm{P}$ and $\mathrm{S}$ laughing at their synchronicity and empathetic responses. D extends the conversation, situating her experience of moving into a calm state as an experience that is sustained throughout the day. $\mathrm{Z}$ and $\mathrm{O}$ develop the thread using the term 'relaxing' which refers back to the earlier descriptors of calming. F concludes this episode describing his experience as peaceful.

An integral part of the daily student-teacher 'meeting and greeting' protocol with these students was a conversation about their previous evening and the morning before school. As their classroom teacher for the previous one (year fives) or four (year six) terms respectively, I was familiar with the student's possible morning experiences and the degree of stress with which they might be struggling.

The conversational threads in this cogen are contextualised in these early morning experiences of stress. The laughter was a dual response to the student's amusement at their simultaneity and empathetically acknowledging their shared experiences of stressful starts to their morning. The student's dominant discourse which was also reflected in their journaling, was that they found meditative breathing calming.

\section{Journal entries}

N. who is articulate, but tends to lose his confidence when asked to record his ideas in text, chose this image from the gallery in the Explorer tool on Google Docs. He used the search terms' calm' and 'meditation'. The image shows a person sitting on the front of a promontory overlooking the water, 
facing a golden sunset (or sunrise) with a sky of shades of blue. The scene is calm and reflective. N. has added the words' good balance' and added a picture of a flute playing notes. This reflects his enjoyment of the Native American flute music and his experience of MB calming and balancing him. He corroborated this in a later conversation.

Figure 11. MB is calming and it balances me.

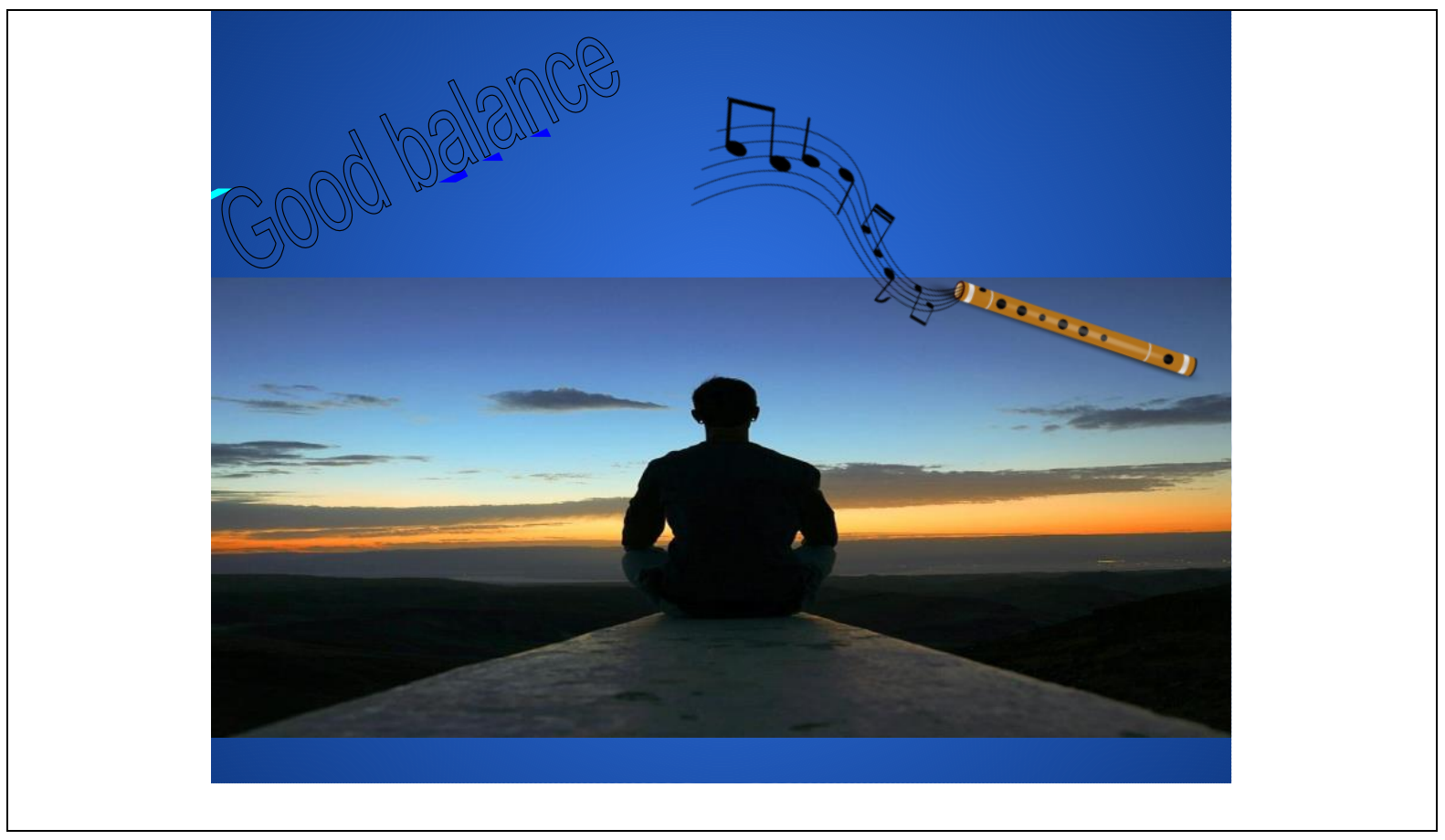

In the context of phenomenology, participant's artistic representations or chosen images can give invaluable insight into the lived world of the individual's experience (Cohen-Miller, 2018). 
Figure 12. Thumbs up to MB.

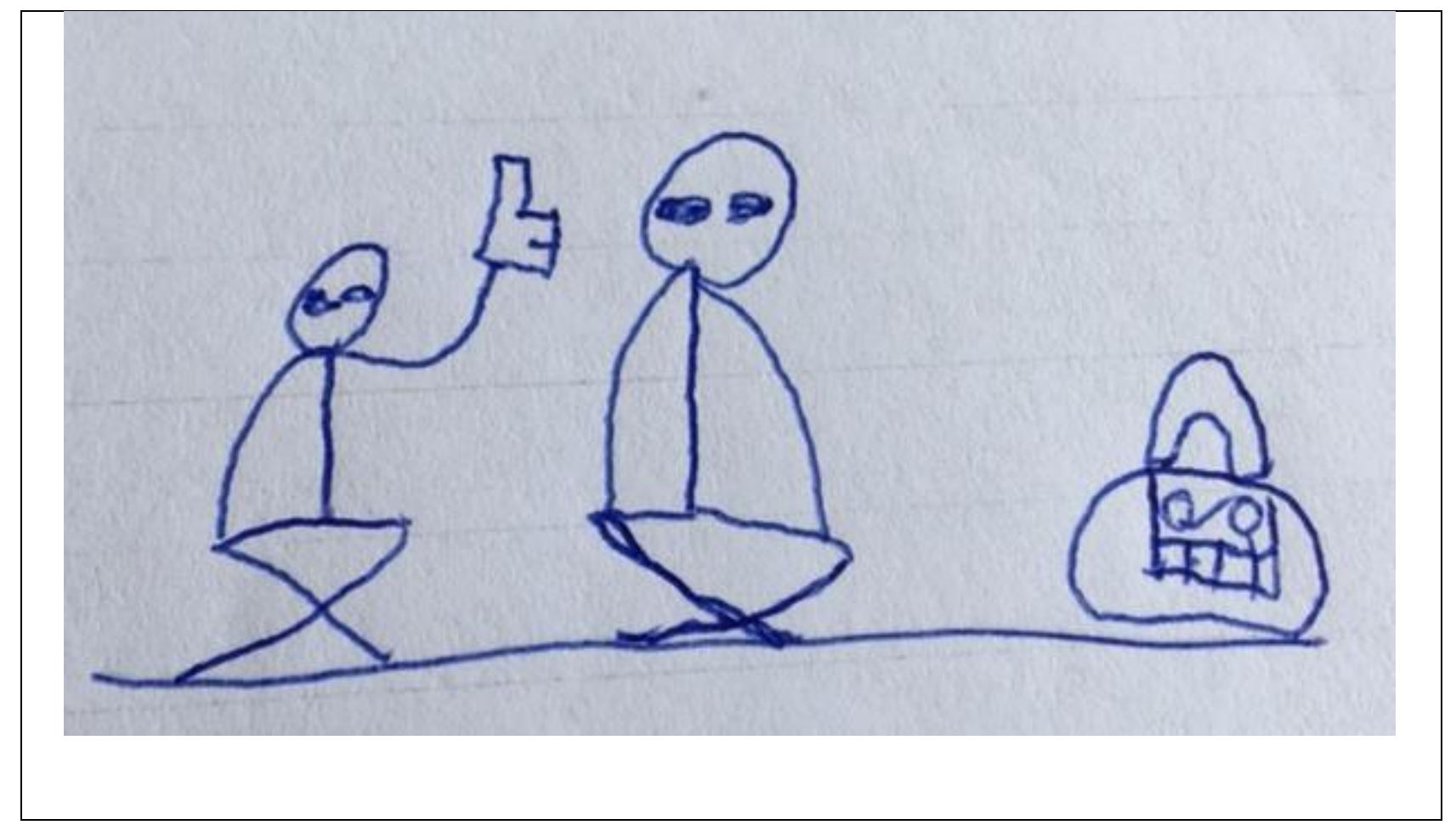

C. who struggles to record his ideas in text explained to me that he had captured his experience in his drawing which shows a seated figure with a disproportionate 'thumbs up', himself calmly meditating and the CD player with the MB programme. He describes MB as "cool" and "very helpful".

Drawings can provide a vehicle for students to “...think about, reflect and actually see their experiences" (Cohen-Miller, 2018). Several research studies demonstrate experiences of calming reported by students, teachers and researchers (Black \& Fernando, 2013: Rix \& Bernay, 2014 and Milligan, et al., 2017). MBI's were found to ameliorate low-grade depressive symptoms and showed positive indications of the programme's effectiveness in reducing stress and enhancing well-being (Kuyken et al., 2013; Rix \& Bernay, 2014). Forty-one per cent of the studies in an evidenced-based review of MBIs in education found that meditation had a significant effect on emotional regulation (Waters, Barsly, Ridd \& Allen, 2015).

\subsubsection{Meditative breathing - a catalyst enabling calm after exercise}

\section{Episode Two}

A few turns on. 
15. Researcher: We usually do our MB after our exercise, how is that for you?

16. J: Calming...best after our run BOOM BOOM BOOM! Then ...boom...boom...boom...

17. A: I find it helpful and calming.

18. C: Me too it gives me energy after every run I do.

19. S: MB calms your body.

Here the students refer to an essential aspect of meditative breathing, the awareness of the body and how we interact with that awareness. They discussed how they found the meditative breathing helpful as the first activity that they did after their morning exercise which was usually a run.

$\mathrm{J}$ describes the calming of his heart from loud pounding to a quieter beat using capital letters which reduce to lower case, to represent his more settled heartbeat and increased calm after meditative breathing. A shows empathy, adding detail to Jo's response by describing the consistency of her experience with MB consistently calming and energising after every run. S draws together the descriptions of feelings of calm expressed by the others and relates them to an experience of the physical calming of his body. These are descriptions of MB calming the mind, the emotions, and the physical self.

The integration or juxtaposition of exercise with Mindfulness programmes is relevant to holistic considerations of 'Hau Ora'6 as described in the New Zealand Curriculum Framework (2007). Milligan et al. (2017) found author reported positive results for calmness, increased awareness and increased self-esteem in their intervention which incorporated martial arts and mindfulness activities. Many of the programmes that have been developed from Kabat-Zinn's (2013) MBSR programme include movement in the form of yoga (e.g., Huppert \& Johnson, 2010). The association of a shift from an experience of emotional stress to an experience of emotional calm and from an experience of physical stress (increased heart rate and breathing rate) to an experience of physical calm positions $\mathrm{MB}$ as a catalyst for change.

\subsection{Thread 2: Meditative breathing - a catalyst promoting well-being by:}

a) Energising

\footnotetext{
${ }^{6}$ Hau Ora is a Maori term for a holistic approach to wellness that includes four dimensions: physical wellbeing; mental and emotional well-being (self-confidence); social well-being (self-esteem); and spiritual wellbeing (personal beliefs)
} 
19. E: After doing the run it (MB) flushes away the tired 'puffer' (puffed) feeling.

20. Z: It's very calming, it's helpful giving me energy after each run.

21. K: Meditation calms your body.

22. E: It makes me feel energized.

The description of MB cleansing (flushing) and refreshing exemplifies an experience of moving from a stressed tired state to one of calm and energy. Z. develops the cogen adding the concept of a helpful calm that is energizing as well as relaxing. E. validates Z's comment by affirming that she shares the same experience.

b) Aiding thinking

Some students described the feeling of being energised and the consequent capacity to think more clearly.

Episode four

23. K: Meditation is peaceful, it gives me energy to think.

24. S: I think meditative breathing makes me calm ... and it helps me to have energy and the energy helps me to think and learn.

25. J: I think meditation breathing makes me calm and it helps me to go to bed and it helps me to have energy for the whole day and the energy helps me to learn and think.

K. describes a peaceful state which has an aspect of an energizing calm that directly supports thinking and learning. S elaborates this further describing the energy that helps her to think positively impacting on her capacity to not only think but to learn. J. wraps the conversational thread in the context of the 'whole day' concluding with his experience of MB expediting bedtime. 
The students describe the energising experience as one that is revitalising, giving them the energy to think and learn. A sense of well-being is included in the 'desired outcomes' of student's well-being indicators of self-confidence and physical well-being (Education Review Office, 2015). Increases in student self-confidence and wellbeing are a priority for change in New Zealand education.

Student's self-perception as capable learners may lead to positive student outcomes, both socialemotional and academic. The potentially positive impact of MBIs on student's executive functioning is described in the research literature. MBIs have the potential to have a positive impact (Desmond \& Hanich, 2010), or to be associated with significant improvement, (Schonert-Reichl et al., 2015) in students' executive functions. Flook et al. (2010) found that the students who had the poorest skills at baseline were those who made the most improvement.

c) Promoting experiences of well-being

Episode Five

26. D: It helps me with my mood throughout the day, it makes my brain feel like sunshine.

27. K: It makes me feel good, strong.

28. R. Healthy. It helps me to get on with my day.

29. S: It refreshes me.

30. W: Meditation today I felt like I had cool water crawling down my body and it felt so good and I love MB so much.

D opens this episode with a statement referring to how MB helps her positive mood regulation and uses the metaphor (cognitive representation) of the 'sunshine brain'. This metaphor is permeated with experiences of health, warmth, energy, growth, and enjoyment. K extends this with descriptors of wellness and strength. S describes her feelings of moving from a non-refreshed to a refreshed state. The students attribute this experience of feeling healthy and experiencing wellbeing, as well as an experience of readiness for the learning day ahead to their time spent practising MB. K and R echo and extend this with their descriptions of feeling healthy and being ready for their learning day. Enthusiastically continuing this idea, $\mathrm{W}$ utilises the practice of body scan expressed as a metaphor of cooling water to describe her MB experience.

As early as 2008, researchers were finding evidence of decreased anxiety in adolescents with learning disabilities as an outcome of MBI interventions (Beauchemin, et al., 2008). Schonert-Reichl \& Lawlor (2010) found increases in optimism and positive emotions and wellbeing. 


\subsection{Thread 3: Meditative breathing - a catalyst for insight and self-regulation}

Episode six

31. K: MB helps me to focus on my breath and clear my mind.

32. R: Yeah, it helps me to learn more, focus more.

33. Z: It helps me to focus, it gets you ready for your day.

Using MB for emotional regulation is expressed concerning 'tiredness, grumpiness' and the management of negative feelings.

34. S: It's helpful when I am tired or grumpy.

35. Za: When I'm doing my breathing it helps me to move all the negative things on my mind and focus on the positive things.

36. Cay: It helps when I am angry and sad.

37. C: It helps me when I am grumpy, tired or frustrated

38. P: I think meditative breathing is really good for you like for example if you were angry 'it' will calm you down.

$\mathrm{K}$. begins this episode of cogen describing her experience of how MB helps her to focus on her breath and to clear her mind. $\mathrm{R}$ and $\mathrm{Z}$ develop $\mathrm{K}$ 's description explaining their experience of $\mathrm{MB}$, helping them to focus, enabling successful learning. Preparing for the learning day is a term that was frequently used in this class by students, the teacher and myself. The sense of calm is applied here to the concept of preparing for the next part of the day, which is their classroom learning. S shifts the cogen focus to emotional regulation, explaining that she finds MB helpful in moving her away from feelings of tiredness or grumpiness. $\mathrm{Z}$ shows insight in positioning his experience regarding negative and positive things and how MB helps him to choose to focus on the positive things. $\mathrm{Ca}, \mathrm{C}$ and $\mathrm{P}$ add to the conversation explaining that they find that MB helps them to manage anger, sadness, grumpiness, tiredness, and frustration.

Being able to notice when the focus of attention has been distracted away from the breathing is a crucial skill which is practised during mindfulness. In my experience tudents who can generalise this skill to the classroom setting are likely to show improved socio-emotional and academic outcomes. 
Journal Entry

Excerpt Three-Behind bars.

Z: Sometimes you can feel like you're behind bars and you don't really have choices but if you meditate, pretty much you're not behind bars anymore and you're really free and can do whatever you want.

In this journaling $\mathrm{Z}$ shows insight and increased cognitive awareness, as he describes how he uses MB to manage feelings of helplessness in a way that frees him to embrace his potential. Mindfulness based cognitive therapy increased patients' metacognitive awareness in regard to negative thoughts and feelings by altering the patients' relationship to negative thoughts and feelings, not their content (Teasdale, Moore, Hayhurst, Pope, Williams \& Segal, 2002).

Crane et al. (2017) explain this development of a new relationship with experience which is:

“... characterised by present moment focus, decentring and an approach orientation". This new relationship is the catalyst for "... the development of qualities such as joy, compassion, wisdom, equanimity, and greater attentional, emotional and behavioural self-regulation”, p.990.

\section{Excerpt Four - Helpful at home.}

J: It's helpful at home, for example, like when I get frustrated so I go downstairs into my room and start my 'mitation' (meditation).

$\mathrm{J}$ who has a history of chronic extreme behaviour outbursts, found MB very helpful in helping him to be in control of himself and his responses. Other teachers anecdotally described the changes in his observed playground behaviour as 'transformational'. He explains how he extended his participation in the classroom programme to home highlighting the potential portability of an MB programme. It is interesting to note that this student was also receiving support from the principal in developing his understanding and use of Glasser's (1999) Choice theory. Anecdotal conversations with his Mum describe J's behaviour at home as being a great deal calmer.

The core efficacy of $\mathrm{MB}$ for $\mathrm{J}$ is that the training helps him to modulate the onset, extremity and duration of his emotional response to an environmental stressor (Chiesa, Serretti \& Jakobsen, 2013). 
This training has enlightened him about his relationship to his reactions and enabled him to feel more in control as he reduces the frequency and intensity of his angry outbursts.

Three students were less positive about the programme.

C thought the programme was good, saw its positive effect on has classmates but did not experience it being helpful for him. S was initially negative about the programme 'boring' but over the ten weeks found it increasingly useful. In further conversation with me she explained she did not like closing her eyes as she was uncomfortable thinking that someone might be watching her.

\subsection{Teacherfeedback}

The classroom teacher participated in the daily MB. He also observed the students throughout each teaching day as part of his classroom practice. The aspects of the MB experience he chose to focus on were the outcome of a collaborative discussion between the teacher and the researcher.

Calm

Practising calm has contributed to observably increased levels of calmness (in the class). Time has value! Valuing silence, stillness, peacefulness, and calm we promote its legitimacy and its validity/currency on the spectrum of possibility. As we give time to something, we give value to it.

\section{Self-management}

Being present to oneself in meditation helps to support the idea that 'I am the boss of me'. If this is true, I have choices to make. Stillness and being present to myself enlarges my self-management menu.

\section{Skill Acquisition}

Skill acquisition expands my sense of being active and present in the world. Through a skill/tool/ability such as meditation, I move from being a passive consumer to an active producer/contributor. Doing meditation, making silence, building peace/calmness, using my body and mind to create a mindful presence. This is important work, I am in control of me! I like being present to myself!

The teacher observations describe increased levels of calm in the class. He engages with the construct of 'class capital' and the valuing that is assigned to an activity that is deemed worthy of having time spent on it. The teacher articulates his observations of students developing insight and extending both their sense of themselves and their relationship with themselves. He points out the agency of students 
who are in control of themselves, moving from the role of unassertive compliance to agentic 'producer/contributor'. Finally, he touches on the meditative concept of 'loving kindness', with his observations about using the body and mind to create a mindful presence and a compassionate valuing of self.

\subsection{Self-regulation}

Self-regulation involves emotional, attentional and inhibitory control as well as cognitive and behavioural processes that enable children to sustain useful degrees of emotional, motivational and cognitive focus (Molfese et al., 2010). Liew (2012) describes its pivotal influence on student developmental outcomes, particularly social-emotional well-being and academic functions. Wadlinger and Isaacowitz (2011) reference a number of studies in arguing that meditative practices appear to be an effective means of improving emotional well-being. They claim that attentional regulation can be trained through frequent practice. Further examples of studies that support the view of the positive effect of MBIs on self-regulation include Flook et al. (2009); Sanger and Dorjee (2016); and Milligan et al. (2017). Mendelson et al. (2010) found similarly positive student reported outcomes from their intervention with chronically stressed and disadvantaged urban youth. Importantly, students who show self-regulatory improvements over the course of their development are likely to have better physical and psychological outcomes as adults (Moffit et al., 2011).

While interrogating the data, checking carefully for the intent of the descriptions, I noticed a change in the locus of control for the students between thread one calming, thread two energising and that of thread three self-regulation. In Threads one and Two, the students are passively experiencing MB, whereas, in thread three, they are utilising the experience to create anticipated outcomes. This positioning is not exclusive but rather a matter of degree. Students not only appear to be describing taking more initiative, but they also appear to be describing a change in perspective on their sense of self as they use the practice and gently observe themselves. This development of insight on 'self' creates the possibility for enhanced self-regulation as they move beyond a static sense of self to develop the understanding of themselves as separate from, and agentic within, the boundaries of their thoughts and feelings (Holzel et al., 2011). It may be that their learning about the structure of the brain, neuroplasticity, and Glasser's Choice theory (Glasser, 1999) has enabled their receptivity to such a construct.

\subsection{Three-month follow-up}

At the three-month follow-up, I sought clarification as to whether the students purposefully used MB as a tool to meet a variety of needs. Many participants whose reflections are situated in thread three confirmed that they do have these particular expectations in their minds when they practice MB.

\subsubsection{Cogenerative dialogue}


The three-month follow-up cogenerative discussion comprised a group of eight students and the researcher. Students were asked to share their reflections on how they would describe their experiences of MB three months after the ten-week programme. The students had continued to experience MB daily with the classroom teacher having chosen to include $\mathrm{MB}$ in the daily programme in the form of students reflecting on the school's tuku mihi7. The threads that emerged from the discussions are consistent with those expressed during the intervention.

\subsubsection{Thread 1: Meditative breathing - a catalyst enabling calm}

Episode seven- Letting go of tension and becoming calm.

1. Researcher: How would you describe your experiences of MB today?

2. E: When I do meditation... sometimes I can take myself to a happy place and just feel like water or some music or something like that are around me and just calms me down and yeah. When it works it's great.

3. D: Meditating is more than just sitting still cos you're letting go of all the bad thoughts and just being calm.

4. K: Yeah, meditating helps if you are hot. You just think of water flowing through your body and just the tense part of your body just relaxes. It makes you more calm and I definitely recommend it for any other school.

E describes intentionally taking himself to his 'happy place' using the metaphor of running water (body scan) or music, resulting in an experience of calm. His description is qualified with 'sometimes' which reflects the on-going experience $\mathrm{E}$ had of inconsistent experiences with MB. D refers to the unseen work that is going on when she meditates. She may look like she is just sitting there; however, she is experiencing 'letting go of the bad thoughts and just being calm'. $\mathrm{K}$ builds on the other speaker's contributions, referring to the body scan practice of locating and relaxing identified tense parts of the body. She alludes to her feeling of agency within the research project as she recommends that other schools adopt the practice.

\subsubsection{Thread 2: Meditative breathing - a catalyst promoting well-being}

Episode eight - Letting go of worries.

\footnotetext{
7 "Tuku Mihi" is a school-wide opening meditation for the day. It is spoken in both English and Maori, ref appendix C.
} 
5. Researcher: How do you think MB affects you as a person?

6. T: I think meditating to me is leaving of all the worries and just being yourself and having fun.

7. D: Meditating (meditative) breathing is relaxing and its flushing away all of the bad memories and the bad things that you have done in the past.

8. O: I like doing the meditation as it calms me. I even used it before surgery and was calm in seconds. It takes away my worries and lets me focus on the good things in my life. I'm able to let go of all my anxieties.

9. R: I find meditation really useful when I'm pressured for example, when I was doing a quizz with $\mathrm{K}$ and we used it quite a bit and it helped us become more confident and we did it before we were going to speak and I really appreciate it. It is a great skill.

$10 \mathrm{C}$ : When I meditate I usually think of like I can do anything, for example, I can fly, I can go underwater and I can breathe and I can just do anything.

11. K: (With MB) I think I speak for everyone when I say your mind is your own world and stress and pressure is just locked outside and never coming back and you can do whatever you want and just not think of bad things.

Using MB as a way of managing anxieties is a common aspect of this episode. The shared experience of 'letting go' of worries, bad memories and things of the past is expressed in slightly different ways by each of these students. T acknowledges the importance of 'just having fun', as an important contributor to perceptions of well-being. D describes her experience of MB as a restorative cleansing of bad memories and past actions. O references her experience of MB being very useful in her preparation for a recent surgery. She acknowledges MB as an important tool for her. She describes how it helps her to focus on the positive things in her life. R extends these ideas describing MB as a skill that she has utilised in managing pressure and building self-confidence. $\mathrm{C}$ describes his insight into the 'freeing' potential of MB to remind him of his potential and capabilities. K adds to C's description of freedom, referencing her personal locus of control and agency. In contrast to the 'behind bars' experience described in Z's journaling, $\mathrm{K}$ describes barring stress and pressure entry to her mind. She feels very much in control of the world of her own mind.

\subsubsection{Thread 3: Meditative breathing - a catalyst for self-regulation}

Episode 9-Meditation helps me as a learner. 
12. Researcher: How does MB help you as a learner?

13. Z: Meditation helps me as a learner because in the mornings if you meditate it just gets rid of everything that may have happened in the morning and it just lets you feel calm and lets you to be able to focus on things a bit more easily.

14. C: For me meditation relaxes me and gets me all ready for the day...

15. D: I agree with $Z$ because in the mornings when you're really stressed and then you meditate and then you can carry on with the day and have a good day.

16. Z: I agree with what $\mathrm{R}$ said before about if you have a really hard job it is hard to focus on positive things cos you've been stressing a lot and you need to get up early and you don't really have enough time to just think about positive things and really focus.

17. R: I agree with everyone because they're all really good and meditating helps me as a learner to try focus on the future and let the past go and also helps me if I'm time pressured and makes me think of how I can do better things and help others. I agree with $\mathrm{Z}$ and when I meditate I imagine that I'm a Buddha. It makes me feel like I'm in a temple in Thailand and I can just enjoy myself and it helps me develop new skills. It's quite a strong skill in itself.

This cogen focussed on how MB helps the students as learners. $\mathrm{Z}$ describes MB as helping by clearing, calming and supporting focus. $\mathrm{C}$ adds to the conversation describing his experiences of relaxation and preparation for the learning day ahead. D shares her experiences of MB alleviating stress and facilitating a 'good day'. Z includes the notion of MB being helpful when dealing with stressful, challenging tasks. In addition to the shared considerations, $\mathrm{R}$ introduces to the conversation the mindfulness concept of 'kindness to others' with her reflections on self-improvement and helping others. She extends these ideas describing MB as a 'strong skill'.

The students are describing a significant shift in their relationship to their thoughts and emotions (Wisner, 2014). They show increasing equanimity in describing their perceived change in their relation to their self-awareness, calmness, stress management, emotional coping, self-regulation and sense of well-being. They also describe cognitive changes relating to focusing thoughts and improving attention.

\subsection{Meditative breathing is more effective with practice}

Journal entry 
Excerpt Three - You get better with practice.

1. E: Meditation for me in the mornings gets me ready for the day and sometimes it can be quite stressful and then I'm doing meditation in the morning I sometimes get distracted by noises and other things and then as you practice meditation you get better and it just calms you down more every time.

E is the student who mentioned earlier that his experience with MB is not consistently positive. In this journal entry $E$ introduces how the experience of meditation may change with practice, resulting in an increasing experience of calmness. He is describing a developmental process mediated by duration and frequency.

The overall profile of a review on the effect of meditation interventions in schools (Waters, Barsley, Ridd \& Allen, 2015) suggests that meditation leads to small initial improvements in well-being with more frequent meditation producing more significant findings. Huppert and Johnson (2010) also found an increase in adolescent's psychological well-being dependent on the amount of practice undertaken, Rix and Bernay (2014); Maynard, Solis, Miller and Brendel (2017). A factor to be taken into consideration is that initial exposure to mindfulness practice may initially increase awareness of stress and emotional experience before observable benefits occur (Hayes \& Feldman, 2006).

\subsection{Data from the heuristics}

The heuristic was used as a tool to help the students to develop their thinking. The first two questions asked the students to rate their ability to stay focused in class and whether they were able to manage distractions. On further consideration, I excluded these responses from the data as I observed that they detracted from the focus of the students' descriptions of their experiences of MB. The other eight questions in the heuristic sought information regarding experiences of calming; helpfulness in starting the day; anxiety; focus; clear thinking; emotional regulation; portability and observation of MB's perceived influence on peers.

In completing each heuristic, at weeks one, six and ten students were asked to indicate which point on the Likert Scale best represented their experience. Data from the heuristics suggest that most students found MB effective in calming them. To a lesser extent, they found it useful for helping them to start their learning day and to think more clearly, respectively. Reflecting on the student's descriptions of their experiences in the cogen, I noticed that the descriptors 'calming' and 'less anxious' were intending to describe the same experience. I clarified this with the students who agreed that this was the case. Consequently, I combined that data from these two separate categories into one category 
shown in the figure below. This graph shows the three higher-rated responses,' calming/less anxious', 'think more clearly' and 'helpful start to the day'.

Figure 13. Is there change over time?

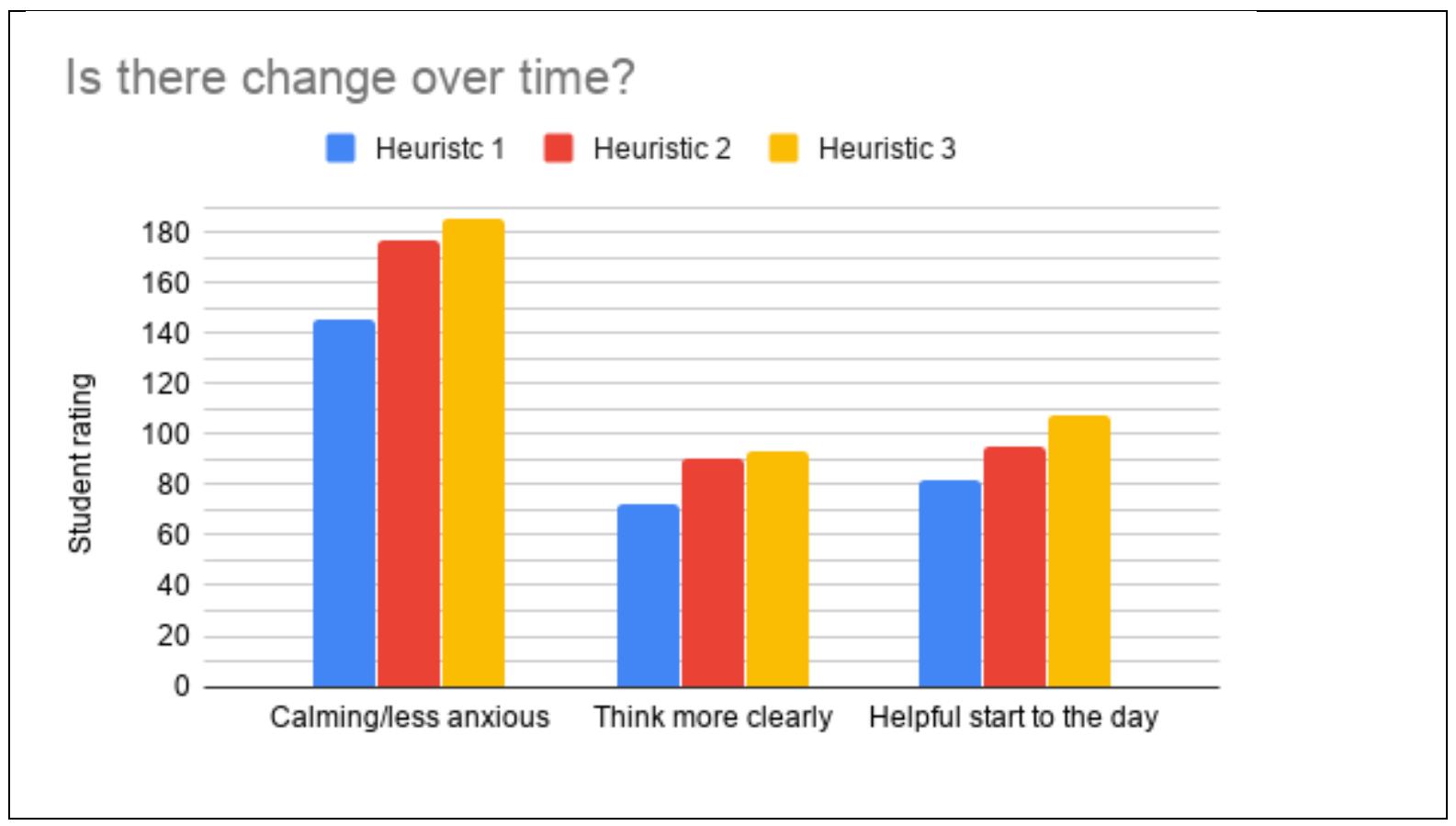

The predominant category chosen by the students as representing their experiences of MB is that of 'calming' and 'becoming less anxious' with week one showing a relatively high start point rating of 145 and week ten showing a score of 185 . This is an increase of forty.

The rating of the experience of 'thinking more clearly' starts at 72 shows an increase of 18 between weeks one and six and then a further small increase of 3 between weeks six and ten. The rating of ' $a$ helpful start to the day' starts at eighty-two and steadily rises by thirteen to week six and by twelve to week ten. This is an overall increase of 25 . Students experienced an increase in calming/feeling less anxious, thinking more clearly and increased ease in starting their learning day as their experience and (possibly) skills in MB increased. 


\section{Chapter Five: Discussion}

Chapter Five revisits the study's goals, questions and literature review. It discusses the outcomes in the context of the relevant research to date. It raises the question: What are the key influencers that affect MBI outcomes in the education sector? It goes on to discuss some of the outcomes of the research from the New Zealand perspective.

\subsection{Research aims, goals and purpose}

This study aims to improve the lives of stakeholders by promoting student wellbeing and agency. It intends to provide insights into student's experiences of MB, which may encourage teachers to include MB in their classroom programmes.

The main question explores student's lived experiences of MB. The sub-questions ask whether the students experienced MB contributing to their wellbeing and their learning.

Research Questions:

The main research question is: What are student's experience of guided meditative breathing?

The sub-questions are:

a) Does it contribute to their wellbeing?

b) Does it contribute to their learning?

Purpose:

This research explored the efficacy of MBIs in the primary school setting. The second purpose was to add nuanced New Zealand student voice (using their own words as they develop their understandings) to the research on MBIs in schools. I hypothesise that MBIs in the classroom have the potential to support the development of self-regulation and well-being in students. The skills and attitudes developed may, over time, lead to a consequent improvement in academic engagement and achievement (Holzel et al., 2011). This could be an emerging tool to help our students who are underachieving and those who suffer from stress, distress and anxiety.

\subsection{Study findings}

This study adds to the developing literature on the benefits of MBIs in education. It builds on prior research and knowledge by adding nuanced student voice, describing their evolving understandings of their experiences of meditative breathing. Study outcomes indicated that $92.8 \%$ of the students described their experiences of MB as positive. For many, it acted as an anchor or an increasingly powerful counterbalance (as suggested by Kabat-Zinn, 2013) alleviating stress and anxiety and making it easier for them to settle into their learning day and manage their attention and emotions. 


\subsubsection{Students' experiences of meditative breathing}

This section shares student's descriptions of their experiences and links them to the literature in this field.

\section{$M B$ catalyses experiences of wellbeing}

Students responses placed MB's helpfulness on a continuum from helpful to liberating them to embrace their potential, describing the development of a new relationship with experience (Crane et al., 2017). 'Meditative breathing calms' was the most frequent description from the students. They described passive experiences of the activity and stress earlier in the morning, easing to experiences of calmness. Further, they described MB, moving them away from negative emotional states (e.g. stress, sadness, anger) and freeing them to happily engage in their day's activities. The students described MB acting as a catalyst which, when applied to negative states of mind, transitioned the meditator to a state of calm. It was described as enabling a state of harmonious balance. Students found MB very helpful. The awareness of the body facilitated by a focus on the breath and body scan is expressed as MB calming and energising after the daily exercise session. MB revitalised, it reenergised after exercise, and it refreshed them. Statements included experiences of positive mood regulation, health, warmth, energy, growth and enjoyment.

As they became more 'mindful', MB changed their perceptions of their relationship with themselves, their bodies, their thoughts and feelings. This simple, always accessible technique helped them to take control and know that they are in charge of themselves. This anchoring (or counterbalancing) in a focused, alert state, increasingly freed them to choose where they put their attention and energy. The experience of MB was described as transformative, making the day happy and calm. Some students found that this experience sustained throughout the day. They found it was both relaxing and enjoyable. The students appeared to be describing MB, the practice that increased their mindfulness. They appear to be describing Gethin's (2011) concept of a 'gatekeeper'. MB appears to be supporting students in developing a 'presence of mind' that helped them not to feel overwhelmed by perceptions, states of mind and emotions. They also described the portability of $\mathrm{MB}$, enabling them to practice this new skill outside the classroom.

\section{$M B$ contributes to learning}

Students described MB, refreshing them as they transitioned from a stressed, tired state to one of calm and energy. The contributions to the cogen develop these ideas into that of a peaceful state which has an aspect of an energising calm. This calm directly supported thinking and learning. The meditative moments anchored the meditator in a calming process that orientated them to the day ahead. The students attributed this experience of feeling healthy and experiencing well-being, in conjunction with a state of readiness for the learning day ahead to their time spent practising MB. Students detailed MB 
as facilitating learning by it clearing, calming and supporting focus; relaxing, alleviating stress and facilitating a 'good day'.

\section{MB helps to manage self-regulation}

The student's descriptions of clearing the mind and emotional regulation include MB helping them to manage anger, sadness, grumpiness, tiredness, and frustration. As student's experience in MB increased they describe choosing, positive thoughts and perspectives. Being able to notice when the focus of attention has been distracted away from the breathing is a crucial attentional regulation skill which is practised during mindfulness. Students described generalising this skill to other activities and the classroom setting in general. They also described instances of the portability of MB, e.g. using it at home when feeling frustrated, moving away from a previous behaviour of angry outbursts.

Students detailed MB as facilitating learning by it clearing, calming and supporting focus; relaxing, alleviating stress and facilitating a 'good day'. Considerations of 'kindness to others' were expressed in the context of self-improvement and helping others. They were now describing MB as a skill to be utilised.

\subsubsection{Differential results}

Three students were initially less positive about the programme. S's early negativity, saw her find the experience of $\mathrm{MB}$ boring. This changed to a more positive response and by the end of the ten weeks an enthusiastic response. $\mathrm{C}$ thought the programme was good, saw its positive effect on his classmates but did not experience it as being helpful for himself. So did not like the experience at all, explaining she did not like closing her eyes as she was uncomfortable thinking that someone might be watching her. When invited to move to a more secluded space, she was much more engaged. Interestingly in her week ten heuristic responses, she indicated that she found MB helped her to focus on her learning. One student who was initially positive became consistently negative about his experiences. As discussed with his family, changes in his home circumstances may have contributed to this change in attitude.

\subsubsection{MB a catalyst for insight at three-month follow-up}

In the last few weeks of the intervention, some students' descriptions suggested developing insight. The data from the three-month follow-up confirmed that they appeared to be describing a change in their relationship with themselves, particularly their emotions and their thoughts. This development of insight on 'self' created the possibility for enhanced self-regulation as they moved beyond a static sense of self to develop the understanding of themselves as separate from and agentic within the boundaries of their thoughts and feelings, (Holzel et al., 2011). As Kabat-Zinn (2013) reminds us, the spirit of meditation prioritises the importance of being your own person and understanding what it 
means to be yourself. Students had begun to use MB as a tool to meet a variety of needs, particularly self-regulation.

Students described experiences of identifying their worries as separate from themselves. This identification of separateness freed them from the burden of anxiety and allowed them to be themselves and have fun. The cogen continued with descriptions of restorative cleansing of bad memories and past actions; managing pressure and building self-confidence; and usefulness in preparing for a recent surgery. One student described barring stress and pressure entry to her mind. MB helps her to feel very much in control of the world of her own mind. Another described her experiences of freedom, referencing her locus of control and agency.

\subsubsection{Meditative skills improve with practice}

Students described their experience of becoming more effective in utilising MB as they increased their experience through practice. This appears to be a developmental process mediated by duration and frequency. These discussions support Tang, Holzel \& Posner (2015) who describe at least three elements that interact synergistically, bringing improved self-regulation: enhanced attention control, improved emotion regulation and altered self-awareness with practice over time.

\subsection{Responses from the heuristics}

The data from the heuristics shows that the predominant category chosen by the students as representing their experiences of MB is that of calming and becoming less anxious. The second was the experience of thinking more clearly, and thirdly, a helpful start to the day.

\subsubsection{Teacher observations and feedback}

The teacher report included observations that the students had to varying degrees, developed insight and were extending both their understanding of themselves and their relationship with themselves. $\mathrm{He}$ pointed out the agency of students who are in control of themselves, moving from the role of unassertive compliance to agentic 'producer/contributor'. Furthermore, he referenced the meditative concept of 'loving-kindness', as he observed students using their bodies and minds to create a mindful presence and a compassionate valuing of self.

\subsection{How does MB influence students and their learning?}

I suggest that in addition to the neurological changes that occur over time in the pre-frontal cortex, they have developed insight, caused by the developing of a changing relationship to their body, thoughts and emotions. They are developing recognising that 'they are the boss of themselves', and have personal agency in managing themselves. The application of this developing understanding and 
'repositioning' is likely to have a positive impact on their learning as they manage themselves as active, engaged learners'.

\subsection{What are the critical influences on MB programme's outcomes in the school setting?}

A multitude of factors contributes to student well-being and academic outcomes. MB interventions occur within the complex dynamic which comprises communities, schools and classrooms and students of varying age, socio-economic and cultural background; schools that have a variety of philosophies and educational approaches; the attitudes of teachers, parents and students; considerations of environment; student developmental stage; relationship with the programme facilitator, facilitator's skills, experience and knowledge, the frequency and duration of the programme, the rewards (intrinsic or extrinsic) that the students experience. In the following paragraphs, I further explore those factors that may be manipulable by schools, e.g. the facilitator, the type of intervention, and the developmental stage of the students.

Is it the case that different variables may influence a variety of outcomes? For example, in an analysis of seven studies Waters, et al. (2015) noticed that factors influencing study outcomes on emotional regulation included frequency, (daily is more effective); age group or developmental period (middle school students appear to gain more benefit than younger or older students); and whether the facilitator is a teacher from the school or an external facilitator.

\subsubsection{Who should be facilitating the intervention?}

Research clearly describes the importance of the trust relationship that students have with their teacher (Bishop \& Berryman, 2006). Programmes delivered by trained teachers were more likely to have significant effects on follow-up. Britton et al. (2014) suggest that it is likely that teachers being more involved with and familiar with the programme are likely to include the elements of mindfulness in their on-going programmes. Interestingly, the authors found that the effects on mental health outcomes post-test were only significant when delivered by a trained teacher, while the effects of mindfulness post-test were only significant when delivered by an outside facilitator who is familiar with mindfulness practices.

Conversely, Crane et al. (2017) strongly advocate for the importance of facilitators having their personal meditation practice and training and experience in delivering the programme. Saltzman (2008) described mindfulness meditation as a form of 'engagement'. She points out that the teaching of such engagement needs to come from the teacher's own practice. Viafora et al. (2011, p.21) reinforces this, insisting that mindfulness meditation is not a "technique that can be picked up at a weekend workshop" and then be taught to others. 
Conflict exists in the literature between Waters et al. (2015) who found that programmes were more effective when teachers delivered them and Crane et al. (2017) who emphasise the importance of the teacher's experience with MB. Carsley, Khoury \& Heath (2017) examined the apparent impact of the facilitator's experience and skillset with reference to particular outcomes. Their analysis of 24 studies showed that only interventions with trained teachers showed significant post-test outcomes of mental health. In contrast, only interventions facilitated by an outside facilitator (likely to be experienced in delivering mindfulness programmes) showed significant outcomes for mindfulness.

The father of MBSR (Kabat-Zinn, 2003) points out that it is experience which enables the facilitator to exemplify mindfulness that is a critical factor. He states that mindfulness trainers need to have considerable experience of mindfulness practice and an embodiment of the qualities and attitudes of mindfulness. It is the communication of mindfulness through the process of teaching as much as through the programme content (Crane, Brewer, Feldman et al., 2017) that is important.

\subsubsection{Is the developmental stage important?}

Adding to the inherent complexity of identifying the attributes of programmes that catalyse the intended outcomes, the development stage at which the intervention takes place is another factor for consideration. Research by Waters, et al., (2015) found that the effects of meditation on cognitive functioning were more significant for older students.

In their meta-analysis of 24 studies, Carsley et al. (2017) point out that interventions delivered during late adolescence (15-18) had the most significant effect on mental health and well-being at follow-up and post-test, with interventions delivered to 6-10-year-olds showing a significant effect at post-test only. Roeser \& Pinela (2014) as cited in Schonert-Reichl et al. (2015) suggest that MBIs may be particularly well-suited to adolescent students helping them to positively familiarise themselves with the outcomes of the changes, that they are experiencing in both their bodies and their minds.

\subsubsection{Programme content}

Crane et al. (2017) have developed a table that defines what they believe to be the essential and less essential components of a Mindfulness-Based Programme developed from the parent programme MBSR. Notably they insist that teachers must be trained in mindfulness. 
Figure 14. The essential (warp) and flexible (weft) of Mindfulness Based Programmes (Crane et al., 2017)

\begin{tabular}{|c|c|}
\hline The essential (warp) and flexible (weft) ingredients of MBPs & \\
\hline Warp & Weft \\
\hline \multicolumn{2}{|l|}{ MBP } \\
\hline $\begin{array}{l}\text { 1. Is informed by theories and practices that draw from a confluence of contemplative } \\
\text { traditions, science, and the major disciplines of medicine, psychology and education }\end{array}$ & $\begin{array}{l}\text { 1. The core essential curriculum elements are integrated with } \\
\text { adapted curriculum elements, and tailored to specific contexts } \\
\text { and populations }\end{array}$ \\
\hline $\begin{array}{l}\text { 2. Is underpinned by a model of human experience which addresses the causes of human } \\
\text { distress and the pathways to relieving it }\end{array}$ & $\begin{array}{l}\text { 2. Variations in program structure, length and delivery are } \\
\text { formatted to fit the population and context }\end{array}$ \\
\hline \multicolumn{2}{|l|}{$\begin{array}{l}\text { 3. Develops a new relationship with experience characterized by present moment focus, } \\
\text { decentering and an approach orientation }\end{array}$} \\
\hline \multicolumn{2}{|l|}{$\begin{array}{l}\text { 4. Supports the development of greater attentional, emotional and behavioral self- } \\
\text { regulation, as well as positive qualities such as compassion, wisdom, equanimity. }\end{array}$} \\
\hline \multicolumn{2}{|l|}{$\begin{array}{l}\text { 5. Engages the participant in a sustained intensive training in mindfulness meditation } \\
\text { practice, in an experiential inquiry-based learning process and in exercises to develop } \\
\text { insight and understanding }\end{array}$} \\
\hline \multicolumn{2}{|l|}{ MBP teacher } \\
\hline 1. Has particular competencies which enable the effective delivery of the MBP & $\begin{array}{l}\text { 1. Has knowledge, experience and professional training related to } \\
\text { the specialist populations that the mindfulness-based course will } \\
\text { be delivered to }\end{array}$ \\
\hline $\begin{array}{l}\text { 2. Has the capacity to embody the qualities and attitudes of mindfulness within the } \\
\text { process of the teaching }\end{array}$ & $\begin{array}{l}\text { 2. Has knowledge of relevant underlying theoretical processes } \\
\text { which underpin the teaching for particular contexts or } \\
\text { populations }\end{array}$ \\
\hline \multicolumn{2}{|l|}{ 3. Has engaged in appropriate training and commits to ongoing good practice } \\
\hline 4. Is part of a participatory learning process with their students, clients or patients & \\
\hline
\end{tabular}

Attentional training and "sustained training in mindfulness meditation practice, in an experiential inquiry-based learning process, and exercises to develop insight and understanding" (Crane et al., 2017) are considered by some to be the essential elements of mindfulness-based programmes in education.

Significant effects were found at both post-test and follow-up when programmes comprised a mixture of mindfulness activities and yoga-based mindfulness activities (Carsley et al., 2017). On reflection, two of the students who had less positive experiences in this intervention were very active individuals. The inclusion of yoga or other physical activity may have increased their engagement in the programme. 


\subsubsection{Duration of programme and frequency of practice}

Student's self-regulation through attentional control is developed through repeated focusing, sustaining and shifting of attention (Meiklejohn et al., 2012). Waters et al. (2015) suggest that longer duration increases the efficacy of the MBI as does increased frequency within the day, e.g. twice daily. Rozenkranz, Dunne and Richardson (2019) raise the important point that it is not uncommon within the MBSR context for participants to experience considerable difficulty in developing their practice. Consequently, just as teachers do not necessarily have expectations of linear development in other learning areas, expectations of a linear improvement may be not only inappropriate but may distract the researcher from more subtle changes that may strengthen in the future. Black and Fernando (2013) found that their control group that received reduced but on-going instruction continued to develop improved attention regulation. In contrast, the students in the discontinued group showed a flattening of development.

Rozenkranz et al. (2019) argue that a pre-condition regarding the effectiveness of any mindfulness intervention is the level of the individual's engagement and the frequency of practice. An important aspect of this study was that students were able to suggest their preferences for each day's meditative session.

\subsubsection{Potential influence of MB on class and school climate}

In addition to intrapersonal and psychosocial changes, the systemic benefits of MB may lead to positive influences in the school environment. This meditative breathing programme was perceived by the students to lead to a calmer and more peaceful classroom climate climate with enhanced student engagement. Wisner points out the importance of realising the potential impact of these programmes by "embedding mindfulness in the culture of the school, with commitment from teachers and other school professionals" (2013, p.635). If self-control develops in a gradient, small changes have the potential, over time, to effect significant change in not only the individual student's, but also in those with whom the individual interacts.

Following up on a study that found teacher reported significant effect on class climate, van de WeijerBergsma et al. (2014) suggested that increased guidance of classroom teachers or an in-school mindfulness trainer would be beneficial in assimilating mindfulness into the school climate. This suggestion is developed further by Sanger \& Dorjee (2015) who recommend the consideration of training teachers in mindfulness such that they develop a personal practice and further training them in the delivery of mindfulness-based curricula. 


\subsection{Implications}

\section{What type of programme is best?}

Experienced education practitioners champion the need to choose programmes that meet the varying needs of the individuals in their classes and schools. I suggest that there is no 'one size fits all' for MBIs and that teacher education is needed to build teacher familiarity with the variety of available approaches and the key factors that predict the likelihood of intervention success. New Zealand has a curriculum framework which requires schools to choose and craft their own programmes to meet the needs of their students and communities. Identifying needs and matching these with appropriate interventions are the New Zealand school's 'modis operandi'. Moreover, the evidence suggests that it is the nature of the development of mindfulness skills that they take time and practice. Tang, Holzel and Posner (2015) describe the synergistic nature of this three-stage developmental process.

\section{Mindfulness in teacher training programmes.}

It appears to me that the given the nature of the process of the development of MB skills, the lack of long-term on-going follow-up is a substantive barrier to our understanding of the long-term outcomes of these programmes. I propose that it is likely that the positive short-term changes in self-regulation and the consequent improvement in well-being, are very likely to lead to improvements in students' academic outcome over time. It seems logical that students who have improved abilities to sustain engagement with their learning will have improved academic outcomes. This raises the issue of how schools can be supported in continuing these programmes after the initial intervention. The inclusion of mindfulness training in teacher training creates a big-picture solution.

Mindfulness interventions have the potential to benefit not only students but teachers, classrooms and the overall school climate. In-service and pre-service training in mindfulness could have significant benefit for teachers operating in the stress of today's classrooms. Many teachers experience stress and potential burnout (Abenavoli, Jennings, Greenberg, Harris \& Katz, 2013). Such an inclusion would embody a new paradigm for educating teachers (Soloway, Poulin, \& MacKenzie, 2011).

Personal training in mindfulness skills has been shown to improve teachers' well-being, teaching selfefficacy, their ability to manage their classroom and to develop and sustain positive relationships with students (Meiklejohn et al., 2012). It has the potential to give teachers the space to choose how they respond to all aspects of the classroom dynamic, (Soloway et al., 2011) enabling 'pause and reflection time' and the choosing of the most productive and useful response to each situation as it arises. This operating in a mindfulness mode repositions classroom management in a very different perspective. Teachers who have strengthened capacities to non-judgementally pay attention to their thoughts and feelings have a more skilful response to situations that they find challenging (Kabat-Zinn, 2013). 
A MBSR adapted especially for teachers boosted aspects of teachers' mindfulness and selfcompassion, reduced psychological symptoms and burnout, increased effective teaching behaviour, and reduced attentional biases (Flook, Goldberg, Pinger, Bonus \& Davidson, 2013). Reducing stress and benefitting their sense of well-being and efficacy in the classroom is likely to correlate with a positive effect on student' well-being and success in learning, classroom climate, and overall school climate.

\subsection{Recommendations}

Based on the findings of this study, I recommend that mindfulness training becomes an intrinsic part of pre-service teacher training. I also recommend that mindfulness training is adopted as a priority for teacher professional development.

All class members increasingly behaving mindfully has the potential to become the 'modis operandi' of the classroom culture. This will be the beginning of a process in which individuals are becoming more present, non-judgementally aware and treating each other with increasing patience and kindness.

\subsection{Recommendations for future research}

Schonert-Reichl, Oberle and Lawlor (2015) recommendation remains relevant today. They called for rigorously designed investigations that are based on developmental theory; that include multi-method, multi-informant interventions; and follow-up after the end of the programme. I suggest that that follow-up should be for a period of at least five years and span developmental stages. Further research into the sustained implementation of MBI programmes across individual schools and clusters of schools would be very useful. In particular it is important that pilot programmes in New Zealand utilise multi-cultural principles and the development of models, their delivery and research need to consider outcomes for Maori and Pasifika, Mental Health Foundation of New Zealand (2012).

More than skills, key competencies are described as drawing "on knowledge, attitudes and values in ways that lead to action" (New Zealand Curriculum, 2007, p.12). This study has focussed on the key competency of 'managing self'. Students who can manage themselves are well prepared for life and learning with their capabilities to be resourceful, resilient, and have strategies for meeting challenges. This study suggests the potential for students to develop increasingly nuanced and deepening experiences and understandings of mindfulness as their skills and knowledge increase over time.

\subsection{Conclusion}

The students in this study report a positive and in many cases agentic experience of meditative breathing. They describe MB as an experience of "Letting go of tension and becoming calm" 4.7.2. They portray their MB practice as not only calming, but also energising. It makes me feel energized" 
(4.3.a). and able to think more clearly. Further, they refer to MB as a catalyst for self-regulation, "For me meditation relaxes me and gets me all ready for the day" (4.7.4).

Student's responses recorded in the heuristic (Figure 13) show ongoing improvement with practice, with reference to experiences of calm/feeling less anxious; thinking more clearly; and helpful start to the day (Waters, et al., 2015: Huppert \& Johnson, 2010; Rix \& Bernay, 2014). The co-generative dialogue indicates what appears to be an emerging understanding of using MB as a tool to support change. "... it helps me to move all the negative things on my mind and focus on the positive things" (4.4). At the three-month follow-up R describes MB as “quite a strong skill in itself". I suggest that she is describing MB as a tool for self-regulation.

Overall, this MB intervention was described by students and the classroom teacher as leading to a calmer and more peaceful classroom climate, with enhanced student engagement. This intervention took place in a school which is working to embed mindfulness in the curriculum and the culture of the school. It is experiencing commitment from an increasing number of members of the school community (Wisner, 2013). Some staff members are engaged in personal training in mindfulness.

An increasing number of the schools in this school's area are showing a growing interest in incorporating mindfulness into their programmes, as discussed in 3.4. Teachers and managers are seeking pragmatic ways of enskilling themselves and developing programmes with the intent of "embedding mindfulness as a school and life norm," (M. Curtis, personal communication, January 12, 2020). We may be close to seeing mindfulness come alive in everyday practices in a growing number of New Zealand classrooms. 


\section{References}

Abenavoli, R., Jennings, P., Greenberg, M., Harris, A., \& Katz, D. (2013). The protective effects of mindfulness against burnout among educators. The Psychology of Education Review, 37(2).

Alexakos, K. (2015). Being a Teacher/Researcher: A Primer on Doing Authentic Research on Teaching and Learning. Bold Visions in Educational Research, 50.

Allen, M., Dietz, M., Blair, K., van Beek, M., Rees, G., \& Vestergaard-Poulsen, P. et al. (2012). Cognitive-Affective Neural Plasticity following Active-Controlled Mindfulness Intervention. Journal of Neuroscience, 32(44), 15601-15610. doi: 10.1523/jneurosci.2957-12.2012

Arthurson, K. (2015). Teaching Mindfulness to Year Sevens as Part of Health and Personal Development. Australian Journal of Teacher Education, 40(5). doi: 10.14221/ajte.2015v40n5.2

Baer, R., Smith, G., Hopkins, J., Krietemeyer, J., \& Toney, L. (2006). Using Self-Report Assessment Methods to Explore Facets of Mindfulness. Assessment, 13(1), 27-45. doi:

$10.1177 / 1073191105283504$

Bakosh, L., Snow, R., Tobias, J., Houlihan, J., \& Barbosa-Leiker, C. (2015). Maximizing Mindful Learning: Mindful Awareness Intervention Improves Elementary School Students' Quarterly Grades. Mindfulness, 7(1), 59-67. doi: 10.1007/s12671-015-0387-6

Bandura, A. (2010). Perceived Self-Efficacy in Cognitive Development and Functioning. Educational Psychologist, 28(2).

Beauchemin, J., Hutchins, T., \& Patterson, F. (2008). Mindfulness Meditation May Lessen Anxiety, Promote Social Skills, and Improve Academic Performance Among Adolescents with Learning Disabilities. Complementary Health Practice Review, 13(1), 34-45. doi: 10.1177/1533210107311624

Bennett, K., \& Dorjee, D. (2016). The Impact of a Mindfulness-Based Stress Reduction Course (MBSR) on Well-Being and Academic Attainment of Sixth-form Students. Mindfulness, 7(1), 105114. doi: 10.1007/s12671-015-0430-7

Berryman, M. (2018). It's time we did better by Maori students [Podcast]. Retrieved 24 July 2019, from Radio New Zealand.

Biegel, G., Brown, K., Shapiro, S., \& Schubert, C. (2009). Mindfulness-based stress reduction for the treatment of adolescent psychiatric outpatients: A randomized clinical trial. Journal of Consulting and Clinical Psychology, 77(5), 855-866. doi: 10.1037/a0016241

Bishop, R., \& Berryman, M. (2006). Culture Speaks: Cultural relationships and classroom learning. Wellington: Huia. 
Bishop, R., O'Sullivan, D., \& Berryman, M. (2010). Scaling up Education Reform: Addressing the Politics of Disparity (1st ed.). Wellington: New Zealand Council for Education Research.

Bishop, S. (2004). Mindfulness: A Proposed Operational Definition. Clinical Psychology: Science and Practice, 11(3), 230-241. doi: 10.1093/clipsy/bph077

Black, D., \& Fernando, R. (2013). Mindfulness Training and Classroom Behavior Among LowerIncome and Ethnic Minority Elementary School Children. Journal of Child and Family Studies, 23(7), 1242-1246. doi: 10.1007/s10826-013-9784-4

Blair, C., \& Diamond, A. (2008). Biological processes in prevention and intervention: The promotion of self-regulation as a means of preventing school failure. Development and Psychopathology, 20(3), 899-911. doi: 10.1017/s0954579408000436

Bluth, K., Campo, R., Pruteanu-Malinici, S., Reams, A., Mullarkey, M., \& Broderick, P. (2016). A School-Based Mindfulness Pilot Study for Ethnically Diverse At-Risk Adolescents. Mindfulness, 7(1), 90-104. doi: 10.1007/s12671-014-0376-1

Borjian, A., \& Padilla, A. (2009). Voices from Mexico: How American Teachers Can Meet the Needs of Mexican Immigrant Students. The Urban Review, 42(4), 316-328. doi: 10.1007/s11256-009-0135-0 Breuing, M. (2011). Problematizing Critical Pedagogy. International Journal of Critical Pedagogy, 3(3).

Britton, W., Lepp, N., Niles, H., Rocha, T., Fisher, N., \& Gold, J. (2014). A randomized controlled pilot trial of classroom-based mindfulness meditation compared to an active control condition in sixth-grade children. Journal of School Psychology, 52(3), 263-278. doi: 10.1016/j.jsp.2014.03.002

Broderick, P., \& Metz, S. (2009). Learning to BREATHE: A Pilot Trial of a Mindfulness Curriculum for Adolescents. Advances in School Mental Health Promotion, 2(1), 35-46. doi: 10.1080/1754730x.2009.9715696

Broderick, P., \& Frank, J. (2014). Learning to BREATHE: An intervention to foster mindfulness in adolescence. New Directions for Youth Development, 2014(142), 31-44. doi: 10.1002/yd.20095

Cairncross, M., \& Miller, C. (2016). The Effectiveness of Mindfulness-Based Therapies for ADHD. Journal of Attention Disorders, 108705471562530. doi: 10.1177/1087054715625301

Carsley, D., Khoury, B., \& Heath, N. (2017). Effectiveness of Mindfulness Interventions for Mental Health in Schools: A Comprehensive Meta-analysis. Mindfulness, 9(3), 693-707. doi: 10.1007/s12671-017-0839-2

CASEL. (2019). Retrieved 27 July 2019, from https://casel.org 
Chapman, M., Hare, D., Caton, S., Donalds, D., McInnis, E., \& Mitchell, D. (2013). The Use of Mindfulness with People with Intellectual Disabilities: a Systematic Review and Narrative Analysis. Mindfulness, 4(2), 179-189. doi: 10.1007/s12671-013-0197-7

Chiesa, A., Serretti, A., \& Jakobsen, J. (2013). Mindfulness: Top-down or bottom-up emotion regulation strategy? Clinical Psychology Review, 33(1), 82-96. doi: 10.1016/j.cpr.2012.10.006 Cohen-Miller, A. (2018). Visual Arts as a Tool for Phenomenology. Forum: Qualitative Social Research, 19(1).

Collins, A., Koechlin, E. Reasoning, learning and creativity: Frontal lobe function and human decision-making. PloS Biology. 2012; 10(3); e1001293. Retrieved from https://journals.plos.org/plosbiology/article?id=10.1371/journal.pbio.1001293

Crane, R., Brewer, J., Feldman, C., Kabat-Zinn, J., Santorelli, S., Williams, J., \& Kuyken, W. (2017). What defines mindfulness-based programs? The warp and the weft. Psychological Medicine, 47(6), 990-999. doi: 10.1017/s0033291716003317

Creed, A., \& McIlveen, P. (2017). Metaphor identification as a research method for the study of career. International JournalfFor Educational and Vocational Guidance, 18(1), 27-44. doi: 10.1007/s10775-017-9345-2

Cresswell, J. (2003). Research Design: Qualitative, Quantitative and Mixed Methods Approaches (2nd ed.). London: Sage.

Cresswell, J. (2007). Qualitative Inquiry and Research Design: Choosing Among Five Approaches (2nd ed.). Thousand Oaks: Sage Publications.

Davidson, R., Kabat-Zinn, J., Schumacher, J., Rosenkranz, M., Muller, D., \& Santorelli, S. et al. (2003). Alterations in Brain and Immune Function Produced by Mindfulness Meditation. Psychosomatic Medicine, 65(4), 564-570. doi: 10.1097/01.psy.0000077505.67574.e3 de Carvalho, J., Pinto, A., \& Marôco, J. (2016). Results of a Mindfulness-Based Social-Emotional Learning Program on Portuguese Elementary Students and Teachers: a Quasi-Experimental Study. Mindfulness, 8(2), 337-350. doi: 10.1007/s12671-016-0603-z

Desmond, C. \& Hanich, L. (2010). The Effects of Mindful Awareness Teaching Practices on the Executive Functions of Students in an Urban, Low Income Middle School

Devcich, D., Rix, G., Bernay, R., \& Graham, E. (2017). Effectiveness of a Mindfulness-Based Program on School Children's Self-Reported Well-Being: A Pilot Study Comparing Effects with An Emotional Literacy Program. Journal of Applied School Psychology, 33(4), 309-330. doi:

10.1080/15377903.2017.1316333 
Diamond, A. (2013). Executive Functions. Annual Review of Psychology, 64(1), 135-168. doi: 10.1146/annurev-psych-113011-143750

Diem-Wille, G. The Handbook of Visual Analysis. A Therapeutic Perspective: the Use of Drawing in Child Psychoanalysis and Social Science Retrieved from https://books.google.co.nz/books?hl=en\&lr=\&id=vSFlLmCR260C\&oi=fnd\&pg=PA119\&dq=DiemWille $+\& o t s=T 7 \mathrm{huNwAGpg} \& \operatorname{sig}=J \mathrm{JvLX} 8 \mathrm{~s} 3 \mathrm{gLzpAMpaW} 82 \mathrm{~S} 0 \mathrm{ff} 1 \mathrm{t} 4 \mathrm{w} \# \mathrm{v}=0$ nepage $\& \mathrm{q}=$ DiemWille \&f=false (2001)

Dunning, D., Griffiths, K., Kuyken, W., Crane, C., Foulkes, L., Parker, J., \& Dalgleish, T. (2018). Research Review: The effects of mindfulness-based interventions on cognition and mental health in children and adolescents - a meta-analysis of randomized controlled trials. Journal of Child Psychology and Psychiatry. doi: 10.1111/jcpp.12980

Education and Science Committee (2008). Inquiry into making the schooling-system work for every child. https://www.parliament.nz/en/pb/sc/reports/document/48DBSCH_SCR3979_1/inquiry-intomaking-the-schooling-system-work-for-every

Education Review Office (2015). Wellbeing for Children's Success at Primary School. Wellington: Education Review Office.

Felver, J., Frank, J., \& McEachern, A. (2013). Effectiveness, Acceptability, and Feasibility of the Soles of the Feet Mindfulness-Based Intervention with Elementary School Students. Mindfulness, 5(5), 589-597. doi: 10.1007/s12671-013-0238-2

Flook, L., Smalley, S., Kitil, M., Galla, B., Kaiser-Greenland, S., \& Locke, J. et al. (2010). Effects of Mindful Awareness Practices on Executive Functions in Elementary School Children. Journal of Applied School Psychology, 26(1), 70-95. doi: 10.1080/15377900903379125

Flook, L., Goldberg, S., Pinger, L., \& Davidson, R. (2015). Promoting prosocial behavior and selfregulatory skills in preschool children through a mindfulness-based kindness curriculum. Developmental Psychology, 51(1), 44-51. doi: 10.1037/a0038256

Franco, C., Mañas, I., Cangas, A., \& Gallego, J. (2011). Exploring the Effects of a Mindfulness Program for Students of Secondary School. International Journal of Knowledge Society Research, 2(1), 14-28. doi: 10.4018/jksr.2011010102

Gethin, R. (2011). On some definitions of mindfulness. Contemporary Buddhism, 12(1), 263-279. doi: 10.1080/14639947.2011.564843

Glasser, W. (1999). Choice Theory: a new psychology of personal freedom. (3rd ed.). New York: Harper Perennial. 
Hayes, A., \& Feldman, G. (2006). Clarifying the Construct of Mindfulness in the Context of Emotion Regulation and the Process of Change in Therapy. Clinical Psychology: Science and Practice, 11(3), 255-262. doi: 10.1093/clipsy.bph080

Higgins, J., \& Eden, R. (2018). Cogenerated understandings of mindfulness-based breathing in elementary mathematics classrooms. The Journal of Educational Research, 111(6), 678-689. doi: $10.1080 / 00220671.2017 .1396438$

Hipkins, R., Bolstad, R., Boyd, S., \& McDowall, S. (2014). Key Competencies for the Future (1st ed., p. p.9). Wellington: New Zealand Council of Education Research.

Hollis-Walker, L., \& Colosimo, K. (2011). Mindfulness, self-compassion, and happiness in nonmeditators: A theoretical and empirical examination. Personality and Individual Differences, 50(2), 222-227. doi: 10.1016/j.paid.2010.09.033

Hölzel, B., Lazar, S., Gard, T., Schuman-Olivier, Z., Vago, D., \& Ott, U. (2011). How Does Mindfulness Meditation Work? Proposing Mechanisms of Action from a Conceptual and Neural Perspective. Perspectives on Psychological Science, 6(6), 537-559. doi: 10.1177/1745691611419671

Honey, I., \& Honey, R. (2015). Doug Dragster's Get Happier Toolbox. Victoria: Ivan Honey \& Associates Pty Ltd.

Huppert, F., \& Johnson, D. (2010). A controlled trial of mindfulness training in schools: The importance of practice for an impact on well-being. The Journal of Positive Psychology, 5(4), 264274. doi: 10.1080/17439761003794148

Innocenti, U. (2018). Innocenti Report Card 15. Retrieved 24 July 2019, from https://www.unicefirc.org/unfairstart

Johnson, R., \& Christensen, L. (2014). Educational Research: Quantitative, Qualitative, and Mixed Approaches. (5th ed.). Thousand Oaks: Sage.

Johnson, A., Howden-Chapman, P., \& Eaqub, S. (2018). A Stocktake of New Zealand's Housing. Wellington.

Kabat-Zinn, J. (1994). Wherever You Go, There You Are: Mindfulness Meditation in Everyday Life. Hyperion.

Kabat-Zinn, J. (2018). Falling Awake: How to practice mindfulness in everyday life (1st ed.). New York: Hatchette Books.

Kabat-Zinn, J. (2013). Full Catastrophe Living: Using the Wisdom of Your Body and Mind to Face Stress, Pain and Illness. (2nd ed.). New York: Bantam Books. 
Kuyken, W., Weare, K., Ukoumunne, O., Vicary, R., Motton, N., \& Burnett, R. et al. (2013). Effectiveness of the Mindfulness in Schools Programme: non-randomised controlled feasibility study. British Journal of Psychiatry, 203(2), 126-131. doi: 10.1192/bjp.bp.113.126649

Leachman, G., \& Victor, D. (2003). Student-Led Class Meetings. Educational Leadership, 6(6).

Liew, J. (2011). Effortful Control, Executive Functions, and Education: Bringing Self-Regulatory and Social-Emotional Competencies to the Table. Child Development Perspectives, 6(2), 105-111. doi: $10.1111 / \mathrm{j} .1750-8606.2011 .00196 . x$

McClelland, M., \& Cameron, C. (2011). Self-regulation and academic achievement in elementary school children. New Directions For Child And Adolescent Development, 2011(133), 29-44. doi: $10.1002 / \mathrm{cd} .302$

Maynard, B., Solis, M., Miller, V., \& Brendel, K. (2017). Mindfulness-based interventions for improving cognition, academic achievement, behavior, and socioemotional functioning of primary and secondary school students. Campbell Systematic Reviews, 13(1), 1-144. doi: 10.4073/csr.2017.5

Meiklejohn, J., Phillips, C., Freedman, M., Griffin, M., Biegel, G., \& Roach, A. et al. (2012). Integrating Mindfulness Training into K-12 Education: Fostering the Resilience of Teachers and Students. Mindfulness, 3(4), 291-307. doi: 10.1007/s12671-012-0094-5

Mendelson, T., Greenberg, M., Dariotis, J., Gould, L., Rhoades, B., \& Leaf, P. (2010). Feasibility and Preliminary Outcomes of a School-Based Mindfulness Intervention for Urban Youth. Journal of Abnormal Child Psychology, 38(7), 985-994. doi: 10.1007/s10802-010-9418-x

Ministry of Social Development. Family violence and sexual violence initiatives - Retrieved 23 July 2019, from https://www.msd.govt.nz/about-msd-and-our-work/work-programmes/initiatives/familyand-sexual-violence/index.html

Mental Health - Site search. (2019). Retrieved 6 August 2019, from https://www.mentalhealth.org.nz/home/site-search/?query=mindfulness+in+education $\& x=0 \& y=0$ Milligan, K., Cosme, R., Wolfe Miscio, M., Mintz, L., Hamilton, L., Cox, M., Woon, S., Gage, M \& Phillips, M. (2017). Integrating Mindfulness into Mixed Martial Arts Training to Enhance Academic, Social, and Emotional Outcomes for At-Risk High School Students: a Qualitative Exploration. Contemporary School Psychology, 21(4), 335-346. doi: 10.1007/s40688-017-0142-1 Mindfulness in Schools Project (MiSP) | Bringing Mindfulness to Schools. (2019). Retrieved 31 July 2019, from https://mindfulnessinschools.org/

MindUP | Helping Children Thrive in School, Work and Life! (2019). Retrieved 21 July 2019, from https://mindup.org/ 
Moffitt, T., Arseneault, L., Belsky, D., Dickson, N., Hancox, R., \& Harrington, H. et al. (2011). A gradient of childhood self-control predicts health, wealth, and public safety. Proceedings of The National Academy of Sciences, 108(7), 2693-2698. doi: 10.1073/pnas.1010076108

Molfese, V., Molfese, P., Molfese, D., Rudasill, K., Armstrong, N., \& Starkey, G. (2010). Executive function skills of 6-8year olds: Brain and behavioral evidence and implications for school achievement. Contemporary Educational Psychology, 35(2), 116-125. doi:

10.1016/j.cedpsych.2010.03.004

Napoli, M., Krech, P., \& Holley, L. (2005). Mindfulness Training for Elementary School Students. Journal of Applied School Psychology, 21(1), 99-125. doi: 10.1300/j370v21n01_05

New Zealand. Ministry of Education. (2007). The New Zealand curriculum. Published for the Ministry of Education: By Learning Media, Wellington, N.Z.

New Zealand Ministry of Education (2018). Site search. (2020) Retrieved 20 January 2020, from https:www.education.govt.nz>assests>KaHikitiaAcceleratingSuccessEnglish

Nhat Hanh, T. (2011). Planting Seeds: Practising Mindfulness with Children. Berkeley, California: Parallax Press.

Office of the Children's Commissioner \& Oranga Tamariki. (2019). What Makes a Good Life? Young People's Views on Wellbeing. Wellington: Office of the Children's Comissioner \& Oranga Tamariki. Retrieved from https://www.occ.org.nz/assets/Uploads/What-makes-a-good-life-report-OCC-OT2019-WEB2.pdf

Ricarte, J., Ros, L., Latorre, J., \& Beltrán, M. (2015). Mindfulness-Based Intervention in a Rural Primary School: Effects on Attention, Concentration and Mood. International Journal of Cognitive Therapy, 8(3), 258-270. doi: 10.1521/ijct_2015_8_03

Rix, G., \& Bernay, R. (2014). A Study of the Effects of Mindfulness in Five Primary Schools in New Zealand. Teachers' Work, 11(2), 201-220. doi: 10.24135/teacherswork.v11i2.69

Rosenkranz, M., Dunne, J., \& Davidson, R. (2019). The next generation of mindfulness-based intervention research: what have we learned and where are we headed? Current Opinion in Psychology, 28, 179-183. doi: 10.1016/j.copsyc.2018.12.022

Saltzman, A. (2011). Mindfulness: A Guide for Teachers [Ebook]. Saltzman, A. (2019). Children \& Adolescents | Still Quiet Place. Retrieved 26 July 2019, from http://www.stillquietplace.com/children-adolescents/ 
Sanger, K., \& Dorjee, D. (2016). Mindfulness training with adolescents enhances metacognition and the inhibition of irrelevant stimuli: Evidence from event-related brain potentials. Trends in Neuroscience and Education, 5(1), 1-11. doi: 10.1016/j.tine.2016.01.001

Schonert-Reichl, K., \& Lawlor, M. (2010). The Effects of a Mindfulness-Based Education Program on Pre- and Early Adolescents' Well-Being and Social and Emotional Competence. Mindfulness, 1(3), 137-151. doi: 10.1007/s12671-010-0011-8

Schonert-Reichl, K., Oberle, E., Lawlor, M., Abbott, D., Thomson, K., Oberlander, T., \& Diamond, A. (2015). Enhancing cognitive and social-emotional development through a simple-to-administer mindfulness-based school program for elementary school children: A randomized controlled trial. Developmental Psychology, 51(1), 52-66. doi: 10.1037/a0038454

Schussler, D., Jennings, P., Sharp, J., \& Frank, J. (2015). Improving Teacher Awareness and WellBeing Through CARE: a Qualitative Analysis of the Underlying Mechanisms. Mindfulness, 7(1), 130142. doi: 10.1007/s12671-015-0422-7

Segal, Z. V., Williams, J. M. G., \& Teasdale, J. D. (2002). Mindfulness-based cognitive therapy for depression: A new approach to preventing relapse. New York, NY, US: Guilford Press.

Snel, E., \& Snel, E. (2013). Sitting still like a frog. Boston: Shambhala.

Soloway, G., Poulin, P. \& MacKenzie, C. (2011). Preparing New teachers for the Full Catastrophe of the Twenty-First-Century Classroom: Integrating Mindfulness Training into Initial Teacher Education. In A. Cohan \& A. Honigsfeld, Breaking the mold of preservice and inservice teacher education: Innovative and Successful Practices for the 21st Century. (1st ed., pp. 219-228). Plymouth: Rowan \& Littlefield.

Tang, Y., Holzel, B., \& Posner, M. (2015). The neuroscience of mindfulness meditation. - PubMed NCBI. Retrieved 6 August 2019, from https://www.ncbi.nlm.nih.gov/pubmed/25783612/

Teasdale, J., Moore, R., Hayhurst, H., Pope, M., Williams, S., \& Segal, Z. (2002). Metacognitive awareness and prevention of relapse in depression: Empirical evidence. Journal Of Consulting And Clinical Psychology, 70(2), 275-287. doi: 10.1037//0022-006x.70.2.275

The Dunedin Study - Dunedin Multidisciplinary Health \& Development Research Unit. (2019). Retrieved 2 November 2019, from https://dunedinstudy.otago.ac.nz/ Tomorrow's Schools Independent Task Force. (2018). Our Schooling Futures:Stronger Together Whiria Nga Tuatinitini. Wellington.

Toshalis, E., \& Nakkula, M. (2012). Motivation, Engagement, and Student Voice. 
Ultinar, E. (2012). An Epistemological Glance at the Constructivist Approach: Constructivist Learning in Dewey, Piaget and Montessori. International Journal of Instruction, 5(2).

van de Weijer-Bergsma, E., Formsma, A., de Bruin, E., \& Bögels, S. (2012). The Effectiveness of Mindfulness Training on Behavioral Problems and Attentional Functioning in Adolescents with ADHD. Journal of Child and Family Studies, 21(5), 775-787. doi: 10.1007/s10826-011-9531-7 van de Weijer-Bergsma, E., Langenberg, G., Brandsma, R., Oort, F., \& Bögels, S. (2014). The Effectiveness of a School-Based Mindfulness Training as a Program to Prevent Stress in Elementary School Children. Mindfulness. doi: 10.1007/s12671-012-0171-9

Viafora, D., Mathiesen, S., \& Unsworth, S. (2014). Teaching Mindfulness to Middle School Students and Homeless Youth in School Classrooms. Journal of Child and Family Studies, 24(5), 1179-1191. doi: 10.1007/s10826-014-9926-3

Vickery, C., \& Dorjee, D. (2016). Mindfulness Training in Primary Schools Decreases Negative Affect and Increases Meta-Cognition in Children. Frontiers in Psychology, 6. doi: 10.3389/fpsyg.2015.02025

Wadlinger, H., \& Isaacowitz, D. (2010). Fixing Our Focus: Training Attention to Regulate Emotion. Personality and Social Psychology Review, 15(1), 75-102. doi: 10.1177/1088868310365565

Waters, L., Barsky, A., Ridd, A., \& Allen, K. (2015). Contemplative Education: A Systematic, Evidence-Based Review of the effect of Meditation Interventions in Schools. Educational Psychology Review, 27(1), 103-134. doi: 10.1007/s10648-014-9258-2

Whiteford, H., Ferrari, A., \& Degenhardt, L. (2016). Global Burden of Disease Studies: Implications for Mental and Substance Use Disorders. Health Affairs, 35(6), 1114-1120. doi: 10.1377/hlthaff.2016.0082

Wisner, B. (2014). An Exploratory Study of Mindfulness Meditation for Alternative School Students: Perceived Benefits for Improving School Climate and Student Functioning. Mindfulness, 5(6), 626638. doi: 10.1007/s12671-013-0215-9

Wink, J. (2005). Critical pedagogy (3rd ed.). Boston, Mass.: Pearson Education. Yates, C., Partridge, H., \& Bruce, C. (2012). Exploring information experiences through phenomenography. Library and Information Research, 36(112), 96-119. doi: 10.29173/lirg49 


\section{Appendices}

Appendix A: Comparing interventions

\begin{tabular}{|c|c|c|c|c|c|}
\hline Authors & $\begin{array}{l}\text { Prime } \\
\text { focus }\end{array}$ & Duration & Numbers & Intervention Programme & Outcomes \\
\hline Napoli et al. (2005) & $\begin{array}{l}\text { Executive } \\
\text { control }\end{array}$ & $\begin{array}{l}2 \mathrm{x} \text { month } 24 \\
\text { weeks }\end{array}$ & $\begin{array}{l}194 \text { students, aged } \\
\text { 5-8 in the U.S.A. }\end{array}$ & $\begin{array}{l}\text { Attention Academy } \\
\text { Programme Breath, Body } \\
\text { Scan, Movement } \\
\text { Professionally trained, } \\
\text { experienced facilitators }\end{array}$ & $\begin{array}{l}\text { Statistically significant decrease in tes } \\
\text { anxiety and increase in selective } \\
\text { attention scores, improved social skills }\end{array}$ \\
\hline Beauchemin et al. (2008) & $\begin{array}{l}\text { Executive } \\
\text { control } \\
\text { Well- } \\
\text { being }\end{array}$ & $\begin{array}{l}5 \text { weekly } \\
\text { sessions of } \\
45 \text { minutes }\end{array}$ & $\begin{array}{l}34 \text { students aged } \\
13-18 \text { years in } \\
\text { Vermont U.S.A. }\end{array}$ & Mindfulness meditaion & $\begin{array}{l}\text { Decreased state and trait anxiety and } \\
\text { enhanced social skills. }\end{array}$ \\
\hline Flook et al. (2010) & $\begin{array}{l}\text { Executive } \\
\text { control }\end{array}$ & $\begin{array}{l}30 \mathrm{~m} \text {, twice } \\
\text { per week for } 8 \\
\text { weeks }\end{array}$ & $\begin{array}{l}64 \text { students aged } 7- \\
9 \text { years }\end{array}$ & Meditation, Body Scan, AR. & $\begin{array}{l}\text { Gains in behavioral regulation, } \\
\text { metacognition, and overall global } \\
\text { executive control. }\end{array}$ \\
\hline Mendelson et al. (2010) & $\begin{array}{l}\text { Executive } \\
\text { control }\end{array}$ & $\begin{array}{l}45 \mathrm{~m}, 4 \text { days } \\
\text { for } 12 \text { weeks }\end{array}$ & $\begin{array}{l}97 \text { disadvantaged } \\
\text { youth, aged 9- }\end{array}$ & $\begin{array}{l}\text { Holistic Life Foundation } \\
\text { (HLF) }\end{array}$ & $\begin{array}{l}\text { Gains in behavioural regulation, } \\
\text { metacognition, and overall global }\end{array}$ \\
\hline
\end{tabular}


11years in

Baltimore, USA

Franco et al. ( 2011) Executive

(2012)

Van de Weijer-Bergsma et

al. (2012) control

\begin{abstract}
Executive $45 \mathrm{mins}$
\end{abstract}
function

12 eeeks

Executive 45mins x 10

control

weeks

61 16-18 years in rural Spain

97 9-11 years

$4011-12$ years in a low-income urban middle school

\section{Executive}

control
$30 \operatorname{mins} 8$

weeks
ADHD
Meditacion Fleur and Acceptance and Commitment Therapy

Yoga, breathing techniques, guided mindfulness practice

Wellness Works in Schools

Teachers had six years of experience in leading MBIs

Mindfulness exercises

Netherlands executive control. Effect stronger on those with EF difficulties

Significant improvement in academic performance $\&$ increase in selfconcept dimensions, significant decrease in in anxiety states and traits.

Gains in behaviour regulation, overall executive function

\section{Significant effect for attention control positive overall trend re executive control.}

Majority of results pointed to improvement.

Small effect on teacher-reported selfregulation persisted throughout the year. 
Felver et al. (2013)

Executive
control

$30 \mathrm{~m}$

on 5

consecutive

days

Black and Fernando (2013)

Executive
control

$\begin{array}{ll}3 \text { x 15 mins } & 409 \text { students aged } \\ \text { per week for 5 } & 5-12 \text { years } \\ \text { weeks, MS+ } & \text { 17 teachers } \\ \text { extra 3x 15 } & \\ \text { mins for 5 } & \text { Richmond } \\ \text { weeks } & \text { elementary school }\end{array}$

Bakosh rt al. (2015)

Sanger and Dorjee (2016)

$\begin{array}{lll}\begin{array}{l}\text { Executive } \\ \text { control }\end{array} & \begin{array}{l}8 \text { weeks of } \\ \text { weekly } 8 \text { mins }\end{array} & 90 \text { 9-10 year olds } \\ & \begin{array}{l}\text { listening, } 2 \\ \text { mins }\end{array} & \\ & \text { journaling } & \\ & & \\ \text { Executive } & 50 \text { mins x } 8 & 40 \text { students aged } \\ \text { control } & \text { weeks } & 16-18 \text { years }\end{array}$

Soles of our Feet - Attention

shifting, breathing,

movement, relaxation, group

discussion.

\section{Mindful Schools (MS)}

listening, breathing, body

awareness, heartfulness,

mindful walking, eating, test-

taking, discussion about

thoughts and emotions. Exp

Mindfulness teachers

Adapted MBSR audio

programme. Facilitators

experienced mindfulness

instructors

MiSP Paws .b delivered by

classroom teachers
Effective short-term, resource nonintensive and socially valid and acceptable intervention

\section{Teacher reported improvements in} attention regulation, calm and selfcontrol, participating in activities and caring and respect for others.

Improved quarterly grades in reading and science

Enhances SR and WB with the potential to support academic success. 


\begin{tabular}{|c|c|c|c|c|c|}
\hline Vickery and Dorjee (2016) & $\begin{array}{l}\text { Executive } \\
\text { control }\end{array}$ & 8 weeks & $\begin{array}{l}71 \text { students aged } 7 \text { - } \\
9 \text { years in } 3 \\
\text { primary schools in } \\
\text { Nth Wales }\end{array}$ & $\begin{array}{l}\text { Paws b delivered by } \\
\text { classroom teachers }\end{array}$ & $\begin{array}{l}\text { Significant improvements in meta- } \\
\text { cognition at follow-up. initial evidence } \\
\text { that the Paws b program in children (a) } \\
\text { can be feasibly delivered by primary } \\
\text { school teachers as part of the regular } \\
\text { curriculum, (b) is acceptable to the } \\
\text { majority of children, and (c) may } \\
\text { significantly decrease negative affect } \\
\text { and improve meta-cognition. }\end{array}$ \\
\hline Milligan et al. (2017) & $\begin{array}{l}\text { Executive } \\
\text { control } \\
\text { Well- } \\
\text { being }\end{array}$ & & $\begin{array}{l}24 \text { students aged } \\
14-17 \text { years }\end{array}$ & Integra Martial Arts & $\begin{array}{l}\text { Teacher and student reported ratings } \\
\text { showed an increase in approaching } \\
\text { social interactions, making friends, } \\
\text { interactions with peers and teachers. } \\
\text { Student behaviours became more } \\
\text { adaptive and appropriate with } \\
\text { improved emotional regulation, self- } \\
\text { confidence and increased awareness of } \\
\text { themselves and the environment. }\end{array}$ \\
\hline Biegel et al. (2009) & $\begin{array}{l}\text { Well- } \\
\text { being }\end{array}$ & $\begin{array}{l}8 \text { weeks of } 2 \\
\text { hour training } \\
\text { sessions }\end{array}$ & $\begin{array}{l}102 \text { patients aged } \\
14-18 \text { years }\end{array}$ & $\begin{array}{l}\text { Body scan, meditation, Hatha } \\
\text { yoga and walking meditation }\end{array}$ & $\begin{array}{l}\text { Decreased symptoms of anxiety, } \\
\text { depression and somatic distress, }\end{array}$ \\
\hline
\end{tabular}




\begin{tabular}{|c|c|c|c|c|c|}
\hline & & & & & $\begin{array}{l}\text { increased self-esteem, and sleep } \\
\text { quality }\end{array}$ \\
\hline $\begin{array}{l}\text { Schonert-Riechl and } \\
\text { Lawlor (2010) }\end{array}$ & $\begin{array}{l}\text { Well- } \\
\text { being }\end{array}$ & $\begin{array}{l}10 \text { lessons of } \\
50-50 \text { mins } \\
3 \text { times daily } \\
3 \text { mins of } \\
\text { focus }\end{array}$ & $\begin{array}{l}2467-13 \text { years } \\
\text { from } 12 \text { schools in } \\
\text { a large urban city in } \\
\text { W. Canada. }\end{array}$ & $\begin{array}{l}\text { Mindfulness Education } \\
\text { programme. Teacher taught }\end{array}$ & $\begin{array}{l}\text { Teacher reported efficacy to positively } \\
\text { influence the development of social } \\
\text { and emotional skills. }\end{array}$ \\
\hline Beigel and Brown (2010) & $\begin{array}{l}\text { Well- } \\
\text { being }\end{array}$ & $\begin{array}{l}12 \text { weekly } \\
\text { thirty minute } \\
\text { sessions }\end{array}$ & $\begin{array}{l}208 \text { Eight to } \\
\text { Twelve year olds in } \\
\text { Amsterdam, the } \\
\text { Netherlands }\end{array}$ & $\begin{array}{l}\text { Adapted from MBSR and } \\
\text { MBCT. }\end{array}$ & $\begin{array}{l}\text { Significant reductions in anxiety, } \\
\text { depression, somatisation, stress, } \\
\text { obsessive symptoms and interpersonal } \\
\text { problems statistically significant } \\
\text { improve self-esteem mindfulness and } \\
\text { mental health }\end{array}$ \\
\hline $\begin{array}{l}\text { Huppert and Johnson } \\
\text { (2010) }\end{array}$ & $\begin{array}{l}\text { Well- } \\
\text { being }\end{array}$ & $\begin{array}{l}\text { 40mins } 4 \\
\text { weeks }\end{array}$ & $\begin{array}{l}15514-15 \text { years } \\
\text { from fee-paying } \\
\text { schools. England }\end{array}$ & Adapted MBSR & $\begin{array}{l}\text { Overall differences between the groups } \\
\text { were not significant. Students reported } \\
\text { benefit from the programme and most } \\
\text { indicated that they would like to } \\
\text { continue with it in future. }\end{array}$ \\
\hline Viafora et al.(2014) & $\begin{array}{l}\text { Well- } \\
\text { being }\end{array}$ & 8 weeks & $\begin{array}{l}12-14 \text { year olds } \\
38 \text { from a charter } \\
\text { middle school \& } 18\end{array}$ & $\begin{array}{l}\text { Planting Seeds: Practicing } \\
\text { Mindfulness with Children } \\
\text { (Nhat Hanh, 2011) and 'Still }\end{array}$ & $\begin{array}{l}\text { Students from standard classrooms } \\
\text { showed significant improvement in } \\
\text { mindful awareness and acceptance. }\end{array}$ \\
\hline
\end{tabular}


from a school

serving homeless

youth in United

States
Quiet Places: (Saltzman,

2008). Facilitator undertook

additional training during

research (Saltzman)

$\begin{array}{llll}\begin{array}{l}\text { Well- } \\ \text { being }\end{array} & \begin{array}{l}\text { 9 scripted } \\ \text { lessons of 40 }\end{array} & \begin{array}{l}\text { 522 students aged } \\ \text { 12-16 years at 12 }\end{array} & \begin{array}{l}\text { Mindfulness in Schools } \\ \text { (MiSP). }\end{array} \\ & \text { to 60mins } & \text { secondary schools } & \\ & \text { in England. } & \text { Teachers trained in MiSP } \\ & & \begin{array}{l}\text { curriculum or had expressed } \\ \text { interest in being trained. }\end{array}\end{array}$

8 weeks and 126 students aged
3- month

follow-up
6-11 years and

6 teachers from 5 primary schools in NZ.

$\begin{array}{ll}\text { being } & \text { 6- month } \\ \text { follow-up } & \\ & 6 \text { teachers from } 5 \\ & \text { primary schools in } \\ & \text { NZ. }\end{array}$

Pause, Breathe, Smile written by one of the authors.

Mindful breathing, sensory awareness, practices for promoting kindness and gratitude, emotion-
Students facing homelessness reported significantly higher evaluations of the course, greater emotional well-being from mindfulness practice, and were more likely to use mindfulness practice at school, in interpersonal situations, for dealing with anger and other difficult emotions, and to recommend it to friends.

Positive impacts on depressive symptoms as well as positive indications of the programme's effectiveness in reducing stress and enhancing well-being and a high level of acceptability.

Improvement in student's conflict resolution skills, the developing of more positive relationships, their ability to see other's point of view, improved emotional regulation and a happier classroom culture. Teachers 
12 weekly

99 students aged 8-

Schonert-Reichl et al.

(2015)

Britton et al. (2014) lessons of 40-

50 mins

being

Executive

3x3mins daily

function

$\begin{array}{ll}\text { Well- } & 15 \text { minutes } \\ \text { being } & \text { daily for } 8 \\ & \text { weeks }\end{array}$

90 children aged 7-

9 years in Spain

weeks

Well-
being

6 weeks of 3

increasing to

12 minutes at
101 students aged

$11-13$ years at an

independent regulation, and

interconnectedness
Integrated Contemplative

Pedagogy (Roth). reported improved calmness of classes and students showed improved focus over time.

Increased emotional flexibility through the use of EC skills and attitudes of acceptance and non-judgment.

Significant improvement self-reported measures of well-being and other psychological variables as well as peer-reported pro-social behaviour.

Significant decreases in trait anxiety levels and improved well-being. mandala meditation, present moment meditation on sounds and body scan.

High level of participant engagement and student perceived benefit. 


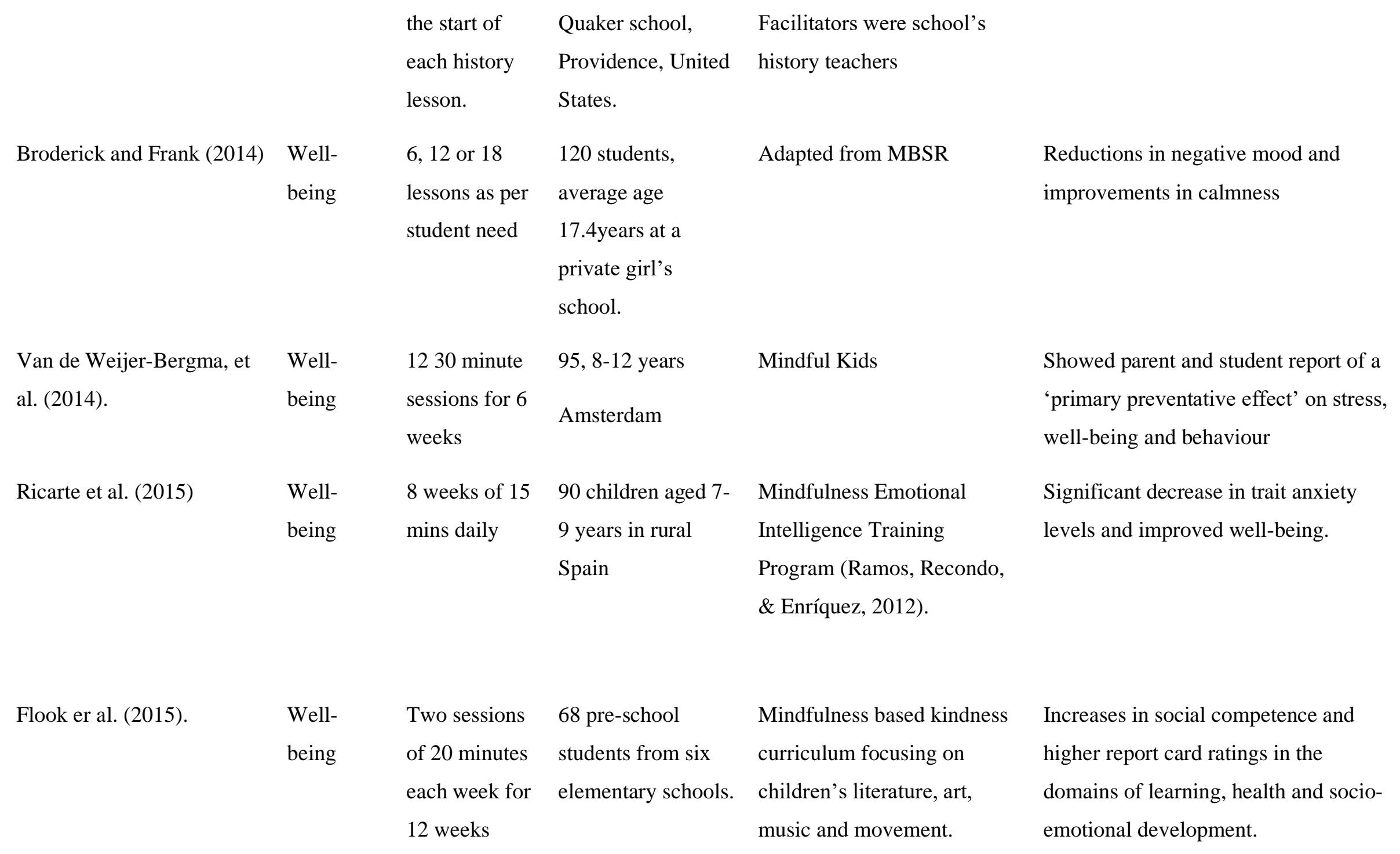




\begin{tabular}{|c|c|c|c|c|}
\hline Bennet and Dorjee (2016) & $\begin{array}{l}\text { Well- } \\
\text { being } \\
\text { Executive } \\
\text { function }\end{array}$ & $\begin{array}{l}8 \text { weeks for } 2 \\
\text { hours after } \\
\text { school. }\end{array}$ & $\begin{array}{l}23 \text { students aged } \\
16-18 \text { years in NW } \\
\text { England }\end{array}$ & $\begin{array}{l}\text { Adapted from MBSR. } \\
\text { Facilitator experienced } \\
\text { teacher and MBSR } \\
\text { instructor. }\end{array}$ \\
\hline Bluthet al.(2016) & $\begin{array}{l}\text { Well- } \\
\text { being }\end{array}$ & $\begin{array}{l}6 \text { 0ne hour or } \\
1820 \text { mins } \\
\text { sessions }\end{array}$ & $\begin{array}{l}14 \text { ethnically } \\
\text { diverse at-risk } \\
\text { adolescents at an } \\
\text { alternative High } \\
\text { School in Nth } \\
\text { Carolina. School } \\
\text { admin or parent } \\
\text { referred. }\end{array}$ & Learning to BREATHE \\
\hline Sanger and Dorjee (2016) & $\begin{array}{l}\text { Well- } \\
\text { being }\end{array}$ & $\begin{array}{l}8 \text { sessions of } \\
50 \text { minutes }\end{array}$ & $\begin{array}{l}42 \text { students aged } \\
16-18 \text { years in } 4 \\
\text { schools in Nth } \\
\text { Wales }\end{array}$ & MiSP .b Foundations, \\
\hline
\end{tabular}




\begin{tabular}{|c|c|c|c|c|}
\hline Devcich et al. (2017) & $\begin{array}{l}\text { Well- } \\
\text { being }\end{array}$ & $\begin{array}{l}\text { One hour per } \\
\text { week for } 8 \\
\text { weeks }\end{array}$ & $\begin{array}{l}106 \text { students aged } \\
9-11 \text { years } \\
\text { Auckland, New } \\
\text { Zealand. }\end{array}$ & $\begin{array}{l}\text { Pause, Breathe, Smile - } \\
\text { developed by one of the } \\
\text { authors }\end{array}$ \\
\hline Arthurson (2015) & $\begin{array}{l}\text { Well- } \\
\text { being }\end{array}$ & $\begin{array}{l}45 \mathrm{mins} \text { per } \\
\text { week for } 9 \\
\text { weeks }\end{array}$ & $\begin{array}{l}30 \text { 12-13, Adelaide, } \\
\text { Melbourne }\end{array}$ & $\begin{array}{l}\text { Developed from Mind-up, } \\
\text { Meditation Capsules and } \\
\text { Smiling Mind. Adapted to } \\
\text { the Australian context. }\end{array}$ \\
\hline Milligan et al. (2017). & $\begin{array}{l}\text { Well- } \\
\text { being }\end{array}$ & & $\begin{array}{l}2414-17 \text { years in a } \\
\text { rural high school. }\end{array}$ & Integra Mixed Martial Arts \\
\hline Higgens and Eden (2017) & $\begin{array}{l}\text { Well- } \\
\text { being }\end{array}$ & $\begin{array}{l}\text { Ten minutes } \\
\text { breathing } \\
\text { before the } \\
\text { maths lesson } \\
\text { and fifteen } \\
\text { minutes of } \\
\text { cogen in the } \\
\text { final } 15 \\
\text { minutes }\end{array}$ & $\begin{array}{l}30 \text { students aged } \\
10-12 \text { in a large } \\
\text { urban centre in } \\
\text { New Zealand }\end{array}$ & $\begin{array}{l}\text { Mindfulness-based breathing } \\
\text { and co-generative dialogue. }\end{array}$ \\
\hline
\end{tabular}

Significant increase in mindfulness scores and some indication of sustainability of the effects at 12 weeks.

High level of acceptability.

\section{Authors findings of increasing awareness, calm, attention, and acceptance, all supporting positive change.}




\section{Appendix B: The Heuristic}

\section{Mindfulness in Education Heuristic}

Your name:

Date:

For each question circle the number that most sounds like you.

1. I find it easy to stay focussed on my learning.

$5=$ Very often or always, $4=$ Often, $3=$ Sometimes, $2=$ Rarely, $1=$ Never or very rarely

Comments:

2. I feel calm when I am in class.

$5=$ Very often or always; $4=$ Often; $3=$ Sometimes; $2=$ Rarely; $1=$ Hardly ever or never Comments:

3. I don't let others distract me.

$5=$ Very often or always; $4=$ Often; $3=$ Sometimes; $2=$ Rarely; $1=$ Hardly ever or never

Comments:

4. I find the meditative breathing is a helpful way of getting me ready for my learning day.

$5=$ Very often or always; $4=$ Often; $3=$ Sometimes; $2=$ Rarely; $1=$ Hardly ever or never Comments:

5. I feel less anxious after I have done my meditative breathing.

$5=$ Very often or always; $4=$ Often; $3=$ Sometimes; $2=$ Rarely; $1=$ Hardly ever or never Comments:

6. I find it easier to pay attention to what is happening in class after I have done my meditative breathing.

$5=$ Very often or always; $4=$ Often $; 3=$ Sometimes; $2=$ Rarely $; 1=$ Hardly ever or never

Comments:

7. I think that the meditative breathing helps me to think more clearly. 
$5=$ Very often or always; $4=$ Often; $3=$ Sometimes; $2=$ Rarely; $1=$ Hardly ever or never Comments:

8. I notice that the other children look more relaxed after they have done their meditative breathing.

$5=$ Very often or always; $4=$ Often; $3=$ Sometimes; $2=$ Rarely; $1=$ Hardly ever or never Comments:

9. When I am feeling upset the meditative breathing helps me to calm down.

$5=$ Very often or always; $4=$ Often $; 3=$ Sometimes; $2=$ Rarely; $1=$ Hardly ever or never Comments:

10. I use the meditative breathing when I am not in class.

$5=$ Very often or always; $4=$ Often; $3=$ Sometimes; $2=$ Rarely; $1=$ Hardly ever or never Comments: 
Appendix C: Tuku Mihi

\section{Tuku Mihi}

(Giving Thanks)

\section{Kia hora te marino}

(May peace be wide-spread)

Kia whakapapa pounamu te moana

(May the sea glisten like greenstone)

Kia wātea ai te ara

(Making a clear pathway)

He maunga rongo ki te whenua

(From the peace of the mountains to the land)

\section{He whakaaro pai ki ngā tāngata katoa}

(Positive thoughts to everyone)

Me manaaki tētahi ki tētahi

(To look after one another)

Tihei Mauri Ora

(Good health to us all) 


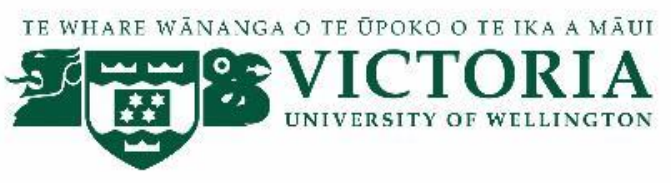

\section{Children's experiences of guided meditation \\ INFORMATION SHEET FOR PRINCIPAL}

I am seeking permission to include the children in room 12 in this research. Please read this information before deciding whether or not to give your consent. If you decide to allow this research to take place at your school, thank you. If you decide not to allow this research to take place at your school, thank you for considering this request.

\section{Who am I?}

My name is Robyn Browne and I am a Masters student in Education at Victoria University of Wellington. This research project is work towards my thesis.

\section{What is the aim of the project?}

This project aims to investigate the usefulness of guided meditative breathing as a tool that teachers can use to help children with their learning. Your student's participation will support this research by helping us to understand the ways in which guided meditative breathing may help the students with their learning. This research has been approved by the Victoria University of Wellington Human Ethics Committee ref 0000027332.

\section{How can you help?}

Your students have been invited to participate because children of their age are good at sharing information about their experiences and reflecting on their learning. If you agree to this research taking place at your school the selected students will be involved in daily meditative sessions that will last less than ten minutes. At the end of each week they will take part in a group discussion about their experiences of the meditation. They will be given the opportunity to express their ideas through drawing, making a voice recording on their chrome book or recording their ideas in a google doc. In weeks one, six and at the conclusion of the programme a group of students will be given a set of questions to answer about their experience of this meditation programme. This reflection time will take twenty minutes. I will video record these discussions with their permission and write it up later. These video recordings will only be used for the purpose of analysis and will not be shown or included in the thesis and publications. The students can withdraw from the study by contacting me, their class teacher or yourself at any time. 


\section{What will happen to the information they give?}

This research is confidential. This means that the researcher named below will be aware of their identity but the research data will be combined and their identity will not be revealed in any reports, presentations, or public documentation. Only my supervisors and the transcriber (who will be required to sign a confidentiality agreement) and I will read the notes or transcript of the interview. The interview transcripts, summaries and any recordings will be kept securely and destroyed on 30 March 2024.

\section{What will the project produce?}

The information from my research will be used in my Master's Thesis and academic publications.

\section{If you accept this invitation, what are their rights as a research participant?}

The students do not have to accept this invitation if they don't want to. If they do decide to participate, they have the right to:

- withdraw from the study;

- $\quad$ ask any questions about the study at any time;

- be able to read any reports of this research by emailing the researcher to request a copy.

If they have any questions or problems, who can they contact?

If they have any questions, either now or in the future, please feel free to contact :

\section{Student:}

Name: Robyn Browne

Robyn.b@waitohu.school.nz

\section{Supervisor:}

Name: Joanna Higgins

Role: Associate Professor

School: Education

Phone:04 4639576

Joana.higgins@vuw.ac.

\section{Human Ethics Committee information}

If you have any concerns about the ethical conduct of the research you may contact the Victoria University HEC Convenor: Dr Judith Loveridge. Email hec@ vuw.ac.nz or telephone +64-4-463 6028. 


\section{Children's experiences of guided meditation \\ PRINCIPAL'S CONSENT TO PARTICIPATE}

This consent form will be held for five years.

Researcher: Robyn Browne, Education, Victoria University of Wellington.

- I have read the Information Sheet and the project has been explained to me. My questions have been answered to my satisfaction. I understand that I can ask further questions at any time.

- I agree to the selected students in my school being invited to take part in this study.

I understand that:

- I may withdraw my school from this study at any point, and any information that I have provided will be returned to me or destroyed.

- $\quad$ The identifiable information I have provided will be destroyed on 30 March 2024.

- Any information I provide will be kept confidential to the researcher, the supervisor and the transcriber.

- I understand that the findings may be used for a Master's thesis or academic publications.

- I understand that the recordings will be kept confidential to the researcher, the supervisor and the transcriber.

- My school's name will not be used in reports and utmost care will be taken not to disclose any information that would identify it.

Signature of principal:

Date:

Contact details: 


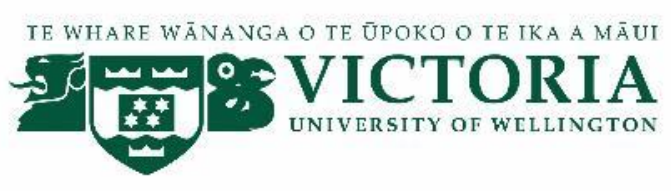

\section{Children's experiences of guided meditation}

\section{INFORMATION SHEET FOR PARENTS}

I am seeking permission to include your child in this research. Please read this information before deciding whether or not to give your consent. If you decide to allow your child to take part in this research, thank you. If you decide not to allow your child to take part in this research, thank you for considering this request. Please return your responses to the principal via the school office.

\section{Who am I?}

My name is Robyn Browne and I am a Masters student in Education at Victoria University of Wellington. This research project is work towards my thesis.

\section{What is the aim of the project?}

This project aims to investigate the usefulness of guided meditative breathing as a tool that teachers can use to help children with their learning. Your child's participation will support this research by helping us to understand the ways in which guided meditative breathing may help them with their learning. This research has been approved by the Victoria University of Wellington Human Ethics Committee ref 0000027332.

\section{How can you help?}

Your child has been invited to participate because children of their age are good at sharing information about their experiences and reflecting on their learning. If you agree to your child participating in this research your child will be involved in daily meditative sessions that will last approximately ten minutes. At the end of each week they will take part in a group discussion about their experiences of the meditation. I will video record these discussions with their permission and write it up later. They will be given the opportunity to express their ideas through drawing, making a voice recording on their chrome book or recording their ideas in written form. In weeks one, six and at the conclusion of the study students will complete questionnaires about their sense of wellbeing associated with the guided meditative breathing intervention. This reflection time will take twenty minutes. I will video record these discussions with their permission and write it up later. These video recordings will only be used for the purpose of analysis and will not be shown or included in the thesis and publications. The students can withdraw from the study by contacting me, their classroom teacher or the principal at any time.

\section{What will happen to the information they give?}

This research is confidential. This means that the researcher named below will be aware of their identity but the research data will be combined and their identity will not be revealed in any reports, presentations, or public documentation. Only my supervisor and the transcriber (who will be required to sign a confidentiality agreement) and I will read the notes or transcript of the interview. The interview transcripts, summaries and any recordings will be kept securely and destroyed on 30 March 2024.

\section{What will the project produce?}

The information from my research will be used in my Master's Thesis and possibly academic publications. 
If you accept this invitation, what are their rights as a research participant?

Neither you nor your child have to accept this invitation if they don't want to. If they do decide to participate, they have the right to:

- $\quad$ withdraw from the study;

- $\quad$ ask any questions about the study at any time;

- be able to read any reports of this research by emailing the researcher to request a copy.

If they have any questions or problems, who can they contact?

If they have any questions, either now or in the future, please feel free to contact:

\section{Student:}

Name: Robyn Browne

Robyn.b@waitohu.school.nz

\section{Supervisor:}

Name: Joanna Higgins

Role: Associate Professor

School: Education

Phone: 044639576

Joanna.higgins@vuw.ac

\section{Human Ethics Committee information}

If you have any concerns about the ethical conduct of the research you may contact the Victoria University HEC Convenor: Dr Judith Loveridge. Email hec@ vuw.ac.nz or telephone +64-4-463 6028. 
Children's experiences of guided meditation

\section{PARENT'S CONSENT FOR THEIR CHILD TO PARTICIPATE}

This consent form will be held for five years.

Researcher: $\quad$ Robyn Browne, Education, Victoria University of Wellington.

- I have read the Information Sheet and the project has been explained to me. My questions have been answered to my satisfaction. I understand that I can ask further questions at any time.

- I agree for my child to participate in the research.

I understand that:

- I may withdraw my child from this study at any point.

- $\quad$ The identifiable information they have provided will be destroyed on 30 March 2024.

- $\quad$ Any information my child provides will be kept confidential to the researcher, the supervisor and the transcriber.

- I understand that the findings may be used for a Master's thesis and academic publications.

- I understand that the video recordings will be kept confidential to the researcher and the supervisor and the transcriber.

- My child's name will not be used in reports and utmost care will be taken not to disclose any information that would identify them.

Signature of parent:

Name of parent:

Name of child

Date:

Contact details: 


\section{Children's experiences of guided meditation}

\section{INFORMATION SHEET FOR STUDENTS}

You are invited to take part in this research. Please read this information before deciding whether or not to take part. If you decide to participate, thank you. If you decide not to participate, thank you for considering this request.

\section{Who am I?}

My name is Robyn Browne and I am a Masters student in Education at Victoria University of Wellington. This research project is work towards my thesis.

\section{What is the aim of the project?}

This project aims to investigate how useful a programme of relaxing and paying attention to your breathing may be as a tool that teachers can use to help children with their learning. Your taking part will help this research by helping us to understand the ways in which this programme may help you with your learning. This research has been approved by the Victoria University of Wellington Human Ethics Committee ref 0000027332.

\section{How can you help?}

You have been invited to take part because children of your age are good at sharing information about their experiences and reflecting on their learning. If you agree to take part you will be involved in classroom daily meditative sessions that will be less than ten minutes. At the end of each week you will take part in a group discussion about your experiences of the meditation. I will video record these discussions with your permission and write it up later. You will be given the opportunity to express your ideas through drawing, making a voice recording on your chrome book or recording your ideas in written form. In weeks one, six and at the end of this study you will be given a set of questions to answer about your experience of this meditation programme. This reflection time will take twenty minutes. I will video record these discussions with their permission and write it up later. These video recordings will only be used for the purpose of analysis and will not be shown or included in the thesis and publications. The students can withdraw from the study by contacting me at any time. You can withdraw from the study by contacting me at any time.

\section{What will happen to the information you give?}

This research is confidential. This means that I will know who you are, but all of the information will be joined together and your identity will not be revealed in any reports, presentations, or other documents. Only my supervisor and the transcriber (who will be required to sign a confidentiality agreement) and I will read the notes or transcript of the interview. The interview transcripts, summaries and any recordings will be kept safe and be destroyed on 30 March 2024. 


\section{What will the project produce?}

The information from my research will be used in my Master's thesis and university publications.

\section{If you accept this invitation, what are your rights as a research participant?}

You do not have to accept this invitation if you don't want to. If you do decide to take part, you have the right to:

- withdraw from the study;

- $\quad$ ask any questions about the study at any time;

- $\quad$ be able to read any reports of this research by emailing me to request a copy

If you have any questions or problems, who can you contact?

If you have any questions, either now or in the future, please feel free to contact:

\section{Student:}

Name: Robyn Browne

Robyn.b@waitohu.school.nz

\section{Supervisor:}

Name: Joanna Higgins

Role: Associate Professor

School: Education

Phone: 044639576

Joanna.higgins@vuw.ac

\section{Human Ethics Committee information}

If you have any concerns about the ethical conduct of the research you may contact the Victoria University HEC Convenor: Dr Judith Loveridge. Email hec@vuw.ac.nz or telephone +64-4-463 6028. 


\section{Children's experiences of guided meditation STUDENT'S CONSENT TO PARTICIPATE}

This consent form will be held for five years.

Researcher: Robyn Browne, Education, Victoria University of Wellington.

- I have read the Information Sheet and the project has been explained to me. I am happy with the answers to my questions. I understand that I can ask more questions at any time.

- I agree to take part in the guided meditative breathing programme including reflective activities in the form of writing, drawing, oral recording of my reflections on my chrome book, completing a questionnaire (heuristic) and video recorded discussions.

I understand that:

- I may withdraw from this study at any point.

- The information that comes from me will be destroyed on 30 March 2024.

- Any information I provide will be kept confidential (private) to the researcher, the supervisor and the transcriber.

- I understand that the findings may be used for a Master's thesis or academic publications.

- I understand that the recordings will be kept confidential (private) to the researcher, the supervisor And the transcriber.

- $\quad$ My name will not be used in reports and utmost care will be taken not to reveal any information that would identify me.

Signature of participant:

Name of participant:

Date:

Contact details: 


\section{Children's experiences of guided meditation \\ INFORMATION SHEET FOR TEACHER}

I am seeking permission to include the children in room 12 in this research. Please read this information before deciding whether or not to give your consent. If you decide to allow this research to take place in your class, thank you. If you decide not to allow this research to take place in your class, thank you for considering this request.

\section{Who am I?}

My name is Robyn Browne and I am a Masters student in Education at Victoria University of Wellington. This research project is work towards my thesis.

\section{What is the aim of the project?}

This project aims to investigate the usefulness of guided meditative breathing as a tool that teachers can use to help children with their learning. Your student's participation will support this research by helping us to understand the ways in which they experience guided meditative breathing helping them with their learning. This research has been approved by the Victoria University of Wellington Human Ethics Committee ref 0000027332.

\section{How can you help?}

Your students have been invited to participate because children of their age are good at sharing information about their experiences and reflecting on their learning. If you agree to this research to taking place in your class the students will be involved in daily meditative sessions that will last approximately ten minutes. At the end of each week they will take part in a group discussion about their experiences of the meditation. They will be given the opportunity to express their ideas through drawing, making a voice recording on their chrome book or recording your ideas in a google doc. In weeks one, six and at the conclusion of the programme a group of students will be given a set of questions to answer about their experience of this meditation programme. This reflection time will take twenty minutes. These discussions will be video recorded with their permission and I will write it up later. These video recordings will only be used for the purpose of analysis and will not be shown or included in the thesis and publications. The students can withdraw from the study by contacting yourself, the principal or me at any time. 


\section{What will happen to the information they give?}

This research is confidential. This means that the researcher named below will be aware of their identity but the research data will be combined and their identity will not be revealed in any reports, presentations, or public documentation. Only my supervisors and the transcriber (who will be required to sign a confidentiality agreement) and I will read the notes or transcript of the interview. The interview transcripts, summaries and any recordings will be kept securely and destroyed on 30 March 2024.

\section{What will the project produce?}

The information from my research will be used in my Master's Thesis and academic publications.

\section{If you accept this invitation, what are your rights as a research participant?}

You do not have to accept this invitation if you don't want to. If you do decide to participate, you have the right to:

- $\quad$ withdraw from the study;

- $\quad$ ask any questions about the study at any time;

- be able to read any reports of this research by emailing the researcher to request a copy.

\section{If you have any questions or problems, who can you contact?}

If they have any questions, either now or in the future, please feel free to contact:

\section{Student:}

Name: Robyn Browne

Robyn.b@waitohu.school.nz

\section{Supervisor:}

Name: Joanna Higgins

Role: Associate Professor

School: Education

Phone:04 4639576

Joanna.higgins@vuw.ac

\section{Human Ethics Committee information}

If you have any concerns about the ethical conduct of the research you may contact the Victoria University HEC Convenor: Dr Judith Loveridge. Email hec@vuw.ac.nz or telephone +64-4-463 6028. 


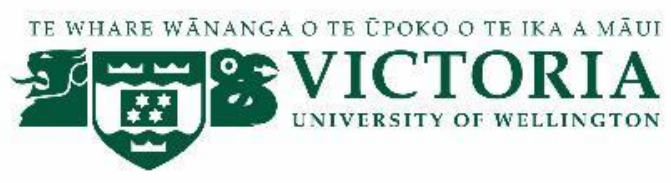

\section{Children's experiences of guided meditation \\ TEACHER'S CONSENT TO PARTICIPATE}

This consent form will be held for five years.

Researcher: Robyn Browne, Education, Victoria University of Wellington.

I have read the Information Sheet and the project has been explained to me. My questions have been answered to my satisfaction. I understand that I can ask further questions at any time.

I agree to the students in my class being invited to take part in this study.

I understand that:

- I may withdraw my school from this study at any point, and any information that I have provided will be returned to me or destroyed.

- The identifiable information I have provided will be destroyed on 30 March 2024.

- Any information I provide will be kept confidential to the researcher, the supervisor and the transcriber.

- I understand that the findings may be used for a Master's thesis or academic publications.

I understand that the recordings will be kept confidential to the researcher, the supervisor and the transcriber.

- My students' names will not be used in reports and utmost care will be taken not to disclose any information that would identify it.

Signature of teacher:

Date:

Contact details: 


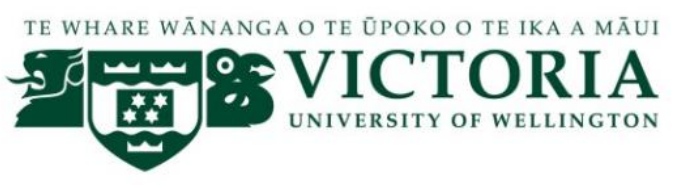

\section{Transcribing Confidentiality Agreement}

Project Title:_Children's Experiences of Guided Meditation

Principal Investigator:_Robyn Browne

I, $\longrightarrow$ agree to ensure that the [audiotapes/videotapes] I transcribe will remain confidential to_Robyn Browne, her supervisor_and myself.

I agree to take the following precautions:

1. I will ensure that no person, other than_-, [hears/sees] the recording.

2. I will ensure that no other person has access to my computer/device.

3. I will delete the files from my computer/device once the transcription has been completed.

4. I will not discuss any aspect of the recording with anyone except

Signature:

Date: 
